JOSÉ RICARDO DE MELLO BRANDÃO

\title{
Análise do Programa Qualidade Integral em Saúde - QUALIS - a partir de inquérito domiciliar
}

Tese apresentada à Faculdade de Medicina da Universidade de São Paulo para obtenção do título de Doutor em Ciências

Área de concentração: Medicina Preventiva Orientador: Prof. Dr. Moisés Goldbaum Co-orientador: Prof. Dr. Reinaldo José Gianini

São Paulo 
Análise do Programa Qualidade Integral em Saúde - QUALIS - a partir de um inquérito domiciliar.

\section{INTRODUÇÃO}

A análise de um programa pressupõe conhecerem-se as bases conceituais que levaram à sua construção, assim como apresentar-se o referencial a partir do qual ela será efetuada. Complementa-se a introdução com o histórico, as peculiaridades e os limites do instrumento escolhido para se proceder a essa análise, no caso, um inquérito domiciliar.

\subsection{Programa de Saúde da Família (PSF)}

O PSF é fruto do desenvolvimento recente de políticas de atenção primária que, mundialmente, ganharam grande impulso com a Conferência Internacional de Cuidados Primários em Saúde, realizada pela Organização Mundial da Saúde (OMS) e pelo Fundo das Nações Unidas para a Infância (UNICEF), em Alma-Ata (Casaquistão), em 1978 (Silva e Dalmaso, 2002).

Na Europa, desde o pós-guerra, na segunda metade do século XX, diversos países criaram sistemas de proteção social, basicamente divididos em seguros sociais de saúde (SHI - "Social Health Insurance") e os serviços nacionais de saúde (NHS - "National Health Service"), onde os serviços de atenção primária funcionam com diversas peculiaridades locais, tendo sido alvo de importantes reformas na década de 90 (Giovanella, 2006). Essas reformas, tendo o sistema inglês como referência, ocorreram, segundo Green 
et al. (2007), devido a diversas circunstâncias político-econômicas que, ainda hoje, modulam o NHS inglês no sentido de valorizar a escolha por parte do consumidor, dandolhe um caráter mais individualizado, em contraposição à preocupação com a eqüidade bem estabelecida em Alma Ata. Esses autores referem também que, por ocasião dessa histórica conferência, a assunção era de que a atenção primária já estava organizada nos países desenvolvidos e que, portanto, se tratava de uma proposta de estímulo à sua criação e organização nos países não desenvolvidos.

O PSF, por sua vez, pode ter a sua origem traçada, de forma mais específica, a partir de diversos conceitos e experiências internacionais, quase todos eles oriundos da Medicina Comunitária, Medicina de Família e Serviços de Saúde Comunitária, campos que muitas vezes se sobrepõem, mas têm nascimentos diversos e se complementam em vários aspectos. Porto Alegre (RS) e Niterói (RJ), no Brasil, foram cidades pioneiras na montagem de estratégias de atendimento que serviram de inspiração para o PSF. Relatos bastante personalizados da história dessas experiências podem ser encontrados em Vasconcellos (1998) e Sousa (2001). Franco e Merhy (2003) também destacam a experiência do município de Itacarambi (MG).

O PSF foi oficialmente proposto pelo Ministério da Saúde em 1994. O seu caráter de eixo estruturante da atenção primária e substituto do modelo tradicional de assistência foi sendo enfatizado a partir de documentos do ministério, de 1998 para cá (Conill, 2002). Silva e Dalmaso (2002) apresentam uma meticulosa análise da evolução da proposta do PSF no Brasil. Do que se vislumbrava até então (embora alguns aspectos estejam longe de estarem resolvidos) Franco e Merhy (2003) fizeram críticas de maneira perspicaz e rigorosa ao PSF, cujas diversas fragilidades dificultariam em muito a possibilidade de o programa mudar o modelo assistencial. E, cautelosamente, apontam as "raízes comuns" do 
movimento da reforma sanitária e a proposta do PSF, ao justificarem "a força de atração" do programa, correspondendo às adesões iniciais à sua proposta. Talvez exemplo-vivo dessa realidade se encontre na defesa apaixonada do programa realizada por Sousa, 2002.

Na origem de ao menos parte das críticas ao PSF, está a discussão sobre universalismo e focalismo. Historicamente, a proposta de Alma-Ata era universalista (definindo, segundo Viana e Fausto, 2005, a “atenção básica como componente estratégico da estruturação, operação, coordenação e instrumento de eqüidade dos sistemas nacionais de saúde.”). Porém, mal se expandiam as idéias de Alma Ata, já no ano seguinte, segundo as mesmas autoras, "a Conferência de Bellagio, intitulada 'Health and Population in Development' (1979), foi o evento que marcou a definição de SPHC (Selective Primary Health Care)”, reconhecida como sendo uma proposta eminentemente "focalista", instrumental ("atenção básica como componente importante das estratégias de combate à pobreza e às desigualdades sociais"). Essa proposta permitiria uma espécie de atalho para a consecução das metas do programa Saúde para Todos no ano 2000, da OMS, e ganharia grande impulso nas duas décadas seguintes, graças ao apoio do Banco Mundial e às políticas neoliberais que tiveram o seu auge nesse período. Foi a identificação do PSF, principalmente nos seus primeiros anos, como sendo, conceitualmente, de caráter focalista que lhe trouxe algumas de suas mais pesadas críticas.

Há, porém, na literatura, autores que utilizam o termo focalismo de uma maneira um pouco diversa, de forma quase contemporizadora. Chamam de focalização o fato de o PSF abordar, prioritariamente (ou exclusivamente, dependendo da opção do gestor municipal) populações com IDH (Índice de Desenvolvimento Humano) mais baixo. Viana e Dal Poz (1998), ao constatar o avanço do PSF para “áreas e populações de risco”, defendem que 
essa focalização é compatível com a universalização, não sendo necessariamente esses dois conceitos excludentes.

Outro conceito que freqüentemente surge nas referências ao PSF é o da eqüidade. Segundo Elias (2002), recorrendo a Aristóteles, “a própria natureza da eqüidade é a retificação da Lei onde esta se revela insuficiente pelo seu caráter universal.” O autor chama-a de "corretora da igualdade", no sentido de que ela é aplicável no momento em que a igualdade cria injustiças ou imperfeições. Aponta a dificuldade de se operacionalizar esse conceito, mas defende a sua utilização como "noção orientadora, como um norte a ser seguido nas políticas de saúde."

Senna (2002), escrevendo sobre eqüidade, política de saúde e PSF, faz distinção entre eqüidade em saúde e eqüidade no uso de serviços de saúde. Sob esse último aspecto, considera que, apesar da complexidade da questão no PSF, “a focalização assume o caráter de inclusão de grandes parcelas da população tradicionalmente alijadas do acesso a um mínimo de garantias sociais", ressaltando a necessidade dessa de estar no bojo de "uma política mais ampla que forneça suporte social" e universalidade de direitos, sob pena de "reproduzir desigualdades e reforçar a segmentação social."

Oficialmente, o PSF é apresentado como propiciador de "melhoria dos indicadores de saúde das populações atendidas, [capacidade de] ampliação do acesso da população a serviços básicos de saúde, [capacidade de] ampliação da resolubilidade dos serviços de atenção básica, contribuindo para o reordenamento dos demais níveis de assistência” (Brasil, 2000a).

Em consonância com a evolução da proposta do PSF, o Ministério da Saúde publica, em 2006, a "Política Nacional de Atenção Básica", revogando inúmeras portarias anteriores. Nesse documento, define que cada equipe do PSF é composta basicamente por 
médico, enfermeira, auxiliar de enfermagem e agentes comunitários de saúde (ACS), “com jornada de trabalho de 40 horas semanais para todos os seus integrantes", sendo responsáveis pelo atendimento de uma área previamente definida (a chamada territorialização), que comporta "no máximo, 4.000 habitantes, sendo a média recomendada de 3.000 habitantes". O "número de ACS (deve ser) suficiente para cobrir 100\% da população cadastrada, com um máximo de 750 pessoas por ACS e de 12 ACS's por equipe de Saúde da Família” (Brasil, 2006).

Constata-se um impressionante avanço do PSF no país no decorrer dos últimos seis anos (conforme tabela abaixo), o que só vem reforçar a necessidade de se aprofundar a análise do possível impacto dessa estratégia na saúde da população brasileira.

Tabela 1. Evolução do PSF no Brasil. (Brasil, 2007a)

\begin{tabular}{|c|c|c|}
\hline & 2001 & 2007 \\
\hline $\begin{array}{c}\text { Número de pessoas incluídas } \\
\text { no programa }\end{array}$ & 45,4 milhões & 86,7 milhões \\
\hline Cobertura populacional & $25,4 \%$ & $46,7 \%$ \\
\hline $\begin{array}{c}\text { Número de equipes de SF } \\
\text { Número de municípios com } \\
\text { o programa }\end{array}$ & 13200 & 27000 \\
\hline
\end{tabular}

\subsection{Avaliação do PSF}

Avaliar, segundo Champagne et al (1985), "pode ser definido como uma atividade que consiste fundamentalmente em aplicar um julgamento de valor a uma intervenção, (...) 
permitindo aos diferentes atores envolvidos, (...) se posicionarem e construírem (...) um julgamento capaz de ser traduzido em ação.” Em outras palavras, avaliar supõe dar instrumentos para que os tomadores de decisão possam agir de acordo com um racional técnico-científico, seja ele uma pesquisa avaliativa ou uma avaliação normativa, ainda segundo esse mesmo autor.

Demarteau (2002), ao propor um referencial teórico para a avaliação de programas, parte também de três componentes incluídos na definição acima (processo, julgamento e decisão) e suas três dimensões (social, estratégica e técnica) para propor um modelo que abarcaria as diversas propostas de avaliação existentes.

Os esforços de diversos autores que têm procurado avaliar programas de saúde nacionais têm sido estimulados pelo próprio Ministério da Saúde. Felisberto (2004) procura justificar a importância da avaliação na Atenção Básica, defendendo a sua institucionalização, apresentando inclusive a missão ("monitorar e avaliar a Atenção Básica instrumentalizando a gestão e fomentar/consolidar a cultura avaliativa nas três instâncias de gestão do SUS” - Sistema Único de Saúde) e os objetivos estratégicos da Coordenação de Acompanhamento e Avaliação, criada no Departamento de Atenção Básica (DAB) do Ministério da Saúde, que podem ser resumidos em: identificar indicadores da atenção básica para monitoramento, pactuar metas com os gestores, capacitar técnicos para análise dos bancos de dados, democratizar essa informação e fomentar estudos avaliativos.

Segundo Medina e Aquino (2002), “a avaliação do Programa de Saúde da Família constitui hoje tarefa primordial para todos os envolvidos no debate sobre as perspectivas da consolidação deste programa e dos avanços possíveis do Sistema Único de Saúde no país".

Santana e Carmagnani (2001), após retomarem o histórico do programa e procurarem apontar as suas vantagens e desvantagens, afirmam (acreditar) "que o próximo passo seja 
avaliar o impacto do PSF com base na investigação de mudanças comportamentais e culturais em torno do processo saúde-doença”.

Já em 1999, no período de abril a julho, o Ministério da Saúde realizou a "Pesquisa de Avaliação da Implantação e Funcionamento do PSF” (Brasil, 2000b), por meio do envio de questionários a todos os 1.219 Secretários Municipais de Saúde dos municípios que tinham equipes implantadas até dezembro de 1998, assim como questionário para todas essas equipes (3.119). Também os Coordenadores Estaduais de PSF foram entrevistados. Cerca de $80 \%$ dos Secretários responderam, assim como 75\% das equipes. Os resultados cobrem diversas áreas, com destaque para indicadores de estrutura e processo, esses últimos com resultados bastante animadores. Em suma, mostraram aumento expressivo na oferta de atividades ligadas a todos os "programas", a saber: pré-natal, assistência à puérpera, atenção à criança, coleta para exame Papanicolaou, planejamento familiar, atenção ao adulto, consulta ginecológica, controle de hipertensão, diabetes, DST, hanseníase, tuberculose, ações de vigilância epidemiológica, ações voltadas para o idoso e os adolescentes e pequena cirurgia.

Diversos autores têm produzido análises e avaliações do PSF, alguns deles restringindo-se a aspectos específicos, apesar de pertinentes e interessantes, como Mano e Pierin (2005), que avaliaram hipertensos acompanhados pelo PSF, inclusive com grupo controle, no Centro de Saúde Escola (CSE) da Barra Funda (São Paulo), mostrando "redução significativa dos níveis pressóricos" no grupo acompanhado pelo PSF, embora, ao final do estudo, a porcentagem de hipertensos controlados, acompanhados pelo programa tradicional, fosse maior do que o do PSF (30\% vs 20\%). Outros abordaram o programa como um todo, seja em determinada área, como o morro do Borel, no Rio de Janeiro (Cezar, 2003) seja em grandes capitais, como Natal (Rocha, 2000). Com ênfase na 
avaliação de estrutura e processo, o Ministério da Saúde e a Escola Nacional de Saúde Pública (ENSP) avaliaram a implementação do PSF em dez grandes centros urbanos (Brasil, 2002), todos com mais de 100 mil habitantes - Aracaju (SE), Camaragibe (PE), Vitória (ES), Vitória da Conquista (BA), Palmas (TO), Manaus (AM), Goiânia (GO), Brasília (DF), São Gonçalo (RJ) e Campinas (SP). Em extenso relatório, poucos aspectos de avaliação de resultados são apontados. Entre eles, a satisfação das famílias com o PSF: “em todos os municípios, as famílias consideraram, de maneira geral, que com a implantação do PSF melhoraram as condições de saúde do bairro, de sua família e o atendimento em caso de doença". Destaque também para um dos elementos facilitadores apontados para o desenvolvimento da Estratégia de Saúde da Família (ESF) - como o PSF passou a ser oficialmente chamado a partir da "Política Nacional de Atenção Básica" editada em 2006 - em grandes centros urbanos: “a população atendida pelo PSF é extremamente vulnerável, podendo considerar que a estratégia de Saúde da Família promove expansão de cobertura para grupos desfavorecidos e potencialmente contribui para a inclusão social". Entretanto, quanto ao acesso, a pesquisa incluiu nessa categoria, em relação aos problemas de saúde apresentados pelas famílias adscritas ao programa, nas comunidades estudadas (Camaragibe - PE, Palmas, Vitória da Conquista - BA, Vitória, Aracaju, Goiânia, Manaus e Brasília), o “grande tempo de espera mesmo com consulta marcada, falta de vagas para consultas, atendimento precário, dificuldade de atendimento quando encaminhado, dificuldade em obter consultas". Mostrou que problemas de acesso ao atendimento eram o segundo grupo de problemas de saúde apontados, com freqüência menor do que "doenças", mas mais prevalentes do que as categorias "profissionais de saúde", "infraestrutura de saneamento" e "medicamentos". Foram apontados por 12\% (Manaus) a 38\% (Goiânia) das famílias pesquisadas. No entanto, em todos os municípios, 
a maioria das famílias considerava "ser mais fácil obter consulta quando agendada previamente na USF (Unidade de Saúde da Família) em comparação com as UBS”. Quando a comparação era com consultas não marcadas, em apenas três municípios (Camaragibe, Vitória da Conquista e Brasília), a maioria das famílias considerava ser mais fácil obter consulta nas USF's, em comparação com as Unidades Básicas de Saúde (UBS's), ressaltando uma crônica dificuldade da ESF no atendimento aos chamados "forade-dia”. Mesmo assim, com exceção de Goiânia, em todos os outros municípios, a maioria das famílias dizia ter procurado menos hospitais, especialistas e serviços de urgência.

Bertoncini (2000), tendo estudado, em sua dissertação de mestrado, o PSF de Blumenau, afirma que ele "induziu melhorias na integralidade da atenção pelo aumento das ações de promoção e prevenção e manutenção das de reabilitação e cura.”

Conill (2002), avaliando o PSF de Florianópolis (SC) entre 1994 e 2000, afirma que “os problemas no acesso, decorrentes do quantitativo insuficiente de recursos humanos e as dificuldades na referência, determinam uma situação que este estudo identifica como das mais relevantes."

Goldbaum et al. (2005), estudando acesso e utilização de serviços no QUALIS, mostraram perfil de acesso diferenciado na população coberta pelo PSF, apontando na direção de uma maior eqüidade nessa utilização.

Elias et al. (2006) compararam o PSF com as UBS's da cidade de São Paulo, utilizando um instrumento chamado PCAT ("Primary Care Assessment Tool”), ajustado para a nossa realidade. Dentre as oito dimensões desse instrumento, a acessibilidade, apesar de obter a pior avaliação entre todas elas, mostrou ser superior nas unidades com PSF em relação às UBS's tradicionais, sob a óptica dos usuários, exatamente nos estratos de maior exclusão social, embora esse quadro não se mantivesse nos outros estratos 
(acessibilidade melhor nas UBS's quanto aos estratos intermediários e semelhante nos superiores). De acordo com a opinião de gestores e profissionais (médicos e enfermeiros), não havia diferença de acessibilidade entre os dois modelos de atenção básica. Vale ressaltar que, na avaliação como um todo, se bem que, na opinião dos usuários, o PSF seja superior à UBS (opinião não compartilhada por gestores e profissionais, que não viram “diferenças relevantes” entre os modelos). Ainda nesse artigo, "quanto maior a exclusão, menor o índice de aprovação ao PSF”.

Utilizando-se do mesmo instrumento usado na pesquisa anteriormente citada, apesar da descrição da dimensão "acesso" estar caracterizada de forma um pouco diferente (“envolve a localização da unidade de saúde próxima da população a qual atende, o horário e os dias em que está aberta para atender, e o grau de tolerância para consultas não agendadas”), Ibañez (2006) estudou os municípios com mais de 100.000 habitantes do Estado de São Paulo. Os valores de avaliação de acessibilidade estiveram novamente entre os mais baixos da pesquisa, situando-se "num patamar apenas razoável", havendo concordância de opinião entre usuários e trabalhadores em saúde. A comparação entre PSF e unidade tradicional foi realizada apenas a partir da opinião dos trabalhadores. Embora na acessibilidade não tenha havido diferença entre os modelos, de um modo geral, "os profissionais que trabalham no PSF avaliam o desempenho como sendo melhor do que julgam aqueles que trabalham em unidades tradicionais", sendo essas diferenças "mais evidentes nos 'clusters' 1, 2 e 3" (aqueles com indicadores sociais mais desfavoráveis), não havendo "nenhuma diferença estatisticamente significante" no cluster 6 (produção de saúde de alta complexidade e melhores indicadores sociais).

Merece citação estudo feito por técnicos do Ministério da Saúde (Brasil, 2006b), ainda que caracterizado pelos seus próprios autores como "ecológico e de caráter exploratório", 
em que as taxas de mortalidade infantil e cobertura vacinal da tetravalente no primeiro ano de vida mostraram, respectivamente, diminuição e aumento mais substanciais nos municípios com maiores taxas de cobertura pelo PSF.

\subsection{Inquéritos domiciliares}

Os inquéritos domiciliares surgiram como evolução natural na busca por informações que melhor refletissem as características de uma dada população. Precedidos historicamente pelos levantamentos de dados de mortalidade, os indicadores de morbidade passaram a ser de maior interesse a partir do momento em que se conseguiu minimamente debelar algumas causas de morte, trazendo interesse pelo estudo das formas de adoecimento. Inicialmente construídos a partir de dados coletados em locais de atendimento médico (principalmente hospitais), aproximaram-se da realidade ao serem criados os inquéritos domiciliares (Carvalheiro, 1981; Kroeger, 1983).

Segundo Cesar et al. (1996), "esses levantamentos iniciaram-se na década de 20, nos países industrializados, e a partir da década de 50, nos países em desenvolvimento". Chadwick (1965), citado por Campos (1993), teria sido o primeiro realizador de um inquérito de saúde (publicado originalmente em 1842), porém ainda não domiciliar. Desde então, particularmente no final do século passado e início do atual, vêm surgindo diversas orientações de cunho metodológico, de forma a se aprimorar a realização desse importante instrumento da saúde pública (Kroeger, 1983; Kroeger, 1986 McDowell e Newell, 1996).

Chadwick E. Report on Sanitary Condition of the Labouring Population of Great Britain, 280. Edinburgh: Edinburgh University Press; 1965 (reimpression). 
Ainda segundo Campos (1993), “os inquéritos de saúde podem ser definidos como tipos de estudos descritivos ou analíticos, longitudinais ou transversais, sobre diversos aspectos relacionados ao estado de saúde, demanda e utilização de serviços de saúde, através de amostras representativas de uma população". De forma mais particularizada, White (1985) afirma que os inquéritos de saúde obtêm “informação essencial sobre necessidades individuais, comportamento, atitude, conhecimento, morbidade, gasto (tempo, esforço e dinheiro) e assuntos relacionados à saúde e serviços de saúde". Particular interesse existe sobre as condições e hábitos de vida da população, mormente os que implicam qualidade de vida ou fatores de risco para determinadas doenças. Realizados, geralmente, nos locais de moradia das pessoas, recebem o nome de inquéritos domiciliares.

Esses inquéritos domiciliares podem se efetivar de forma sistemática, em intervalos de tempo regulares, principalmente abrangendo todo um país, ou serem realizados em determinados momentos, atendendo a necessidades locais de planejamento ou trabalhos acadêmicos. No primeiro caso, os chamados inquéritos populacionais de saúde, temos, nos Estados Unidos da América (EUA), o "National Health Interview Survey - NHIS", realizado desde 1957 pelo "US Bureau of the Census" para o "National Center for Health Statistics" e o "National Health and Nutrition Examination Survey - NHANES” -, realizado desde 1971; no Reino Unido, existem o "General Health Survey - GHS", realizado pelo "Office of Population Censuses and Surveys", desde 1971 e o "Health Survey for England - HSE -, iniciado em 1993. No Brasil, a "Pesquisa Nacional por Amostragem de Domicílios - PNAD", realizada pelo Instituto Brasileiro de Geografia e Estatística - IBGE, incluiu o suplemento de saúde pela primeira vez em 1981 ("PNAD Saúde”), inaugurando no país esse tipo de coleta de dados em saúde (Viacava, 2002). 
Inquéritos com abrangência mais circunscrita, mas ainda com base populacional, vêm aumentando no Brasil, principalmente relacionados a doenças específicas ou hábitos e condições de vida, sendo Haddad (1967-8) um dos pioneiros que, em 1963/4, fez um levantamento sobre cardiopatias crônicas na Vila Virgínia, bairro periférico de Ribeirão Preto. Com foco em diferentes questões, inclusive avaliação de serviços, encontramos relatos referentes à Bahia (Carvalho et al., 1988), Botucatu/SP (Lebrão et al., 1991) e região Sudoeste da Grande São Paulo (Cesar e Tanaka, 1996). Mesmo em áreas geográficas mais restritas, esses levantamentos não podem prescindir de processos amostrais, muitas vezes bastante sofisticados, de forma a permitirem inferências efetivas da população estudada ou mesmo de subgrupos populacionais, conforme se pode ver no inquérito realizado na década de 80 em Botucatu (Carandina et al., 1986). Naturalmente, isso implica procedimentos estatísticos de análise que levarão em conta o procedimento utilizado.

As razões para a realização desses levantamentos, segundo White (1985), são definir prioridades, possibilitar a tomada de decisões, conhecer os resultados obtidos e fazer comparações. A definição de prioridades envolve geralmente a escolha de problemas ou grupos populacionais para intervenção. O autor destaca a importância de se coletarem adequadamente as informações relacionadas ao aspecto a ser estudado como forma de permitir a consecução do segundo objetivo, qual seja, a tomada de decisões, intrinsecamente ligada ao primeiro. Conhecer resultados está bastante ligado à monitorização e avaliação de alguma intervenção específica ou do resultado de diversas ações que compõem, por exemplo, o sistema de saúde de determinado local. Ressalta o fato de que o resultado obtido muitas vezes deve-se, em grande parte, a fenômenos de difícil mensuração, como os efeitos Hawthorne e placebo, assim como dos aspectos 
afetivos da relação "profissional de saúde-paciente". A realização de comparações, por sua vez, pode ocorrer temporalmente, com levantamentos servindo como "linha de base" e após determinada intervenção ou mudança de política de saúde, por exemplo. Ou geograficamente, entre diferentes locais.

Há vários outros aspectos a serem observados na realização de inquéritos de saúde. Um deles relaciona-se à possibilidade de haver vieses que colocarão em risco a qualidade do levantamento. Dois deles são particularmente importantes: o viés de seleção e o de informação (Hennekens e Buring, 1987). No primeiro, a não-inclusão de determinados segmentos sociais de uma dada comunidade gerará informações que não serão fidedignas quanto ao conjunto dessa população. Outra situação geradora de viés de seleção pode ser encontrada quando a taxa de recusa a responder ao inquérito é elevada. Freqüentemente esse grupo apresenta características distintas do restante do universo pesquisado. Manter essa taxa no mínimo possível é normalmente a maneira de contornar essa questão. Isso pode ser conseguido, por exemplo, aumentando-se o número de revisitas aos domicílios, ampliando os horários dessas visitas, treinando adequadamente os visitadores para a correta maneira de se apresentarem e mostrarem os objetivos do levantamento, divulgando antecipadamente a existência do levantamento assim como seus objetivos (por intermédio da mídia ou envio de cartas). Outra maneira, geralmente mais difícil e custosa, envolve a tentativa de se conseguirem ao menos informações básicas dos não-respondentes, como forma de compará-los aos demais e eventualmente demonstrar que não se trata de grupo específico não representado na amostra como um todo. Também a escolha de um inquérito domiciliar para determinar a prevalência de condições de saúde que freqüentemente levam o indivíduo a permanecer longos períodos internado (como é o caso de algumas doenças mentais mais graves, por exemplo) irá falsear o resultado obtido. 
O viés de informação pode ocorrer por diversas razões. Uma delas diz respeito à dificuldade dos indivíduos de se lembrarem de determinado fato ou, contrariamente, a facilidade de se lembrarem de determinada exposição, particularmente quando se conhece a relação com a doença pesquisada (por exemplo, fumo e infarto agudo do miocárdio). $\mathrm{Ou}$ seja, na prática, indivíduos que sofreram ou sofrem de determinada patologia tendem a se lembrar mais facilmente de supostos fatores de risco, ao contrário dos indivíduos saudáveis. De qualquer forma, há que se atentar para o período de tempo que se utiliza para alguns questionamentos. Fatos mais marcantes são naturalmente lembrados com mais facilidade, daí a razão para se perguntar, por exemplo, sobre eventual internação hospitalar no último ano e ocorrência de doença aguda nos últimos quinze dias, períodos esses testados em diversos inquéritos de saúde. Outra dificuldade refere-se à capacidade do indivíduo de fornecer informações "corretas" quando questionado sobre determinadas doenças, particularmente aquelas que dependem de diagnóstico médico, quando então o maior ou menor acesso a esse profissional alterará a possibilidade de se conseguir uma informação confiável. Perguntas sobre sinais e sintomas possibilitarão uma maior acurácia dos dados. Outra questão relacionada diz respeito ao diagnóstico referido e à sua constatação in loco. Há tendência a uma subestimação quando ocorre a auto-avaliação do estado de saúde, em comparação com a efetiva constatação da doença, embora pareça não haver grandes discrepâncias, em relação a doenças crônicas (Blaxter, 1990). Há estudos demonstrando a possibilidade de se incluir a Hipertensão Arterial Sistêmica (HAS) nos inquéritos de morbidade referida, ainda que com algumas restrições (Vargas, 1997).

Conquanto a constatação de algumas condições de saúde possa ser realizada por intermédio de exames físicos ou laboratoriais relativamente simples (se bem que invariavelmente impliquem aumento de custos com pessoal ou material para a realização da 
pesquisa), outras exigirão uma razoável incerteza na definição desse diagnóstico (caso da hipertensão arterial, por exemplo) ou serão inexeqüíveis em um levantamento domiciliar. Outra dificuldade que se apresenta refere-se ao fato de a informação ser colhida do próprio indivíduo do qual se deseja obter dados ou de um informante no domicílio, situação essa bastante comum nos levantamentos domiciliares, por razões de logística. Naturalmente, como regra, o uso de informantes tende a piorar a qualidade da informação.

Apesar de quase sempre os resultados desses inquéritos dizerem respeito a grupos populacionais, mesmo que desagregados para subgrupos dessas populações, há que se utilizar essa informação da maneira mais ética possível, garantindo-se a não-identificação de indivíduos ou grupos, particularmente quando esses podem ser vulneráveis à ação de seguradoras ou empregadores. Ditames éticos também devem ser cumpridos durante as realizações das entrevistas, eventuais exames físicos ou coletas de materiais biológicos. À lisura desses procedimentos corresponderá a confiança da população nesses inquéritos, tornando possível a realização sistemática desses levantamentos, principalmente os de base populacional (Viacava, 2002).

Uma limitação dos inquéritos de saúde transversais, assim como de qualquer levantamento que utilize esse desenho de pesquisa, é a impossibilidade de se definirem relações de causa e efeito entre os fenômenos observados. O estudo da literatura pertinente permitirá, quando muito, algumas inferências e hipóteses sobre a realidade instantaneamente fotografada.

Mesmo com um desenho cuidadoso, levando em consideração os aspectos apontados, embora esses levantamentos gozem de boa reputação entre os pesquisadores, há críticas em relação à efetiva utilidade deles. Campos (1993) afirma serem "raros os relatos de sua aplicabilidade". White (1985) critica a falta de comunicação das informações aos 
responsáveis pelo planejamento, assim como certo virtuosismo na manipulação estatística dos dados. Nordberg (1988), após listar uma série de ações que podem ser desencadeadas a partir dos inquéritos domiciliares, diz que "isso raramente tem sido feito na atualidade".

Essas afirmações, mais do que desestimular esse tipo de pesquisa, aumentam a responsabilidade dos agentes envolvidos com a concepção e realização desses inquéritos.

$\mathrm{Na}$ presente tese, decidiu-se analisar os dados obtidos em um extenso inquérito domiciliar, cuja descrição segue adiante, permitindo uma avaliação inicial do programa e gerando informações que possam servir como "linhas de base" para possíveis novas utilizações dessa metodologia na avaliação dessa estratégia de atenção à saúde. 


\section{OBJETIVOS}

\subsection{Geral}

Avaliar possível impacto do Projeto QUALIS no perfil de morbidade aguda e crônica e no perfil de exposição a determinados fatores de risco comportamentais, a partir de um inquérito domiciliar em saúde.

\subsection{Específicos}

a) Analisar as condições de vida das populações adstritas ou não ao Projeto QUALIS por meio de variáveis demográficas, sociais e econômicas.

b) Descrever e comparar o perfil de morbidade referida, aguda e crônica, destas populações.

c) Descrever e comparar o perfil de exposição a alcoolismo, tabagismo e sedentarismo (aqui referidos como estilo de vida) destas populações.

d) Relacionar morbidade referida, aguda e crônica, com o estilo de vida nestas populações. 


\section{MÉTODOS}

\subsection{Programa QUALIS}

Na cidade de São Paulo, o programa iniciou-se em abril de 1996, com a formação das primeiras equipes de saúde da família no bojo do Projeto QUALIS, uma parceria da Secretaria de Estado da Saúde (SES) em articulação com o Ministério da Saúde e a Casa de Saúde Santa Marcelina (CSSM), entidade filantrópica detentora de importante hospital da zona Leste de São Paulo. Na época, a atenção primária em saúde em todo o restante do município de São Paulo estava estruturando- se no Programa de Assistência à Saúde - PAS, modelo que era bastante diverso da estratégia de saúde da família.

A escolha do local para o início do projeto não foi aleatória, visto que a parceria entre SES e CSSM já havia criado, no final dos anos 80, o Programa de Consultórios de Médico de Família, nos moldes do modelo cubano, “com o médico de família trabalhando com um auxiliar de enfermagem e residindo na área de abrangência" (Silva e Damaso, 2002). Apesar de o programa ter-se iniciado com 17 consultórios, restavam apenas sete em funcionamento em 1995. Nesses consultórios remanescentes e em unidades básicas da região, foram implantadas as primeiras equipes, culminando, ao final de 1998, com 40 equipes de saúde da família, atuando em 12 unidades e com um ambulatório de especialidades (particularidade do projeto QUALIS), com cerca de 100 mil pessoas cadastradas.

Em outubro de 1997, o projeto se ampliou para as regiões Norte e Sudeste, dessa vez em parceria com a Fundação Zerbini, surgindo o QUALIS II nos subdistritos de Vila Nova Cachoeirinha, Parque São Lucas e Sapopemba. Nessas áreas, houve ajustes na proposta inicial, particularmente no tocante à contigüidade das áreas cobertas pelo programa, bem 
como um incremento na retaguarda de especialidades. Assim, no final de 1998, o QUALIS II abrangia "35 equipes, sendo 22 na zona Norte e 13, na zona Sudeste, com dois ambulatórios de especialidades, atendimento em saúde bucal e saúde mental, uma casa de parto em Sapopemba" (Silva e Damaso, 2002), cobrindo cerca de 120 mil pessoas.

Ao final de 2000, o QUALIS contava com 802 ACS, parte deles compondo as equipes do Programa de Agentes Comunitários de Saúde (PACS), em que um grupo de ACS era coordenado por uma enfermeira, sem a presença do médico incorporado à equipe. Esse modelo, criado pelo Ministério da Saúde em 1991, a partir de experiências bem sucedidas no estado do Ceará, perdura ainda em alguns locais de São Paulo, embora a tendência seja que essas equipes se transformem paulatinamente em equipes de PSF. É importante que se diga que, formalmente, nunca houve a proposta de implantação de equipes de PACS na cidade de São Paulo. O que houve foi o início da implantação de equipes de PSF com a contratação de ACS, coordenados por uma enfermeira, enquanto se aguardava a contratação dos outros profissionais. Esse processo, algumas vezes, inviabilizou-se pela dificuldade de se incorporarem profissionais médicos, principalmente em locais distantes na periferia. Em 2003, “611.475 paulistanos estavam cadastrados em equipes constituídas apenas por enfermeiros e ACS" (Bousquat et al.,2005). Essa dificuldade perdura ainda hoje.

Já a partir de 2001, com uma nova gestão na cidade, propôs-se a efetiva implantação do PSF no município (Alves Sobrinho et al., 2001), com a criação de novas equipes, em uma parceria entre a Prefeitura Municipal de São Paulo e diversas organizações. Passando a atuar em diversas áreas da capital, o programa atingiu, em agosto de 2002, uma cobertura de $10,3 \%$ da população, com um total de 445 equipes de PSF (incluindo 200 do Projeto QUALIS). Inicialmente, as áreas escolhidas para implantação do programa municipal 
(posteriormente, todas as unidades do QUALIS foram municipalizadas) eram provenientes de Distritos de Saúde com os maiores índices de exclusão social, "configurando um verdadeiro círculo em torno da cidade, que compreende os distritos situados em toda a periferia" (Sousa, 2002). Conquanto aquela administração pensasse em cobrir, com o PSF, cerca de 58\% da população de São Paulo ao final de 2004 (São Paulo, 2001), o que, na prática, ampliaria bastante o perfil socioeconômico da população atendida, isso não ocorreu. A cobertura em 2007 situa-se em algo próximo de 30\% (informação prestada pelo Departamento de Atenção Básica da Secretaria Municipal de Saúde), mantendo, portanto, com raras exceções, o enfoque inicial de atender principalmente as áreas menos favorecidas da cidade.

\section{2 Formato do estudo}

Trata-se de um estudo transversal, na forma de inquérito de saúde domiciliar, realizado entre janeiro e abril de 2001, desenvolvido como parte do projeto "Estudo de Morbidade e de Utilização de Serviços de Saúde da População Coberta pelo Projeto QUALIS”, coordenado pelo Departamento de Medicina Preventiva da Faculdade de Medicina da Universidade de São Paulo. Este projeto, por sua vez, está inserido no estudo multicêntrico "Novos modelos de assistência à saúde: Avaliação do Programa de Saúde (PSF) no Município de São Paulo”.

Este projeto foi aprovado pelo Comitê de Ética em Pesquisa do Hospital das Clínicas da Faculdade de Medicina da Universidade de São Paulo (CAPPesq).

O projeto original foi financiado pela Fundação de Amparo à Pesquisa no Estado de São Paulo (FAPESP). 


\section{3 Área do estudo e população}

Os dados foram coletados de dois distritos de saúde de São Paulo: a Vila Nova Cachoeirinha e a Vila Curuçá, ambos, na época, parcialmente cobertos pelo Programa de Saúde da Família por intermédio do Projeto QUALIS. Cada um dos distritos foi subdividido em dois: um deles correspondente à área coberta pelo PSF e outro à área não coberta. A população de ambos os distritos compreendia cerca de 190 mil pessoas, sendo cerca de 137 mil maiores de 15 anos (faixa etária enfocada no nosso presente estudo), distribuídos da maneira que, a seguir, se apresenta.

a) Distrito de Vila Nova Cachoeirinha - área de abrangência do PSF (UBS's - de Vila Galvão e Ilza Hutzler): 33.949 residentes, sendo 25.957 maiores de 15 anos.

b) Distrito de Vila Nova Cachoeirinha - fora da área de abrangência do PSF: 76.638 residentes, sendo 55.939 maiores de 15 anos.

c) Distrito de Vila Curuçá - área de abrangência do PSF (UBS's Silva Teles e Santa Rita): 27.589 residentes, sendo 18.389 maiores de 15 anos.

d) Distrito de Vila Curuçá - fora da área de abrangência do PSF: 52.521 residentes, sendo 36.468 maiores de 15 anos.

\subsection{Estratégia de amostragem}

Foi feita uma amostragem por conglomerados. Calculou-se o tamanho da amostra com a seguinte fórmula:

$n=\frac{P \cdot(1-P) \cdot t^{2}}{d^{2}} \cdot d e f f$ 
sendo $\mathrm{P}$ a proporção populacional de interesse, $\mathrm{t}$ o valor associado à curva normal correspondente ao nível de confiança desejado (1- $\alpha$ ), d o erro de amostragem tolerado e deff o efeito do delineamento.

Adotando-se $\hat{P}=0,50$, valor que leva à determinação do tamanho máximo de amostra; $\mathrm{t}=1,96$, para o nível de confiança de $95 \%(\alpha=0,05)$, deff=2 e d=8\%, obtém-se $\mathrm{n}=300$.

Utilizando-se como parâmetro uma proporção de 30\% de indivíduos com uma queixa de episódio agudo de morbidade nos 15 dias anteriores à entrevista (valor aproximado da literatura) e levando-se em conta o interesse em se calcular amostra para indivíduos desse subgrupo, o tamanho da amostra passa a ser de 300/0,30=1000 indivíduos.

Como a população é identificada no espaço geográfico pelo domicílio em que reside, o tamanho da amostra será determinado em função do número de domicílios, considerando m=1000/média de indivíduos por domicílio. Na contagem do IBGE de 1996, essa média foi de aproximadamente 4 para os distritos de Cachoeirinha e Vila Curuçá, resultando em $\mathrm{m}=1000 / 4=250$ domicílios.

Considerando-se, ainda, que a taxa de não-resposta será de $15 \%$, foram sorteados 250/0,85=295 domicílios em cada estrato.

A amostra será estratificada, com sorteio em dois estágios: estratos b) e d), fora da área de abrangência do Projeto Qualis; e estratos a) e c), dentro da área de abrangência do Projeto.

Foram adotados como unidades primária e secundária de amostragem, respectivamente, o setor censitário e o domicílio. Todos os moradores dos domicílios sorteados devem ser incluídos na amostra. 
No primeiro estágio, trinta setores censitários foram sorteados com probabilidade proporcional ao tamanho, dado pelo número de domicílios existentes em cada setor, $M_{\alpha}$, segundo a contagem feita pelo IBGE em 1996. Em cada um desses setores, foram sorteados 10 domicílios com probabilidade $1 / M_{\alpha}$.

As frações de amostragem foram:

$1^{\mathrm{o}}$. Estágio $\rightarrow f_{1}=\frac{30 \cdot M_{\alpha}}{M}$

$2^{\circ}$. Estágio $\rightarrow f_{2}=\frac{10}{M_{\alpha}}$

global $\rightarrow f=\frac{300}{M}$

Para se efetuar o sorteio, os setores censitários com 500 a 1000 domicílios foram divididos em dois e aqueles com mais de 1000 domicílios foram desmembrados em três. Os setores que tinham parte de seus domicílios dentro da área de abrangência do Qualis tiveram seus limites também redefinidos, sendo que, quando havia somente uma pequena parte do setor fora da área do Projeto e essa pequena parte foi anexada ao setor contíguo. As estimativas dos números de domicílios dos setores alterados foram feitas com base nas áreas (identificadas nos mapas do IBGE) incluídas ou excluídas.

Já nos extratos a) e c) (áreas de abrangência do Qualis), aproveitou-se a divisão por microáreas, que correspondem às áreas cobertas por um único agente comunitário de saúde. As microáreas constituíram as unidades primárias de amostragem, sorteadas com probabilidade proporcional ao número de famílias cadastradas em cada uma delas, $M_{\alpha}$, 
conforme registro das unidades de saúde. A unidade secundária de amostragem foi família, sorteada a partir dos cadastros existentes.

Foram sorteadas 30 microáreas e 10 famílias em cada microárea.

A fração de amostragem foi $f=\frac{30 \cdot M_{\alpha}}{M} \cdot \frac{10}{M_{\alpha}}=\frac{300}{M}$

\section{Estimadores}

Os estimadores de proporções serão expressos por:

$r=\frac{y}{x}=\frac{\sum_{i=1}^{n} w_{i} \cdot y_{i}}{\sum_{i=1}^{n} w_{i} \cdot x_{i}}$

onde $w_{i}$ é o peso de cada elemento, dado pelo inverso de sua fração de amostragem

$$
\begin{aligned}
& y_{i} \text { é o valor da característica do elemento i } \\
& x_{i}=1 \text { para os elementos da amostra. }
\end{aligned}
$$

A precisão das estimativas será indicada pelo intervalo de confiança (nível de confiança de 95\%):

$$
\begin{aligned}
& I C=\left[\frac{y}{x}-1,96 \sqrt{\operatorname{var}\left(\frac{y}{x}\right)} ; \frac{y}{x}+1,96 \sqrt{\operatorname{var}\left(\frac{y}{x}\right)}\right] \\
& \operatorname{var}\left(\frac{y}{x}\right)=\frac{1}{x^{2}}\left[\operatorname{var}(y)+\left(\frac{y}{x}\right)^{2} \operatorname{var}(x)-2\left(\frac{y}{x}\right) \operatorname{cov}(x, y)\right] \\
& \operatorname{var}(y)=(1-f) \frac{a}{a-1}\left(\sum_{\alpha=1}^{a} y_{\alpha}^{2}-\frac{y^{2}}{a}\right)
\end{aligned}
$$


$y_{\alpha}$ é o total da característica de interesse na unidade primária $\alpha$

$$
y=\sum_{\alpha=1}^{a} y_{\alpha}
$$

De tal forma que a amostra foi constituída por 1.200 famílias residentes nessas áreas (300 famílias por estrato), sendo 1.180 efetivamente entrevistadas, com cada morador sendo entrevistado e fazendo parte do espaço amostral, perfazendo um total de 3.886 entrevistas, sendo 2.515 realizadas com maiores de 15 anos. A taxa de recusa familiar foi de 3,1\%, tendo-se encontrado $7,5 \%$ de domicílios vazios ou fechados.

\subsection{Coleta de dados}

As equipes de entrevistadores foram treinadas para realizar o trabalho de campo e foram as mesmas que atuaram em cada uma das quatro áreas da pesquisa.

\subsection{Questionário e variáveis}

Foram utilizados, no trabalho atual, os blocos 1, 2, 6, 7, 8, 9 e 13 (anexos) do questionário original. Neles, encontramos o quadro de indivíduos do domicílio, com dados sociodemográficos; morbidade aguda (15 dias anteriores à entrevista) e crônica (último ano); fumo, atividade física e álcool, além das condições socioeconômicas. Com exceção desse último bloco, cujas respostas foram dadas pelo chefe de família, as demais foram respondidas pelo próprio indivíduo. 
A variável renda per capita foi construída dividindo-se a renda do chefe da família pelo número de pessoas do domicílio.

Em relação a estilo de vida, quando utilizadas como variáveis independentes, foram formadas as categorias que se seguem. Atividade física também permaneceu nessa forma quando utilizada como variável dependente na análise univariada.

Fumo

- Não fumante: nunca usou cigarros, cachimbo, cigarrilha, charuto ou cigarro de palha.

- Fumante passivo: qualquer resposta positiva à questão "quantas horas você fica exposto ou próximo de alguém fumando" (só perguntada para não-fumantes).

- Ex-fumante: qualquer referência a consumo anterior de fumo.

- Fumante leve: menos de 20 cigarros/dia.

- Fumante pesado: mais de 20 cigarros/dia.

\section{Álcool}

- Nunca consumiu: nunca fez uso de bebida alcoólica na vida.

- Ex-consumidor: fez uso de bebida alcoólica na vida, porém, não nos últimos 12 meses.

- Consumidor leve: nos últimos 7 dias, fez uso de no máximo 1 dose por dia.

- Consumidor moderado: no caso dos homens, nos últimos 7 dias, fez uso de mais de uma dose e no máximo 3 doses/dia; para as mulheres, mais de uma dose e no máximo 2 doses/dia. 
- Consumidor excessivo: no caso dos homens, nos últimos 7 dias, fez uso de 4 ou mais doses/dia; para as mulheres, 3 ou mais doses/dia.

\section{Atividade física}

- Ativo : faz 120 ou mais minutos de atividade física por semana, seja nos esportes, lazer ou trabalho "pesado".

- Pouco ativo: faz mais de zero e menos de 120 minutos de atividade física por semana nos esportes, lazer ou trabalho "pesado", ou pelo menos 150 minutos ou mais de atividade física "leve" no trabalho.

- Sedentário: todos os outros indivíduos que não se enquadravam na classificação apresentada.

Quando fumo e álcool foram considerados variáveis dependentes, optou-se por uma simplificação das categorias de análise, agrupando-as em duas, como segue:

a) não-fumante e fumante (ex-fumante + fumante leve + fumante pesado); b) não consumidor de álcool (nunca consumiu) e consumidor de álcool (ex-consumidor + consumidor leve + consumidor moderado + consumidor excessivo).

Atividade física, quando considerada dependente na sua análise multivariada, foi dividida entre sedentário e não-sedentário (ativo + pouco ativo). 


\subsection{Análise dos dados}

Descrevem-se no presente estudo as características socioeconômicas de cada um dos distritos, delineando-se o perfil das famílias cobertas e não cobertas pelo PSF em cada um deles e a faz-se comparação, com as populações dos dois distritos agrupadas, entre as áreas cobertas e não cobertas pelo programa. A análise estatística empregou estimativa de proporções, própria para conglomerados, e teste do qui-quadrado de Pearson, corrigido pela aproximação de Satterthwaite e transformado em distribuição F, como recomendado no programa Stata (StataCorp.,2005).

Foi utilizada a análise univariada para apresentar-se a morbidade aguda (qualquer doença nos últimos 15 dias), morbidade crônica (hipertensão arterial sistêmica, diabetes mellitus e doença isquêmica do coração - insuficiência coronariana e infarto agudo do miocárdio - e tuberculose) e estilo de vida. Quando encontradas diferenças significantes de prevalência para o conjunto de categorias de determinada variável, para se definirem melhor essas diferenças estabeleceu-se a primeira categoria descrita como categoria referência e calculou-se a significância das diferenças existentes entre cada uma das outras categorias e a categoria referência. Apenas excepcionalmente, quando este procedimento não foi capaz de elucidar a questão, recorreu-se a outros modos de comparação entre categorias para situar diferenças significantes encontradas no conjunto de categorias de determinada variável.

O procedimento original foi repetido, dividindo-se por área coberta ou não pelo PSF.

Na análise multivariada foi realizada a Regressão de Poisson para conglomerados (Mendoza-Sassi et al., 2003), estimando-se a razão de prevalência (com intervalo de 95\% de confiança e nível de significância das associações), tendo-se excluído a tuberculose por 
apresentar resultados inconsistentes, possivelmente devido ao limitado número de casos. Iniciou-se o modelo incluindo todas as potenciais variáveis de confusão (sexo, idade, consumo de álcool, tabaco, nível de atividade física e as variáveis socioeconômicas) que apresentaram $\mathrm{p}<0,20$ na análise univariada. Subseqüentemente foram excluídas as variáveis, uma por vez e segundo ordem decrescente do valor de p, que apresentaram $\mathrm{p} \geq 0,05$.

Quando se fez a análise multivariada das amostras divididas por área (PSF e não-PSF), colocaram-se no modelo apenas as quatro variáveis consideradas de maior potencial explicativo (sexo, faixa etária, escolaridade e renda), já que as variáveis restantes, mesmo que permanecessem como independentes, dificilmente poderiam justificar a sua associação. 


\section{RESULTADOS}

\subsection{Características sociodemográficas.}

Quando se compara o perfil dos indivíduos residentes nas Vilas Nova Cachoeirinha VNC (Zona Norte de São Paulo) e Curuçá - VC (Zona Leste) incluídos na amostra, verifica-se um perfil bastante semelhante das populações (dados não apresentados). Em ambas as regiões, há um discreto predomínio do sexo feminino e claro predomínio da faixa etária dos 15 aos 29 anos; as proporções de solteiros e de casados apresentam valores bem próximos; é maior a proporção de pessoas com escolaridade entre a $5^{\mathrm{a}}$ série e o último ano do curso médio, há maior proporção de pessoas empregadas, há um predomínio de cobertura previdenciária pelo Instituto Nacional de Seguridade Social (INSS) e de quem procura o setor público (SUS/PSF) para assistência à saúde, sendo que aqueles que referem convênio ou seguro-saúde variam de 27,1\% na VNC a 23,6\% na VC (incluindo UNIMED), sendo o tipo de moradia mais freqüente as casas, em ambos os bairros.

Em cada bairro, podem ser comparadas as populações segundo a cobertura PSF (dados não apresentados). $\mathrm{Na} \mathrm{VNC}$ as diferenças significantes são: a população coberta apresenta maior proporção de indivíduos com 60 anos ou mais, maior proporção de procedentes do interior de São Paulo - SP - (enquanto a proporção de procedentes de outros estados é maior na área não coberta), maior proporção de desempregados, maior proporção de moradias de aluguel (em contrapartida a uma maior proporção de famílias quitando a sua moradia própria na área não-PSF), maior proporção de famílias domiciliadas em casas (com proporcionalmente mais apartamentos e barracos na área não-PSF, onde há maior quantidade de moradias em conjuntos habitacionais e favelas), quase toda ela tem conta 
com a rede de abastecimento de água (contra 13,7\% sem conta na área não-PSF), é atendida pelo sistema público de coleta de esgotos (vs 10,9\% sem esse sistema na área não-PSF) e tem energia elétrica com pagamento de conta (vs 8,1\% com energia elétrica, mas sem pagamento de conta, na área não-PSF). Ressalte-se que apenas pouco mais de um terço da população da área do PSF $(38,2 \%)$ referem procurar assistência médica no próprio PSF, enquanto $2,3 \%$ dos indivíduos da área não-PSF referem procurar assistência junto a esse programa.

Já na VC, as semelhanças entre as populações são maiores. Encontram-se diferenças significantes no tipo de procura por assistência (por exemplo, a utilização de convênio/medicina de grupo é de $14,2 \%$ na área PSF vs $24,1 \%$ na área não-PSF), maior percentagem de residência própria quitada ou aluguel na área PSF (vs própria pagando e cedida na área não-PSF) e menor quantidade de esgoto por sistema público na área PSF (88,3 vs 96,9\% na área não-PSF). Também aqui há uma porcentagem relativamente pequena de pacientes que procuram o PSF, mesmo na sua área de abrangência $(42,6 \%)$, convivendo com um percentual elevado de procura ao SUS/Público (35,7\%), assim como na VNC.

Quando se analisa em conjunto a população de ambas as áreas e elas são observadas segundo a cobertura do PSF (dados não apresentados), parte das diferenças significantes existentes principalmente na VNC, se mantêm: maior proporção de idosos no PSF, maior proporção nas categorias de maior renda na área não-PSF, maior proporção de moradias em casas (vs apartamentos na área não-PSF), maior proporção de residências próprias quitadas e de aluguel na área PSF (contra um maior número de próprias quitando na área não-PSF) e maior proporção de ausência de contas de água na área não-PSF (10,3 vs 1,1\% da área PSF). A utilização do PSF, na área de cobertura, restringe-se a 40\%. 


\subsection{Morbidade}

\subsubsection{Morbidade aguda}

Na tabela 2, encontra-se a apresentação da prevalência de morbidade aguda, ou seja, qualquer episódio de doença referido nos 15 dias anteriores à entrevista. Observa-se que estes episódios agudos foram significantemente mais prevalentes nas mulheres $(20,4$ vs $13,4 \%$ ), nas categorias de idade maior que 44 anos, nos casados, divorciados ou separados quando comparados aos solteiros, nos procedentes de outros estados, nos inativos quando comparados aos informais/autônomos e nos indivíduos da VNC; e menos prevalentes na categoria de escolaridade de $5^{\mathrm{a}}$ a $8^{\mathrm{a}}$ séries e naqueles com cobertura previdenciária privada. Não se observam diferenças significantes entre as categorias de renda, de cobertura PSF e de religião. Há tendência linear significativa para idade.

Tabela 2. Distribuição da prevalência de morbidade aguda segundo variáveis sóciodemográficas. Vila Nova Cachoeirinha e Vila Curuçá, São Paulo, 2001.

\begin{tabular}{|c|c|c|c|c|c|}
\hline \multirow[t]{2}{*}{ VARIÁVEL CATEGORIA } & \multicolumn{5}{|c|}{ Tiveram episódios agudos } \\
\hline & $\begin{array}{c}\text { Total } \\
\mathrm{N} \\
\end{array}$ & $\mathrm{N}$ & $\%$ & IC (95\%) & $\mathrm{P}$ \\
\hline \multicolumn{6}{|l|}{ SEXO } \\
\hline Feminino & 1491 & 305 & 20,4 & $17,0-24,1$ & \\
\hline Masculino & 1273 & 154 & 13,4 & $11,0-16,3$ & * \\
\hline \multicolumn{6}{|l|}{ FAIXA ETÁRIA (anos) } \\
\hline $15-29$ & 1072 & 124 & 11,9 & $9,0-15,5$ & \\
\hline $30-44$ & 854 & 129 & 15,3 & $11,4-20,2$ & \\
\hline $45-59$ & 529 & 117 & 22,6 & $18,1-27,9$ & * \\
\hline 60 ou mais & 309 & 89 & 31,3 & $25,7-37,6$ & * \\
\hline
\end{tabular}

Continua 
Tabela 2. Distribuição da prevalência de morbidade aguda segundo variáveis sóciodemográficas. Vila Nova Cachoeirinha e Vila Curuçá, São Paulo, 2001. (Continuação)

\begin{tabular}{|c|c|c|c|c|c|c|}
\hline \multirow[t]{2}{*}{ VARIÁVEL } & \multirow[t]{2}{*}{ CATEGORIA } & \multicolumn{5}{|c|}{ Tiveram episódios agudos } \\
\hline & & $\begin{array}{c}\text { Total } \\
\mathrm{N} \\
\end{array}$ & $\mathrm{N}$ & $\%$ & IC $(95 \%)$ & $\mathrm{P}$ \\
\hline \multicolumn{7}{|c|}{ ESTADO CIVIL } \\
\hline & Solteiro & 1020 & 145 & 14,5 & $11,8-17,9$ & \\
\hline & Casado & 1007 & 171 & 18,1 & $14,8-21,9$ & $*$ \\
\hline & Divorciado ou separado & 67 & 16 & 26,9 & $17,1-39,6$ & * \\
\hline & "Concubinato" & 73 & 13 & 20,4 & $11,5-33,4$ & \\
\hline & Viúvo & 422 & 59 & 12,5 & $8,6-17,6$ & \\
\hline \multicolumn{7}{|c|}{ ESCOLARIDADE } \\
\hline & Nenhuma & 139 & 33 & 21,3 & $14,0-31,0$ & \\
\hline & Ensino Fundamental $1^{\mathrm{a}}$ a $4^{\mathrm{a}}$ séries & 753 & 167 & 24,4 & $19,8-29,6$ & \\
\hline & Ensino Fundamental $5^{\mathrm{a}}$ a $8^{\mathrm{a}}$ séries & 848 & 122 & 14,3 & $11,5-17,8$ & * \\
\hline & Ensino Médio completo ou incompleto & 812 & 118 & 15,2 & $11,3-20,1$ & \\
\hline & Superior completo ou incompleto & 175 & 18 & 12,3 & $7,7-19,0$ & \\
\hline \multicolumn{7}{|c|}{ PROCEDÊNCIA } \\
\hline & SP capital & 1320 & 174 & 13,9 & $11,1-17,2$ & \\
\hline & SP interior & 302 & 55 & 19,3 & $14,2-25,7$ & \\
\hline & Outros estados & 1096 & 223 & 20,9 & $17,3-25,0$ & * \\
\hline \multicolumn{7}{|l|}{ RELIGIÃO } \\
\hline & Catolicismo & 1764 & 282 & 16,5 & $13,9-19,4$ & \\
\hline & Evangélico & 640 & 126 & 20,7 & $16,6-25,4$ & \\
\hline & Outras & 343 & 51 & 15,4 & $10,0-23,0$ & \\
\hline \multicolumn{7}{|c|}{ RENDA (SM per capita) } \\
\hline & $<0,5$ & 275 & 39 & 14,1 & $9,5-20,5$ & \\
\hline & $0,50-0,99$ & 425 & 87 & 18 & $13,7-23,4$ & \\
\hline & $1,00-1,99$ & 667 & 119 & 20,6 & $16,0-26,2$ & \\
\hline & $2,00-4,99$ & 691 & 129 & 19,2 & $15,1-24,0$ & \\
\hline & 5,00 ou mais & 162 & 27 & 17,7 & $10,3-26,7$ & \\
\hline SITUAÇÃO & ATUAL DE TRABALHO** & & & & & $*$ \\
\hline & Empregado & 1128 & 174 & 16,7 & $12,6-21,8$ & \\
\hline & Desempregado & 203 & 31 & 15,2 & $9,7-22,9$ & \\
\hline & Informal/Autônomo & 687 & 96 & 13,1 & $10,0-16,8$ & \\
\hline & Inativo & 709 & 152 & 22,8 & $18,3-28,0$ & \\
\hline \multicolumn{7}{|c|}{ COBERTURA PREVIDENCIÁRIA } \\
\hline & Nenhuma & 898 & 152 & 17,7 & $14,1-22,1$ & \\
\hline & INSS & 1481 & 249 & 17,7 & $14,6-21,2$ & \\
\hline & Privada & 182 & 15 & 8,2 & $4,7-13,8$ & $*$ \\
\hline & Setor Público & 147 & 33 & 21,6 & $15,9-28,8$ & \\
\hline \multicolumn{7}{|c|}{ LOCAL DE MORADIA } \\
\hline & Vila Nova Cachoeirinha & 1392 & 264 & 19,5 & $16,0-23,6$ & \\
\hline & Vila Curuçá & 1372 & 195 & 13,6 & $10,9-16,8$ & $*$ \\
\hline
\end{tabular}

\section{Continua}


Tabela 2. Distribuição da prevalência de morbidade aguda segundo variáveis sóciodemográficas. Vila Nova Cachoeirinha e Vila Curuçá, São Paulo, 2001. (Conclusão)

\begin{tabular}{|c|c|c|c|c|c|}
\hline \multirow[t]{2}{*}{ VARIÁVEL CATEGORIA } & \multicolumn{5}{|c|}{ Tiveram episódios agudos } \\
\hline & $\begin{array}{c}\text { Total } \\
\mathrm{N}\end{array}$ & $\mathrm{N}$ & $\%$ & IC $(95 \%)$ & $\mathrm{P}$ \\
\hline \multicolumn{6}{|l|}{ ÁREA DE MORADIA } \\
\hline PSF & 1336 & 261 & 19,9 & $16,9-23,2$ & \\
\hline Não-PSF & 1428 & 198 & 15,8 & $12,6-19,8$ & \\
\hline
\end{tabular}

Realizando-se a análise multivariada, observa-se Razão de Prevalência significantemente maior entre os que tiveram um episódio agudo de doença para as categorias de faixa etária a partir dos 30 a 44 anos e menor, para as categorias masculino, trabalho informal ou autônomo e cobertura previdenciária privada (Tabela 3). Não houve associação significativa com escolaridade, renda e as variáveis de estilo de vida.

Tabela 3. Análise multivariada da prevalência de morbidade aguda. Vila Nova Cachoeirinha e Vila Curuçá, São Paulo, 2001.**

\begin{tabular}{llccc}
\hline Variável & Categorias & $\begin{array}{c}\text { Razão de } \\
\text { prevalência }\end{array}$ & IC 95\%* & p \\
\hline Sexo & Feminino & 1,00 & & \\
& Masculino & 0,69 & $0,56-0,85$ & $*$ \\
Faixa etária (anos) & & & \\
& $15-29$ & 1,00 & & \\
30-44 & 1,33 & $1,02-1,75$ & $*$ \\
& $45-59$ & 1,88 & $1,34-2,65$ & $*$ \\
& 60 ou mais & 2,49 & $1,84-3,37$ & $*$ \\
Situação atual de trabalho & & & \\
& Empregado & 1,00 & & \\
Desempregado & 0,75 & $0,44-1,28$ & \\
Informal/Autônomo & 0,66 & $0,44-0,98$ & $*$ \\
Inativo & 1,04 & $0,77-1,39$ &
\end{tabular}

\section{Continua}


Tabela 3. Análise multivariada da prevalência de morbidade aguda. Vila Nova Cachoeirinha e Vila Curuçá, São Paulo, 2001.** (Conclusão)

\begin{tabular}{ccccc}
\hline Variável Categorias & $\begin{array}{c}\text { Razão de } \\
\text { prevalência }\end{array}$ & IC 95\%* & p \\
\hline Cobertura previdenciária & & & & \\
Nenhuma & 1,00 & & \\
INSS & 0,78 & $0,60-1,01$ & \\
Privada & 0,39 & $0,21-0,72$ & $*$ \\
Setor Público & 0,84 & $0,56-1,27$ & \\
\hline
\end{tabular}

$* \mathrm{p}<0,05$

**resultados ajustados para as variáveis sexo, idade, estado civil, escolaridade, procedência, religião, renda, situação atual de trabalho e cobertura previdenciária, consumo de álcool, consumo de fumo e atividade física.

Realizando-se a análise segundo a cobertura do PSF (Tabela 4), nota-se prevalência significantemente maior de episódios agudos com o aumento da idade, procedência de outros estados em ambas as áreas. Prevalência maior de episódios nos solteiros e casados na categoria estado civil e entre aqueles com escolaridade da $1^{\mathrm{a}}$ à $4^{\mathrm{a}}$ série em relação àqueles da $5^{\mathrm{a}}$ à $8^{\mathrm{a}}$ série encontra-se apenas na área não-PSF. Já na área de cobertura PSF, há prevalência significantemente menor na categoria com cobertura previdenciária privada e na população residente na VC.

Tabela 4. Prevalência de morbidade aguda segundo cobertura PSF e variáveis sociodemográficas. Vila Nova Cachoeirinha e Vila Curuçá, São Paulo, 2001.

\begin{tabular}{|c|c|c|c|c|c|c|c|c|c|c|c|}
\hline \multirow[t]{3}{*}{ VARIÁVEL } & \multirow[t]{3}{*}{ CATEGORIA } & \multicolumn{4}{|c|}{$\begin{array}{c}\text { Área Coberta pelo PSF } \\
\text { Tiveram episódios }\end{array}$} & \multicolumn{6}{|c|}{$\begin{array}{r}\text { Área Não Coberta pelo PSF } \\
\text { Tiveram episódios }\end{array}$} \\
\hline & & \multirow{2}{*}{$\begin{array}{c}\text { Total } \\
\mathrm{N}\end{array}$} & & \multicolumn{2}{|c|}{ agudos } & \multirow[b]{2}{*}{$\mathrm{P}$} & \multicolumn{2}{|c|}{ Total } & \multicolumn{2}{|c|}{ agudos } & \multirow[b]{2}{*}{$\mathrm{P}$} \\
\hline & & & $\mathrm{N}$ & $\%$ & IC $95 \%$ & & $\mathrm{~N}$ & $\mathrm{~N}$ & $\%$ & IC $95 \%$ & \\
\hline \multicolumn{12}{|l|}{ SEXO } \\
\hline & Feminino & 728 & 171 & 23,9 & $20,1-28,1$ & & 763 & 134 & 18,6 & $14,2-24,0$ & \\
\hline & Masculino & 608 & 90 & 15,1 & $11,9-18,9$ & * & 665 & 64 & 12,6 & $9,4-16,7$ & * \\
\hline \multicolumn{12}{|c|}{ FAIXA ETÁRIA (anos) } \\
\hline & $15-29$ & 475 & 69 & 15,2 & $11,6-19,7$ & & 597 & 55 & 10,5 & $6,8-15,7$ & \\
\hline & $30-44$ & 402 & 77 & 18,6 & $14,8-23,1$ & & 452 & 52 & 13,8 & $8,7-21,2$ & \\
\hline & $45-59$ & 273 & 63 & 23,6 & $18,6-29,4$ & $*$ & 256 & 54 & 22,1 & $15,9-29,8$ & * \\
\hline & 60 ou mais & 186 & 52 & 28,5 & $21,5-36,6$ & * & 123 & 37 & 33,6 & $25,3-43,0$ & $*$ \\
\hline
\end{tabular}

Continua 
Tabela 4. Prevalência de morbidade aguda segundo cobertura PSF e variáveis sociodemográficas. Vila Nova Cachoeirinha e Vila Curuçá, São Paulo, 2001. (Continuação)

\begin{tabular}{|c|c|c|c|c|c|c|c|c|c|c|c|}
\hline \multirow[t]{3}{*}{ VARIÁVEL } & \multirow[t]{3}{*}{ CATEGORIA } & \multicolumn{4}{|c|}{$\begin{array}{l}\text { Área Coberta pelo PSF } \\
\text { Tiveram episódios }\end{array}$} & \multicolumn{6}{|c|}{$\begin{array}{r}\text { Área Não Coberta pelo PSF } \\
\text { Tiveram episódios }\end{array}$} \\
\hline & & \multirow{2}{*}{$\begin{array}{c}\text { Total } \\
\mathrm{N}\end{array}$} & \multirow[b]{2}{*}{$\mathrm{N}$} & \multicolumn{2}{|c|}{ agudos } & \multirow[b]{2}{*}{$\mathrm{P}$} & Total & & \multicolumn{2}{|c|}{ agudos } & \multirow[b]{2}{*}{$\mathrm{P}$} \\
\hline & & & & $\%$ & IC $95 \%$ & & $\mathrm{~N}$ & $\mathrm{~N}$ & $\%$ & IC $95 \%$ & \\
\hline \multicolumn{12}{|c|}{ ESTADO CIVIL } \\
\hline & Solteiro & 493 & 93 & 19,3 & $15,2-24,3$ & & 527 & 52 & 11,9 & $8,7-16,2$ & \\
\hline & Casado & 490 & 97 & 19,7 & $15,5-24,8$ & & 517 & 74 & 17,4 & $13,1-22,7$ & $*$ \\
\hline & Divorciado ou separado & 41 & 10 & 24,7 & $14,3-39,4$ & & 26 & 6 & 28,8 & $14,1-49,8$ & $*$ \\
\hline & "Concubinato" & 32 & 6 & 21,8 & $10,2-40,6$ & & 41 & 7 & 19,8 & $9,3-37,4$ & \\
\hline & Viúvo & 179 & 24 & 13,8 & $9,8-19,1$ & & 243 & 35 & 11,9 & $7,1-19,2$ & \\
\hline \multicolumn{11}{|c|}{ ESCOLARIDADE** } & $*$ \\
\hline & Nenhuma & 72 & 19 & 26,8 & $18,1-37,6$ & & 67 & 14 & 18,2 & $8,9-33,4$ & \\
\hline & Ensino Fundamental $1^{\mathrm{a}}$ a $4^{\mathrm{a}}$ séries & 366 & 89 & 24,1 & $19,1-29,9$ & & 387 & 78 & 24,6 & $18,2-32,3$ & \\
\hline & Ensino Fundamental $5^{\mathrm{a}}$ a $8^{\mathrm{a}}$ séries & 412 & 76 & 19,3 & $15,2-24,1$ & & 436 & 46 & 12,0 & $8,5-16,6$ & \\
\hline & $\begin{array}{l}\text { Ensino Médio completo ou } \\
\text { incompleto }\end{array}$ & 399 & 69 & 17,4 & $12,7-23,4$ & & 413 & 49 & 14,1 & $9,0-21,4$ & \\
\hline & Superior completo ou incompleto & 71 & 7 & 11,2 & $5,1-23,0$ & & 104 & 11 & 12,6 & $7,1-21,3$ & \\
\hline \multicolumn{12}{|c|}{ PROCEDÊNCIA } \\
\hline & SP capital & 641 & 104 & 17,0 & $13,5-21,2$ & & 679 & 70 & 12,4 & $8,7-17,3$ & \\
\hline & SP interior & 166 & 31 & 18,2 & $12,9-25,1$ & & 136 & 24 & 20,0 & $12,7-30,2$ & \\
\hline & Outros estados & 506 & 121 & 24,1 & $20,0-28,7$ & $*$ & 590 & 102 & 19,5 & $14,8-25,1$ & $*$ \\
\hline \multicolumn{12}{|l|}{ RELIGIÃO } \\
\hline & Catolicismo & 859 & 165 & 19,6 & $16,4-23,3$ & & 905 & 117 & 15,0 & $11,6-19,2$ & \\
\hline & Evangélico & 319 & 71 & 23,0 & $17,7-29,3$ & & 321 & 55 & 19,4 & $14,0-26,2$ & \\
\hline & Outras & 153 & 25 & 15,5 & $9,9-23,4$ & & 190 & 26 & 15,4 & $8,5-26,3$ & \\
\hline \multicolumn{12}{|c|}{ RENDA (SM per capita) } \\
\hline & $<0,5$ & 131 & 25 & 19,4 & $12,5-28,8$ & & 144 & 14 & 11,5 & $6,1-20,7$ & \\
\hline & $0,50-0,99$ & 230 & 55 & 23,7 & $18,0-30,5$ & & 195 & 32 & 14,4 & $8,9-22,5$ & \\
\hline & $1,00-1,99$ & 359 & 67 & 19,2 & $14,9-24,3$ & & 308 & 52 & 21,5 & $14,7-30,2$ & \\
\hline & $2,00-4,99$ & 376 & 75 & 20,7 & $16,1-26,3$ & & 315 & 54 & 18,3 & $12,9-25,5$ & \\
\hline & 5,00 ou mais & 57 & 7 & 12,3 & $6,9-21,0$ & & 105 & 20 & 18,8 & $10,0-32,4$ & \\
\hline \multicolumn{12}{|c|}{ SITUAÇÃO ATUAL DE TRABALHO } \\
\hline & Empregado & 518 & 99 & 19,8 & $15,3-25,1$ & & 610 & 75 & 15,5 & $10,2-22,8$ & \\
\hline & Desempregado & 87 & 19 & 21,2 & $14,0-30,8$ & & 116 & 12 & 12,7 & $6,2-24,2$ & \\
\hline & Informal/Autônomo & 319 & 49 & 15,0 & $10,9-20,3$ & & 368 & 47 & 12,1 & $8,4-17,3$ & \\
\hline & Inativo & 389 & 90 & 23,6 & $18,2-30,0$ & & 320 & 62 & 22,2 & $15,9-30,3$ & \\
\hline \multicolumn{12}{|c|}{ COBERTURA PREVIDENCIÁRIA } \\
\hline & Nenhuma & 448 & 85 & 18,3 & $14,0-23,5$ & & 450 & 67 & 17,5 & $12,6-23,8$ & \\
\hline & INSS & 665 & 138 & 21,6 & $17,8-26,0$ & & 816 & 111 & 16,0 & $12,2-20,8$ & \\
\hline & Privada & 101 & 8 & 8,8 & $4,4-16,8$ & * & 81 & 7 & 7,9 & $3,6-16,4$ & \\
\hline & Setor Público & 85 & 22 & 26,0 & $15,8-39,6$ & & 62 & 11 & 18,6 & $12,7-26,4$ & \\
\hline \multicolumn{12}{|c|}{ LOCAL DE MORADIA } \\
\hline & Vila Nova Cachoeirinha & 681 & 156 & 22,7 & $18,3-27,8$ & & 711 & 108 & 18,1 & $13,5-23,8$ & \\
\hline & Vila Curuçá & 655 & 105 & 15,9 & $12,9-19,5$ & $*$ & 717 & 90 & 12,5 & $9,0-17,1$ & \\
\hline
\end{tabular}

\section{Continua}


Tabela 4. Prevalência de morbidade aguda segundo cobertura PSF e variáveis sociodemográficas. Vila Nova Cachoeirinha e Vila Curuçá, São Paulo, 2001. (Conclusão)

\begin{tabular}{|c|c|c|c|c|c|c|c|c|c|c|c|}
\hline \multirow[t]{3}{*}{ VARIÁVEL } & \multirow[t]{3}{*}{ CATEGORIA } & \multicolumn{4}{|c|}{$\begin{array}{c}\text { Área Coberta pelo PSF } \\
\text { Tiveram episódios }\end{array}$} & \multicolumn{6}{|c|}{$\begin{array}{r}\text { Área Não Coberta pelo PSF } \\
\text { Tiveram episódios }\end{array}$} \\
\hline & & \multirow{2}{*}{$\begin{array}{c}\text { Total } \\
\mathrm{N}\end{array}$} & & \multicolumn{2}{|c|}{ agudos } & \multirow[b]{2}{*}{$\mathrm{P}$} & \multicolumn{2}{|c|}{ Total } & \multicolumn{2}{|c|}{ agudos } & \\
\hline & & & $\mathrm{N}$ & $\%$ & IC $95 \%$ & & $\mathrm{~N}$ & $\mathrm{~N}$ & $\%$ & IC $95 \%$ & $\mathrm{P}$ \\
\hline \multicolumn{12}{|c|}{ CONSUMO DE ÁLCOOL } \\
\hline & Nunca consumiu & 702 & 144 & 20,5 & $17,0-24,5$ & & 753 & 118 & 17,4 & $13,2-22,6$ & \\
\hline & Ex-consumidor & 106 & 22 & 22,2 & $14,5-32,4$ & & 130 & 29 & 23,8 & $14,5-36,3$ & \\
\hline & Consumidor leve & 330 & 62 & 20,3 & $15,5-26,1$ & & 336 & 30 & 13,0 & $8,6-19,2$ & \\
\hline & Consumidor moderado & 105 & 18 & 15,0 & $9,3-23,4$ & & 87 & 10 & 11,5 & $4,3-27,61$ & \\
\hline & Consumidor excessivo & 81 & 14 & 18,3 & $11,4-28,1$ & & 108 & 10 & 8,8 & $4,4-16,7$ & \\
\hline \multicolumn{12}{|c|}{ CONSUMO DE FUMO } \\
\hline & Nunca fumou & 498 & 103 & 21,1 & $17,1-25,9$ & & 597 & 83 & 15,7 & $11,9-20,5$ & \\
\hline & Fumante passivo & 210 & 45 & 21,9 & $16,8-28,2$ & & 142 & 22 & 17,8 & $11,8-25,8$ & \\
\hline & Ex-fumante & 188 & 31 & 16,4 & $12,2-21,8$ & & 206 & 43 & 21,5 & $14,7-30,2$ & \\
\hline & Fumante leve & 189 & 36 & 19,1 & $13,4-26,3$ & & 191 & 28 & 16,4 & $9,9-25,8$ & \\
\hline & Fumante pesado & 131 & 26 & 19,4 & $14,4-25,7$ & & 128 & 11 & 13,5 & $8,1-21,5$ & \\
\hline \multicolumn{12}{|c|}{ ATIVIDADE FÍSICA } \\
\hline & Sedentário & 627 & 118 & 19,0 & $15,6-22,9$ & & 704 & 108 & 18,6 & $14,6-23,3$ & \\
\hline & Pouco ativo & 149 & 33 & 23,4 & $17,0-31,3$ & & 160 & 25 & 18,6 & $11,8-28,2$ & \\
\hline & Ativo & 440 & 89 & 20,1 & $15,9-25,0$ & & 379 & 53 & 13,7 & $9,8-18,8$ & \\
\hline
\end{tabular}

Aplicando-se a análise multivariada, verifica-se resultado diferente para a variável idade, sendo que, na área do PSF, a Razão de Prevalência entre os que tiveram um episódio agudo de doença já é significantemente maior para a categoria 45 aos 59 anos (Tabela 5). 
Tabela 5. Análise multivariada da prevalência de morbidade aguda segundo cobertura PSF. Vila Nova Cachoeirinha e Vila Curuçá, São Paulo, 2001.*

\begin{tabular}{|c|c|c|c|c|c|}
\hline \multirow[t]{2}{*}{ Variável } & \multirow[t]{2}{*}{ Categorias } & \multicolumn{2}{|c|}{ Cobertura PSF } & \multicolumn{2}{|c|}{ Cobertura não-PSF } \\
\hline & & $\begin{array}{c}\text { Razão de } \\
\text { prevalência }\end{array}$ & IC 95\% & $\begin{array}{c}\text { Razão de } \\
\text { prevalência }\end{array}$ & IC $95 \%$ \\
\hline \multicolumn{6}{|l|}{ Sexo } \\
\hline & Feminino & 1,00 & & 1,00 & \\
\hline & Masculino & 0,63 & $0,49-0,81$ & 0,72 & $0,54-0,96$ \\
\hline \multicolumn{6}{|c|}{ Faixa etária (anos) } \\
\hline & $15-29$ & 1,00 & & 1,00 & \\
\hline & $30-44$ & 1,30 & $0,93-1,80$ & 1,14 & $0,75-1,74$ \\
\hline & $45-59$ & 1,49 & $1,01-2,19$ & 1,65 & $0,90-3,04$ \\
\hline & 60 ou mais & 1,72 & $1,08-2,75$ & 2,63 & $1,40-4,93$ \\
\hline \multicolumn{6}{|c|}{ Renda (SM per capita) } \\
\hline & $<0,5$ & 1,00 & & 1,00 & \\
\hline & $0,50-0,99$ & 1,32 & $0,83-2,09$ & 0,89 & $0,43-1,84$ \\
\hline & $1,00-1,99$ & 1,09 & $0,68-1,74$ & 1,05 & $0,49-2,24$ \\
\hline & $2,00-4,99$ & 1,19 & $0,76-1,85$ & 0,67 & $0,32-1,41$ \\
\hline & 5,00 ou mais & 0,75 & $0,36-1,55$ & 0,54 & $0,22-1,32$ \\
\hline \multicolumn{6}{|c|}{ Escolaridade } \\
\hline & Nenhuma & 1,00 & & 1,00 & \\
\hline & Ensino Fundamental $1^{\mathrm{a}}$ a $4^{\mathrm{a}}$ séries & 1,09 & $0,69-1,72$ & 1,51 & $0,77-2,94$ \\
\hline & Ensino Fundamental $5^{\mathrm{a}}$ a $8^{\mathrm{a}}$ séries & 0,95 & $0,59-1,52$ & 1,16 & $0,55-2,41$ \\
\hline & Ensino Médio completo ou incompleto & 0,87 & $0,49-1,56$ & 1,27 & $0,55-2,96$ \\
\hline & Superior completo ou incompleto & 0,73 & $0,31-1,74$ & 1,02 & $0,36-2,88$ \\
\hline
\end{tabular}

*resultados ajustados para todas as variáveis constantes na tabela

\subsubsection{Morbidade crônica}

Para hipertensão, encontra-se prevalência significantemente maior nas seguintes categorias: sexo feminino, de maior idade, todos os estados civis, em relação a solteiro, de menor escolaridade, procedentes do interior de SP e de outros estados, aqueles com cobertura previdenciária do setor público, moradores na área de cobertura do PSF, exconsumidores de álcool e ex-fumantes. Há prevalência significantemente menor de hipertensos na população com renda de dois ou mais salários-mínimos (SM), religião islâmica e ativos fisicamente (Tabela 6). Há tendência linear significativa para idade, 
escolaridade e renda, sendo a primeira diretamente proporcional (maior prevalência de HAS para aumento de idade) e as duas últimas inversamente proporcionais.

Tabela 6. Distribuição da prevalência de hipertensão segundo variáveis sociodemográficas.

Vila Nova Cachoeirinha e Vila Curuçá, São Paulo, 2001.

\begin{tabular}{|c|c|c|c|c|c|c|}
\hline \multirow[t]{2}{*}{ VARIÁVEL } & \multirow[t]{2}{*}{ CATEGORIA } & \multicolumn{5}{|c|}{ Tem HAS } \\
\hline & & $\mathrm{N}$ Total & $\mathrm{N}$ & $\%$ & IC $95 \%$ & $\mathrm{P}$ \\
\hline \multicolumn{7}{|l|}{ SEXO } \\
\hline & Feminino & 1394 & 423 & 28,6 & $25,8-31,6$ & \\
\hline & Masculino & 1118 & 220 & 20,0 & $17,6-22,7$ & * \\
\hline \multicolumn{7}{|c|}{ FAIXA ETÁRIA (anos) } \\
\hline & $15-29$ & 947 & 72 & 8,0 & $6,2-10,2$ & \\
\hline & $30-44$ & 805 & 170 & 18,3 & $15,3-21,8$ & * \\
\hline & $45-59$ & 476 & 218 & 45,7 & $39,7-51,8$ & $*$ \\
\hline & 60 ou mais & 284 & 183 & 63,3 & $57,4-68,7$ & * \\
\hline \multicolumn{7}{|c|}{ ESTADO CIVIL } \\
\hline & Solteiro & 907 & 96 & 10,0 & $7,9-12,7$ & \\
\hline & Casado & 938 & 305 & 31,3 & $28,0-34,8$ & $*$ \\
\hline & Divorciado ou separado & 62 & 21 & 33,6 & $22,4-47,0$ & $*$ \\
\hline & "Concubinato" & 67 & 28 & 35,8 & $22,1-52,4$ & $*$ \\
\hline & Viúvo & 377 & 84 & 21,0 & $17,1-25,5$ & $*$ \\
\hline \multicolumn{7}{|c|}{ ESCOLARIDADE } \\
\hline & Nenhuma & 131 & 81 & 60,1 & $50,6-68,9$ & \\
\hline & Ensino Fundamental $1^{\mathrm{a}}$ a $4^{\mathrm{a}}$ séries & 685 & 282 & 42,4 & $38,3-46,6$ & $*$ \\
\hline & Ensino Fundamental $5^{\mathrm{a}}$ a $8^{\mathrm{a}}$ séries & 772 & 166 & 20,2 & $17,2-23,6$ & $*$ \\
\hline & $\begin{array}{l}\text { Ensino Médio completo } \\
\text { incompleto }\end{array}$ & 750 & 90 & 12,6 & $10,1-15,7$ & * \\
\hline & Superior completo ou incompleto & 158 & 20 & 11,4 & $6,6-19,1$ & $*$ \\
\hline \multicolumn{7}{|c|}{ PROCEDÊNCIA } \\
\hline & SP capital & 1207 & 194 & 16,3 & $13,7-19,4$ & \\
\hline & SP interior & 275 & 108 & 37,0 & $30,8-43,3$ & $*$ \\
\hline & Outros estados & 999 & 330 & 31,9 & $28,2-35,9$ & $*$ \\
\hline \multicolumn{7}{|l|}{ RELIGIÃO } \\
\hline & Catolicismo & 1607 & 416 & 25,0 & $22,4-27,7$ & \\
\hline & Evangélico & 592 & 166 & 28,2 & $26,9-31,7$ & \\
\hline & Outras & 309 & 61 & 18,4 & $14,2-23,5$ & \\
\hline \multicolumn{7}{|c|}{ RENDA (SM per capita) } \\
\hline & $<0,5$ & 266 & 83 & 32,8 & $27,0-39,2$ & \\
\hline & $0,50-0,99$ & 422 & 118 & 28,3 & $23,6-33,4$ & \\
\hline & $1,00-1,99$ & 666 & 179 & 27,8 & $23,6-32,4$ & \\
\hline & $2,00-4,99$ & 681 & 171 & 23,1 & $19,8-26,7$ & $*$ \\
\hline & 5,00 ou mais & 161 & 32 & 15,3 & $10,6-21,5$ & * \\
\hline
\end{tabular}

\section{Continua}


Tabela 6. Distribuição da prevalência de hipertensão segundo variáveis sociodemográficas. Vila Nova Cachoeirinha e Vila Curuçá, São Paulo, 2001. (Conclusão)

\begin{tabular}{|c|c|c|c|c|c|c|}
\hline \multirow[t]{2}{*}{ VARIÁVEL } & \multirow[t]{2}{*}{ CATEGORIA } & \multicolumn{5}{|c|}{ Tem HAS } \\
\hline & & $\mathrm{N}$ Total & $\mathrm{N}$ & $\%$ & IC $95 \%$ & $\mathrm{P}$ \\
\hline \multicolumn{7}{|c|}{ SITUAÇÃO ATUAL DE TRABALHO } \\
\hline & Empregado & 1040 & 221 & 21,3 & $18,9-23,8$ & \\
\hline & Desempregado & 184 & 49 & 24,8 & $18,4-32,5$ & \\
\hline & Informal/Autônomo & 607 & 130 & 19,2 & $15,1-24,0$ & \\
\hline & Inativo & 651 & 233 & 36,7 & $30,9-42,8$ & * \\
\hline \multicolumn{7}{|c|}{ COBERTURA PREVIDENCIÁRIA } \\
\hline & Nenhuma & 810 & 182 & 23,2 & $20,1-26,7$ & \\
\hline & INSS & 1362 & 377 & 26,5 & $24,1-29,1$ & \\
\hline & Privada & 167 & 30 & 14,1 & $9,1-21,3$ & * \\
\hline & Setor Público & 130 & 43 & 32,6 & $26,3-39,6$ & * \\
\hline \multicolumn{7}{|c|}{ LOCAL DE MORADIA } \\
\hline & Vila Nova Cachoeirinha & 1268 & 332 & 24,4 & $22,0-27,0$ & \\
\hline & Vila Curuçá & 1244 & 311 & 25,4 & $22,5-28,5$ & \\
\hline \multicolumn{7}{|c|}{ ÁREA DE MORADIA } \\
\hline & PSF & 1229 & 346 & 28,7 & $26,3-31,3$ & \\
\hline & Não-PSF & 1283 & 297 & 22,9 & $20,5-25-5$ & * \\
\hline \multicolumn{7}{|c|}{ CONSUMO DE ÁLCOOL } \\
\hline & Nunca consumiu & 1435 & 375 & 24,6 & $21,9-27,5$ & \\
\hline & Ex-consumidor & 231 & 83 & 35,7 & $29,4-42,5$ & * \\
\hline & Consumidor leve & 444 & 104 & 23,4 & $19,3-28,1$ & \\
\hline & Consumidor moderado & 190 & 41 & 22,3 & $16,9-28,7$ & \\
\hline & Consumidor excessivo & 186 & 33 & 17,8 & $11,7-26,2$ & \\
\hline \multicolumn{7}{|c|}{ CONSUMO DE FUMO } \\
\hline & Nunca fumou & 1081 & 262 & 24,3 & $20,9-28,1$ & \\
\hline & Fumante passivo & 345 & 81 & 22,9 & $18,0-28,7$ & \\
\hline & Ex-fumante & 389 & 147 & 35,7 & $30,4-41,4$ & * \\
\hline & Fumante leve & 372 & 80 & 17,9 & $13,6-23,2$ & \\
\hline & Fumante pesado & 253 & 58 & 23,3 & $18,6-28,8$ & \\
\hline \multicolumn{7}{|c|}{ ATIVIDADE FÍSICA } \\
\hline & Sedentário & 1308 & 379 & 28,0 & $25,5-30,7$ & \\
\hline & Pouco ativo & 305 & 77 & 23,9 & $19,4-29,0$ & \\
\hline & Ativo & 808 & 168 & 20,7 & $17,9-23,8$ & * \\
\hline
\end{tabular}

Realizando-se a análise multivariada, verifica-se Razão de Prevalência entre os indivíduos que têm hipertensão e os que não têm significantemente maior para as categorias faixa etária a partir dos 30 a 44 anos, renda de 2,00 ou mais SM per capita, casados e divorciados ou separados; e menor para as categorias masculino e Ensino Médio completo 
ou incompleto (Tabela 7). É interessante notar que escolaridade, que, na análise univariada apresentava constante diminuição da prevalência de HAS, com seu aumento da escolaridade, perde esse perfil quando se corrige para as outras variáveis. Possivelmente, é a faixa etária o maior viés dessa associação previamente encontrada, pois, na nossa população com 15 anos ou mais, a média de idade dos indivíduos com nível superior é menor do que o a média dos analfabetos (dados não apresentados). Não houve associação significativa com as variáveis de estilo de vida.

Tabela 7. Análise multivariada da prevalência de hipertensão. Vila Nova Cachoeirinha e Vila Curuçá, São Paulo, 2001.**

\begin{tabular}{|c|c|c|c|c|}
\hline Variável & Categorias & $\begin{array}{c}\text { Razão de } \\
\text { Prevalência }\end{array}$ & IC 95\% & $\mathrm{P}$ \\
\hline \multicolumn{5}{|l|}{ Sexo } \\
\hline & Feminino & 1,00 & & \\
\hline & Masculino & 0,79 & $0,65-0,95$ & $*$ \\
\hline \multicolumn{5}{|c|}{ Faixa etária (anos) } \\
\hline & $15-29$ anos & 1,00 & & \\
\hline & $30-44$ anos & 1,76 & $1,24-2,49$ & $*$ \\
\hline & $45-59$ anos & 3,71 & $2,51-5,51$ & $*$ \\
\hline & 60 ou mais anos & 4,52 & $3,11-6,56$ & $*$ \\
\hline \multicolumn{5}{|c|}{ Estado civil } \\
\hline & Solteiro & 1,00 & & \\
\hline & Casado & 1,55 & $1,13-2,12$ & $*$ \\
\hline & Divorciado ou separado & 1,75 & $1,15-2,67$ & $*$ \\
\hline & "Concubinato" & 1,28 & $0,81-2,01$ & \\
\hline & Viúvo & 1,37 & $0,97-1,94$ & \\
\hline \multicolumn{5}{|c|}{ Escolaridade } \\
\hline & Nenhuma & 1,00 & & \\
\hline & Ensino Fundamental $1^{\mathrm{a}}$ a $4^{\mathrm{a}}$ séries & 0,82 & $0,61-1,11$ & \\
\hline & Ensino Fundamental $5^{\mathrm{a}}$ a $8^{\mathrm{a}}$ séries & 0,72 & $0,50-1,03$ & \\
\hline & Ensino Médio completo ou incompleto & 0,58 & $0,39-0,85$ & $*$ \\
\hline & Superior completo ou incompleto & 0,53 & $0,28-1,01$ & \\
\hline \multicolumn{5}{|c|}{ Renda (SM per capita) } \\
\hline & $<0,5$ & 1,00 & & \\
\hline & $0,50-0,99$ & 0,92 & $0,72-1,18$ & \\
\hline & $1,00-1,99$ & 0,93 & $0,75-1,16$ & \\
\hline & $2,00-4,99$ & 0,75 & $0,59-0,96$ & $*$ \\
\hline & 5,00 ou mais & 0,60 & $0,40-0,91$ & $*$ \\
\hline
\end{tabular}

$* \mathrm{p}<0,05$

** resultados ajustados para as variáveis sexo, idade, estado civil, escolaridade, procedência, religião, renda, situação atual de trabalho e cobertura previdenciária, consumo de álcool, consumo de fumo e atividade física. 
Comparando-se as áreas segundo cobertura PSF, distingue-se aumento da prevalência no sexo feminino, com o aumento da idade, com a diminuição da escolaridade, com procedência do interior do estado e de outros estados em ambas as áreas. $\mathrm{Na}$ área coberta, uma prevalência significantemente menor de hipertensão para ensino fundamental incompleto, em relação a nenhum estudo, entre os desempregados, com cobertura previdenciária do INSS ou do setor público, morador da $\mathrm{VC}$ e ativo fisicamente. Há tendência linear significativa para idade (diretamente proporcional) e escolaridade (inversamente proporcional). Já na área não coberta, há uma prevalência significantemente menor de hipertensão com renda de dois ou mais SM, com cobertura previdenciária privada. Já os ex-consumidores de álcool e fumo têm maior prevalência de HAS, ainda na área não coberta (Tabela 8). Há tendência linear significativa para idade (diretamente proporcional), escolaridade e renda (inversamente proporcionais).

Tabela 8. Prevalência de hipertensão segundo cobertura PSF e variáveis sóciodemográficas. Vila Nova Cachoeirinha e Vila Curuçá, São Paulo, 2001.

\begin{tabular}{|c|c|c|c|c|c|c|c|c|c|c|c|}
\hline \multirow[t]{3}{*}{ VARIÁVEL } & \multirow[t]{3}{*}{ CATEGORIA } & \multicolumn{4}{|c|}{ Área Coberta pelo PSF } & \multicolumn{6}{|c|}{ Área Não Coberta pelo PSF } \\
\hline & & \multicolumn{2}{|c|}{ Total } & \multicolumn{2}{|c|}{ Tem HAS } & \multicolumn{3}{|c|}{ Total } & \multicolumn{2}{|c|}{ Tem HAS } & \multirow[b]{2}{*}{$\mathrm{P}$} \\
\hline & & $\mathrm{N}$ & $\mathrm{N}$ & $\%$ & IC 95\% & $\mathrm{P}$ & $\mathrm{N}$ & $\mathrm{N}$ & $\%$ & IC $95 \%$ & \\
\hline \multicolumn{12}{|l|}{ SEXO } \\
\hline & Feminino & 689 & 223 & 33,4 & $30,1-36,9$ & & 705 & 200 & 26,3 & $22,5-30,4$ & \\
\hline & Masculino & 540 & 123 & 22,7 & $19,6-26,3$ & * & 578 & 97 & 18,7 & $15,4-22,6$ & * \\
\hline \multicolumn{12}{|c|}{ FAIXA ETÁRIA (anos) } \\
\hline & $15-29$ & 429 & 31 & 7,1 & $4,9-10,2$ & & 518 & 41 & 8,4 & $6,1-11,5$ & \\
\hline & $30-44$ & 381 & 95 & 24,5 & $20,5-29,1$ & * & 424 & 75 & 15,5 & $11,8-20,1$ & * \\
\hline & $45-59$ & 247 & 108 & 44,7 & $37,0-52,7$ & * & 229 & 110 & 46,1 & $38,0-54,5$ & $*$ \\
\hline & 60 ou mais & 172 & 112 & 66,3 & $59,1-72,7$ & $*$ & 112 & 71 & 60,9 & $52,0-69,2$ & $*$ \\
\hline \multicolumn{12}{|c|}{ ESTADO CIVIL } \\
\hline & Solteiro & 444 & 53 & 11,9 & $8,9-15,9$ & & 463 & 43 & 9,0 & $6,3-12,7$ & \\
\hline & Casado & 463 & 166 & 36,7 & $31,8-41,9$ & $*$ & 475 & 139 & 28,9 & $24,7-33,5$ & $*$ \\
\hline & Divorciado ou separado & 36 & 11 & 29,4 & $16,4-46,8$ & $*$ & 26 & 10 & 36,8 & $20,7-56,6$ & $*$ \\
\hline & "Concubinato" & 28 & 13 & 45,3 & $27,6-61,2$ & * & 39 & 15 & 32,6 & $16,3-54,5$ & $*$ \\
\hline & Viúvo & 165 & 42 & 27,2 & $21,5-33,9$ & * & 212 & 42 & 18,5 & $14,1-23,7$ & * \\
\hline
\end{tabular}

Continua 
Tabela 8. Prevalência de hipertensão segundo cobertura PSF e variáveis sóciodemográficas. Vila Nova Cachoeirinha e Vila Curuçá, São Paulo, 2001. (Continuação)

\begin{tabular}{|c|c|c|c|c|c|c|c|c|c|c|c|}
\hline \multirow[t]{3}{*}{ VARIÁVEL } & \multirow[t]{3}{*}{ CATEGORIA } & \multicolumn{4}{|c|}{ Área Coberta pelo PSF } & \multicolumn{6}{|c|}{ Área Não Coberta pelo PSF } \\
\hline & & \multicolumn{2}{|l|}{ Total } & \multicolumn{2}{|c|}{ Tem HAS } & \multicolumn{3}{|c|}{ Total } & \multicolumn{3}{|c|}{ Tem HAS } \\
\hline & & $\mathrm{N}$ & $\mathrm{N}$ & $\%$ & IC $95 \%$ & $\mathrm{P}$ & $\mathrm{N}$ & $\mathrm{N}$ & $\%$ & IC $95 \%$ & $\mathrm{P}$ \\
\hline \multicolumn{12}{|c|}{ ESCOLARIDADE } \\
\hline & Nenhuma & 68 & 45 & 68,3 & $53,6-80,0$ & & 63 & 36 & 55,5 & $43,4-66,9$ & \\
\hline & Ensino Fundamental $1^{\mathrm{a}}$ a $4^{\mathrm{a}}$ séries & 335 & 140 & 43,0 & $37,8-48,4$ & * & 350 & 142 & 42,1 & $36,5-47,9$ & $*$ \\
\hline & Ensino Fundamental $5^{\mathrm{a}}$ a $8^{\mathrm{a}}$ séries & 382 & 102 & 27,1 & $22,5-32,3$ & $*$ & 390 & 64 & 16,8 & $13,2-21,1$ & $*$ \\
\hline & $\begin{array}{l}\text { Ensino Médio completo ou } \\
\text { incompleto }\end{array}$ & 375 & 48 & 13,0 & $9,9-16,9$ & $*$ & 375 & 42 & 12,4 & $9,1-16,8$ & $*$ \\
\hline & Superior completo ou incompleto & 62 & 9 & 14,5 & $8,1-24,6$ & $*$ & 96 & 11 & 10,6 & $5,1-20,7$ & $*$ \\
\hline \multicolumn{12}{|c|}{ PROCEDÊNCIA } \\
\hline & SP capital & 585 & 103 & 18,2 & $15,0-21,8$ & & 622 & 91 & 15,5 & $12,1-19,7$ & \\
\hline & SP interior & 153 & 68 & 45,9 & $37,8-54,2$ & * & 122 & 40 & 31,3 & $22,8-41,2$ & $*$ \\
\hline & Outros estados & 476 & 167 & 35,5 & $31,0-40,3$ & * & 523 & 163 & 30,2 & $25,3-35,7$ & $*$ \\
\hline \multicolumn{12}{|l|}{ RELIGIÃO } \\
\hline & Catolicismo & 795 & 229 & 29,5 & $26,5-32,7$ & & 812 & 187 & 22,7 & $19,2-26,7$ & \\
\hline & Evangélico & 296 & 84 & 28,6 & $23,7-36,1$ & & 296 & 82 & 28,0 & $23,7-32,7$ & \\
\hline & Outras & 138 & 33 & 24,3 & $17,1-33,3$ & $*$ & 171 & 28 & 16,1 & $11,2-22,5$ & \\
\hline \multicolumn{12}{|c|}{ RENDA (SM per capita) } \\
\hline & $<0,5$ & 124 & 42 & 35,4 & $26,9-45,0$ & & 142 & 41 & 31,5 & $24,2-39,9$ & \\
\hline & $0,50-0,99$ & 227 & 63 & 28,4 & $22,6-35,2$ & & 195 & 55 & 28,2 & $21,7-35,7$ & \\
\hline & $1,00-1,99$ & 358 & 97 & 27,3 & $22,4-32,8$ & & 308 & 82 & 28,1 & $22,2-34,8$ & \\
\hline & $2,00-4,99$ & 370 & 108 & 30,1 & $25,1-35,6$ & & 311 & 63 & 19,5 & $15,4-24,4$ & $*$ \\
\hline & 5,00 ou mais & 57 & 16 & 26,4 & $15,7-40,8$ & & 104 & 16 & 12,9 & $8,3-19,2$ & $*$ \\
\hline \multicolumn{12}{|c|}{ SITUAÇÃO ATUAL DE TRABALHO } \\
\hline & Empregado & 484 & 110 & 23,1 & $20,0-26,5$ & & 556 & 111 & 20,6 & $17,5-24,0$ & \\
\hline & Desempregado & 79 & 27 & 35,5 & $24,0-49,1$ & * & 105 & 22 & 20,5 & $13,1-30,6$ & \\
\hline & Informal/Autônomo & 291 & 68 & 22,9 & $17,5-29,2$ & & 316 & 62 & 17,4 & $12,2-24,2$ & \\
\hline & Inativo & 357 & 136 & 39,5 & $34,0-45,3$ & * & 294 & 97 & 34,8 & $26,1-44,6$ & $*$ \\
\hline \multicolumn{12}{|c|}{ COBERTURA PREVIDENCIÁRIA } \\
\hline & Nenhuma & 415 & 95 & 23,3 & $18,8-28,5$ & & 395 & 87 & 23,2 & $19,1-27,9$ & \\
\hline & INSS & 620 & 196 & 32,2 & $28,4-36,2$ & $*$ & 742 & 181 & 24,1 & $21,0-27,4$ & \\
\hline & Privada & 94 & 24 & 25,7 & $16,7-37,4$ & & 73 & 6 & 8,4 & $4,0-16,7$ & $*$ \\
\hline & Setor Público & 73 & 25 & 35,5 & $25,1-47,5$ & $*$ & 57 & 18 & 30,7 & $23,1-39,6$ & \\
\hline \multicolumn{12}{|c|}{ LOCAL DE MORADIA } \\
\hline & Vila Nova Cachoeirinha & 627 & 191 & 30,8 & $27,4-34,4$ & & 641 & 141 & 21,5 & $18,4-24,8$ & \\
\hline & Vila Curuçá & 602 & 155 & 25,8 & $22,4-29,4$ & $*$ & 642 & 156 & 25,2 & $21,2-29,6$ & \\
\hline \multicolumn{12}{|c|}{ CONSUMO DE ÁLCOOL } \\
\hline & Nunca consumiu & 693 & 202 & 29,7 & $26,2-33,5$ & & 742 & 173 & 22,2 & $18,7-26,0$ & \\
\hline & Ex-consumidor & 104 & 38 & 37,2 & $27,4-48,2$ & & 127 & 45 & 35,1 & $27,3-43,9$ & $*$ \\
\hline & Consumidor leve & 237 & 64 & 27,5 & $22,0-33,8$ & & 207 & 40 & 21,2 & $15,7-28,0$ & \\
\hline & Consumidor moderado & 103 & 27 & 27,4 & $20,0-36,2$ & & 87 & 14 & 19,2 & $12,2-28,8$ & \\
\hline & Consumidor excessivo & 80 & 13 & 16,6 & $10,0-26,2$ & & 106 & 20 & 18,3 & $10,5-29,9$ & \\
\hline
\end{tabular}

Continua 
Tabela 8. Prevalência de hipertensão segundo cobertura PSF e variáveis sóciodemográficas. Vila Nova Cachoeirinha e Vila Curuçá, São Paulo, 2001. (Conclusão)

\begin{tabular}{|c|c|c|c|c|c|c|c|c|c|c|c|}
\hline \multirow[t]{3}{*}{ VARIÁVEL } & \multirow[t]{3}{*}{ CATEGORIA } & \multicolumn{4}{|c|}{ Área Coberta pelo PSF } & \multicolumn{6}{|c|}{ Área Não Coberta pelo PSF } \\
\hline & & \multicolumn{2}{|l|}{ Total } & \multicolumn{2}{|c|}{ Tem HAS } & \multicolumn{3}{|c|}{ Total } & \multicolumn{2}{|c|}{ Tem HAS } & \multirow[b]{2}{*}{$\mathrm{P}$} \\
\hline & & $\mathrm{N}$ & $\mathrm{N}$ & $\%$ & IC $95 \%$ & $\mathrm{P}$ & $\mathrm{N}$ & $\mathrm{N}$ & $\%$ & IC 95\% & \\
\hline \multicolumn{12}{|c|}{ CONSUMO DE FUMO } \\
\hline & Nunca fumou & 492 & 139 & 28,8 & $25,2-32,7$ & & 589 & 123 & 22,4 & $17,8-27,8$ & \\
\hline & Fumante passivo & 207 & 52 & 26,0 & $20,4-32,5$ & & 138 & 29 & 20,7 & $13,8-29,8$ & \\
\hline & Ex-fumante & 186 & 68 & 36,8 & $30,3-43,8$ & & 203 & 79 & 35,2 & $28,2-43,0$ & * \\
\hline & Fumante leve & 182 & 47 & 26,2 & $20,6-32,6$ & & 190 & 33 & 13,8 & $8,5-21,5$ & \\
\hline & Fumante pesado & 128 & 31 & 25,4 & $18,7-33,5$ & & 125 & 27 & 22,2 & $16,1-29,8$ & \\
\hline \multicolumn{12}{|c|}{ ATIVIDADE FÍSICA } \\
\hline & Sedentário & 617 & 202 & 33,6 & $29,6-37,8$ & & 691 & 177 & 25,4 & $22,2-28,9$ & \\
\hline & Pouco ativo & 147 & 42 & 28,1 & $21,6-35,7$ & & 158 & 35 & 22,0 & $16,4-28,9$ & \\
\hline & Ativo & 432 & 92 & 21,7 & $17,7-26,5$ & * & 376 & 76 & 20,1 & $16,5-24,3$ & \\
\hline
\end{tabular}

$* \mathrm{p}<0,05$

Aplicando-se a análise multivariada, verificam-se resultados diferentes para as variáveis sexo, renda e escolaridade. Apenas na área do PSF, há correlação estatística de maior prevalência para as mulheres. Já na área não-PSF, a Razão de Prevalência é significantemente menor para as categorias 2,00 ou mais SM e para o Ensino Fundamental de $5^{\mathrm{a}}$ a $8^{\mathrm{a}}$ séries. Ensino Médio Completo ou Incompleto correlaciona-se com menor prevalência de HAS em ambas as áreas (Tabela 9). 
Tabela 9. Análise multivariada da prevalência de hipertensão segundo cobertura PSF. Vila Nova Cachoeirinha e Vila Curuçá, São Paulo, 2001.**

\begin{tabular}{|c|c|c|c|c|c|c|c|}
\hline \multirow[t]{2}{*}{ Variável } & \multirow[t]{2}{*}{ Categorias } & \multicolumn{2}{|c|}{ Cobertura PSF } & \multicolumn{4}{|c|}{ Cobertura não-PSF } \\
\hline & & $\begin{array}{l}\text { Razão de } \\
\text { prevalência }\end{array}$ & IC $95 \%$ & $\mathrm{P}$ & $\begin{array}{l}\text { Razão de } \\
\text { prevalência }\end{array}$ & IC $95 \%$ & $\mathrm{P}$ \\
\hline \multicolumn{8}{|l|}{ Sexo } \\
\hline & Feminino & 1,00 & & & 1,00 & & \\
\hline & Masculino & 0,70 & $0,58-0,84$ & * & 0,87 & $0,68-1,11$ & \\
\hline \multicolumn{8}{|c|}{ Faixa etária (anos) } \\
\hline & $15-29$ & 1,00 & & & 1,00 & & \\
\hline & $30-44$ & 3,29 & $2,17-4,99$ & $*$ & 1,73 & $1,13-2,67$ & $*$ \\
\hline & $45-59$ & 5,53 & $3,42-8,96$ & $*$ & 4,43 & $2,78-7,06$ & $*$ \\
\hline & 60 ou mais & 7,54 & $4,58-12,44$ & $*$ & 5,03 & $3,32-7,61$ & $*$ \\
\hline \multicolumn{8}{|c|}{ Renda (SM per capita) } \\
\hline & $<0,5$ & 1,00 & & & 1,00 & & \\
\hline & $0,50-0,99$ & 0,95 & $0,73-1,23$ & & 0,92 & $0,68-1,24$ & \\
\hline & $1,00-1,99$ & 0,95 & $0,72-1,24$ & & 0,97 & $0,73-1,28$ & \\
\hline & $2,00-4,99$ & 0,98 & $0,74-1,30$ & & 0,65 & $0,47-0,90$ & * \\
\hline & 5,00 ou mais & 0,94 & $0,59-1,50$ & & 0,50 & $0,30-0,83$ & $*$ \\
\hline \multicolumn{8}{|c|}{ Escolaridade } \\
\hline & Nenhuma & 1,00 & & & 1,00 & & \\
\hline & Ensino Fundamental $1^{\mathrm{a}}$ a $4^{\mathrm{a}}$ séries & 0,85 & $0,68-1,07$ & & 0,84 & $0,64-1,11$ & \\
\hline & Ensino Fundamental $5^{\mathrm{a}}$ a $8^{\mathrm{a}}$ séries & 0,89 & $0,68-1,16$ & & 0,63 & $0,42-0,93$ & * \\
\hline & $\begin{array}{l}\text { Ensino Médio completo ou } \\
\text { incompleto }\end{array}$ & 0,56 & $0,40-0,78$ & * & 0,59 & $0,37-0,95$ & $*$ \\
\hline & Superior completo ou incompleto & 0,58 & $0,32-1,05$ & & 0,51 & $0,22-1,20$ & \\
\hline
\end{tabular}

$* \mathrm{p}<0,05$

**resultados ajustados para todas as variáveis constantes na tabela

No que se refere ao diabetes, a prevalência é significantemente maior para as seguintes categorias: sexo feminino, maior idade, casados e divorciados ou separados, procedentes do interior de SP e de outros estados, evangélicos, inativos e ex-fumantes. E significantemente menor, para escolaridade a partir da $5^{\text {a }}$ série, fumantes leves e fisicamente ativos (Tabela 10). Há tendência linear significativa para idade. 
Tabela 10. Distribuição da prevalência de diabetes segundo variáveis sociodemográficas.

Vila Nova Cachoeirinha e Vila Curuçá, São Paulo, 2001.

\begin{tabular}{|c|c|c|c|c|c|c|}
\hline \multirow[t]{2}{*}{ VARIÁVEL } & \multirow[t]{2}{*}{ CATEGORIA } & \multicolumn{5}{|c|}{ Tem diabetes } \\
\hline & & N Total & $\mathrm{N}$ & $\%$ & IC $95 \%$ & $\mathrm{P}$ \\
\hline \multicolumn{7}{|l|}{ SEXO } \\
\hline & Feminino & 1394 & 96 & 6,2 & $4,9-7,8$ & \\
\hline & Masculino & 1118 & 51 & 4,2 & $3,1-5,6$ & * \\
\hline \multicolumn{7}{|c|}{ FAIXA ETÁRIA (anos) } \\
\hline & $15-29$ & 947 & 7 & 0,6 & $0,2-1,3$ & \\
\hline & $30-44$ & 805 & 27 & 2,7 & $1,7-4,1$ & * \\
\hline & $45-59$ & 476 & 60 & 11,3 & $8,3-15,2$ & * \\
\hline & 60 ou mais & 284 & 53 & 18,7 & $14,1-24,3$ & * \\
\hline \multicolumn{7}{|c|}{ ESTADO CIVIL } \\
\hline & Solteiro & 907 & 20 & 2,4 & $1,5-3,8$ & \\
\hline & Casado & 938 & 75 & 6,8 & $5,2-9,0$ & * \\
\hline & Divorciado ou separado & 62 & 6 & 11,3 & $4,5-25,3$ & * \\
\hline & "Concubinato" & 67 & 3 & 1,8 & $0,5-6,6$ & \\
\hline & Viúvo & 377 & 10 & 2,1 & $1,0-4,0$ & \\
\hline \multicolumn{7}{|c|}{ ESCOLARIDADE } \\
\hline & Nenhuma & 131 & 22 & 14,3 & $8,8-22,2$ & \\
\hline & Ensino Fundamental $1^{\mathrm{a}}$ a $4^{\mathrm{a}}$ séries & 685 & 68 & 10,1 & $7,5-13,4$ & \\
\hline & Ensino Fundamental $5^{\mathrm{a}}$ a $8^{\mathrm{a}}$ séries & 772 & 31 & 3,7 & $2,5-5,6$ & * \\
\hline & $\begin{array}{l}\text { Ensino Médio completo ou } \\
\text { incompleto }\end{array}$ & 750 & 21 & 2,5 & $1,5-4,0$ & $*$ \\
\hline & Superior completo ou incompleto & 158 & 4 & 1,7 & $0,5-5,1$ & $*$ \\
\hline \multicolumn{7}{|c|}{ PROCEDÊNCIA } \\
\hline & SP capital & 1207 & 33 & 2,4 & $1,6-3,7$ & \\
\hline & SP interior & 275 & 31 & 11,2 & $7,3-17,0$ & $*$ \\
\hline & Outros estados & 999 & 81 & 7,3 & $5,4-9,9$ & $*$ \\
\hline \multicolumn{7}{|l|}{ RELIGIÃO } \\
\hline & Catolicismo & 1607 & 86 & 4,7 & $3,6-6,2$ & \\
\hline & Evangélico & 592 & 46 & 7,8 & $5,7-10,6$ & * \\
\hline & Outras & 309 & 15 & 4,1 & $2,1-7,6$ & \\
\hline \multicolumn{7}{|c|}{ RENDA (SM per capita) } \\
\hline & $<0,5$ & 266 & 18 & 6,9 & $4,5-10,5$ & \\
\hline & $0,50-0,99$ & 422 & 26 & 6,2 & $3,8-9,8$ & \\
\hline & $1,00-1,99$ & 666 & 36 & 4,7 & $3,1-6,9$ & \\
\hline & $2,00-4,99$ & 681 & 41 & 5,4 & $3,6-8,0$ & \\
\hline & 5,00 ou mais & 161 & 10 & 4,0 & $2,0-7,5$ & \\
\hline \multicolumn{7}{|c|}{ SITUAÇÃO ATUAL DE TRABALHO } \\
\hline & Empregado & 1040 & 43 & 3,6 & $2,5-5,2$ & \\
\hline & Desempregado & 184 & 9 & 5,3 & $2,6-10,6$ & \\
\hline & Informal/Autônomo & 607 & 31 & 4,4 & $3,0-6,4$ & \\
\hline & Inativo & 651 & 62 & 9,5 & $7,4-12,2$ & * \\
\hline
\end{tabular}

Continua 
Tabela 10. Distribuição da prevalência de diabetes segundo variáveis sociodemográficas.

Vila Nova Cachoeirinha e Vila Curuçá, São Paulo, 2001. (Conclusão)

\begin{tabular}{|c|c|c|c|c|c|c|}
\hline \multirow{2}{*}{ VARIÁVEL } & \multirow[t]{2}{*}{ CATEGORIA } & \multicolumn{5}{|c|}{ Tem diabetes } \\
\hline & & $\mathrm{N}$ Total & $\mathrm{N}$ & $\%$ & IC $95 \%$ & $\mathrm{P}$ \\
\hline \multicolumn{7}{|c|}{ COBERTURA PREVIDENCIÁRIA } \\
\hline & Nenhuma & 810 & 44 & 5,0 & $3,6-7,0$ & \\
\hline & INSS & 1362 & 82 & 5,7 & $4,5-7,4$ & \\
\hline & Privada & 167 & 8 & 3,6 & $1,6-7,9$ & \\
\hline & Setor Público & 130 & 11 & 5,6 & $2,8-10,9$ & \\
\hline \multicolumn{7}{|c|}{ LOCAL DE MORADIA } \\
\hline & Vila Nova Cachoeirinha & 1268 & 75 & 5,3 & $4,1-, 6,9$ & \\
\hline & Vila Curuçá & 1244 & 72 & 5,4 & $3,9-7,3$ & \\
\hline \multicolumn{7}{|c|}{ ÁREA DE MORADIA } \\
\hline & PSF & 1229 & 69 & 5,6 & $4,4-7,0$ & \\
\hline & Não-PSF & 1283 & 78 & 5,2 & $3,9-6,9$ & \\
\hline \multicolumn{7}{|c|}{ CONSUMO DE ÁLCOOL** } \\
\hline & Nunca consumiu & 1435 & 96 & 6,3 & $4,9-8,0$ & \\
\hline & Ex-consumidor & 231 & 19 & 7,5 & $4,5-12,2$ & \\
\hline & Consumidor leve & 444 & 20 & 3,6 & $2,2-5,8$ & * \\
\hline & Consumidor moderado & 190 & 5 & 1,9 & $0,8-4,6$ & * \\
\hline & Consumidor excessivo & 186 & 7 & 3,6 & $1,6-7,8$ & \\
\hline \multicolumn{7}{|c|}{ CONSUMO DE FUMO } \\
\hline & Nunca fumou & 1081 & 57 & 4,9 & $3,5-6,6$ & \\
\hline & Fumante passivo & 345 & 14 & 3,4 & $1,8-6,2$ & \\
\hline & Ex-fumante & 389 & 39 & 9,1 & $6,3-13,1$ & $*$ \\
\hline & Fumante leve & 372 & 14 & 2,4 & $1,3-4,4$ & * \\
\hline & Fumante pesado & 253 & 18 & 7,3 & $4,7-11,2$ & \\
\hline \multicolumn{7}{|c|}{ ATIVIDADE FÍSICA } \\
\hline & Sedentário & 1308 & 95 & 6,9 & $5,5-8,7$ & \\
\hline & Pouco ativo & 305 & 18 & 4,4 & $2,7-7,1$ & \\
\hline & Ativo & 808 & 30 & 3,3 & $2,2-4,9$ & $*$ \\
\hline
\end{tabular}

Realizando-se a análise multivariada, verifica-se Razão de Prevalência entre os indivíduos que têm diabetes e os que não têm significantemente maior para as categorias faixa etária a partir dos 30 a 44 anos e fumante pesado; e menor, para as categorias masculino, pessoas em situação de "concubinato" e entre os consumidores moderados de álcool (Tabela 11). Não houve associação significativa com renda, escolaridade e atividade física. 
Tabela 11. Análise multivariada da prevalência de diabetes. Vila Nova Cachoeirinha e Vila

Curuçá, São Paulo, 2001.**

\begin{tabular}{|c|c|c|c|c|}
\hline Variável & Categorias & $\begin{array}{l}\text { Razão de } \\
\text { Prevalência }\end{array}$ & IC 95\% & $\mathrm{p}$ \\
\hline \multicolumn{5}{|l|}{ Sexo } \\
\hline & Feminino & 1,00 & & \\
\hline & Masculino & 0,68 & $0,46-0,99$ & * \\
\hline \multicolumn{5}{|c|}{ Faixa etária (anos) } \\
\hline & $15-29$ & 1,00 & & \\
\hline & $30-44$ & 5,58 & $1,94-16,02$ & * \\
\hline & $45-59$ & 22,18 & $7,80-63,03$ & $*$ \\
\hline & 60 ou mais & 44,77 & $15,28-131,19$ & $*$ \\
\hline \multicolumn{5}{|c|}{ Estado civil } \\
\hline & Solteiro & 1,00 & & \\
\hline & Casado & 0,85 & $0,47-1,56$ & \\
\hline & Divorciado ou separado & 1,66 & $0,64-4,29$ & \\
\hline & "Concubinato" & 0,14 & $0,03-0,59$ & $*$ \\
\hline & Viúvo & 0,49 & $0,24-1,02$ & \\
\hline \multicolumn{5}{|c|}{ Consumo de álcool } \\
\hline & Nunca consumiu & 1,00 & & \\
\hline & Ex-consumidor & 0,81 & $0,46-1,44$ & \\
\hline & Consumidor leve & 0,58 & $0,31-1,11$ & \\
\hline & Consumidor moderado & 0,32 & $0,11-0,92$ & * \\
\hline & Consumidor excessivo & 0,60 & $0,21-1,74$ & \\
\hline \multicolumn{5}{|c|}{ Consumo de fumo } \\
\hline & Nunca fumou & 1,00 & & \\
\hline & Fumante passivo & 1,18 & $0,60-2,31$ & \\
\hline & Ex-fumante & 1,35 & $0,79-2,30$ & \\
\hline & Fumante leve & 0,73 & $0,37-1,44$ & \\
\hline & Fumante pesado & 2,55 & $1,32-4,92$ & $*$ \\
\hline
\end{tabular}

$* \mathrm{p}<0,05$

**resultados ajustados para as variáveis sexo, idade, estado civil, escolaridade, procedência, religião, renda, situação atual de trabalho e cobertura previdenciária, consumo de álcool, consumo de fumo e atividade física.

Quando se observa em relação à cobertura PSF, verifica-se que há prevalência maior do diabetes mellitus (DM) em ambas as áreas, nas categorias: idade (embora, na área não coberta apenas a partir dos 45 anos), casados, procedentes do interior de SP e de outros estados. Prevalência maior na área não coberta pelo PSF: sexo feminino, divorciados ou separados, evangélicos, economicamente inativos e ex-fumantes. Menor prevalência em ambas as áreas: com o aumento da escolaridade (embora, na área não-PSF, apenas a partir 
da $5^{\mathrm{a}}$ série) e fisicamente ativos. Menor prevalência na área não-PSF: “concubinato" e fumantes leves. No tocante a renda, embora não haja associação estatisticamente significante, destaca-se o fato de haver $11,9 \%$ de diabéticos na população de mais alta renda ( $>$ 5,00 SM per capita) na área do PSF, enquanto há 2,2\%, nessa mesma faixa de renda, na área não-PSF. (Tabela 12).

Tabela 12 . Prevalência de diabetes segundo cobertura PSF e variáveis sociodemográficas. Vila Nova Cachoeirinha e Vila Curuçá, São Paulo, 2001.

\begin{tabular}{|c|c|c|c|c|c|c|c|c|c|c|}
\hline \multirow[t]{3}{*}{ Variável Categoria } & \multicolumn{4}{|c|}{ Área Coberta pelo PSF } & \multicolumn{6}{|c|}{ Área Não Coberta pelo PSF } \\
\hline & \multirow{2}{*}{$\begin{array}{c}\text { Total } \\
\mathrm{N}\end{array}$} & \multicolumn{3}{|c|}{ Tem diabetes } & \multirow[b]{2}{*}{$\mathrm{P}$} & \multicolumn{2}{|c|}{ Total } & \multicolumn{3}{|c|}{ Tem diabetes } \\
\hline & & $\mathrm{N}$ & $(\%)$ & $\mathrm{IC}(95 \%)$ & & $\mathrm{N}$ & $\mathrm{N}$ & $(\%)$ & $\mathrm{IC}(95 \%)$ & $\mathrm{P}$ \\
\hline \multicolumn{11}{|l|}{ SEXO } \\
\hline Feminino & 689 & 42 & 6,2 & $4,6-8,4$ & & 705 & 54 & 6,2 & $4,5-8,5$ & \\
\hline Masculino & 540 & 27 & 4,7 & $3,2-6,9$ & & 578 & 24 & 3,9 & $2,6-6,0$ & * \\
\hline \multicolumn{11}{|l|}{ FAIXA ETÁRIA (anos) } \\
\hline $15-29$ & 429 & 1 & 0,2 & $0,0-1,3$ & & 518 & 6 & 0,7 & $0,3-1,8$ & \\
\hline $30-44$ & 381 & 14 & 3,5 & $2,0-6,1$ & $*$ & 424 & 13 & 2,3 & $1,2-4,3$ & \\
\hline $45-59$ & 247 & 29 & 12,0 & $8,5-16,5$ & $*$ & 229 & 31 & 10,9 & $7,0-16,7$ & $*$ \\
\hline 60 ou mais & 172 & 25 & 13,8 & $9,4-19,8$ & $*$ & 112 & 28 & 22,5 & $15,2--32,0$ & $*$ \\
\hline \multicolumn{11}{|l|}{ ESTADO CIVIL } \\
\hline Solteiro & 444 & 8 & 1,8 & $0,9-3,6$ & & 463 & 12 & 2,1 & $1,4-4,9$ & \\
\hline Casado & 463 & 38 & 8,1 & $5,9-11,2$ & * & 475 & 37 & 6,3 & $4,2-9,2$ & $*$ \\
\hline Divorciado ou separado & 36 & 2 & 6,1 & $1,4-22,4$ & & 26 & 4 & 15,3 & $4,7-39,5$ & $*$ \\
\hline "Concubinato" & 28 & 2 & 6,5 & $1,6-23,4$ & & 39 & 1 & $(0,2$ & $0,0-1,5$ & $*$ \\
\hline Viúvo & 165 & 2 & 1,5 & $0,4-5,4$ & & 212 & 8 & 2,3 & $1,0-5,1$ & \\
\hline \multicolumn{11}{|l|}{ ESCOLARIDADE } \\
\hline Nenhuma & 68 & 13 & 17,4 & $9,5-29,7$ & & 63 & 9 & 12,5 & $6,0-24,1$ & \\
\hline Ensino Fundamental $1^{\mathrm{a}}$ a $4^{\mathrm{a}}$ séries & 335 & 25 & 7,4 & $5,0-10,7$ & * & 350 & 43 & 11,6 & $7,8-16,7$ & \\
\hline Ensino Fundamental $5^{\mathrm{a}}$ a $8^{\mathrm{a}}$ séries & 382 & 16 & 4,2 & $2,5-6,9$ & $*$ & 390 & 15 & 3,5 & $2,0-6,2$ & * \\
\hline $\begin{array}{l}\text { Ensino Médio completo ou } \\
\text { incompleto }\end{array}$ & 375 & 11 & 3,3 & $1,8-5,9$ & * & 375 & 10 & 2,1 & $1,0-4,3$ & * \\
\hline Superior completo ou incompleto & 62 & 3 & 4,0 & $1,3-11,9$ & $*$ & 96 & 1 & 1,0 & $0,1-7,3$ & * \\
\hline \multicolumn{11}{|l|}{ PROCEDÊNCIA } \\
\hline SP capital & 585 & 17 & 3,8 & $1,8-5,1$ & & 622 & 16 & 2,1 & $1,1-4,0$ & \\
\hline SP interior & 153 & 14 & 8,5 & $5,1-13,9$ & $*$ & 122 & 17 & 13,0 & $7,2-22,3$ & * \\
\hline Outros estados & 476 & 37 & 7,8 & $5,6-10,7$ & $*$ & 523 & 44 & 7,2 & $4,6-10,8$ & $*$ \\
\hline \multicolumn{11}{|l|}{ RELIGIÃO } \\
\hline Catolicismo & 795 & 47 & 6,0 & $4,5-8,0$ & & 812 & 39 & 4,1 & $2,7-6,2$ & \\
\hline Evangélico & 296 & 15 & 4,9 & $3,0-8,0$ & & 296 & 31 & 9,4 & $6,3-13,7$ & * \\
\hline Outras & 138 & 7 & 4,3 & $1,9-9,2$ & & 171 & 8 & 4,0 & $1,7-9,2$ & \\
\hline
\end{tabular}

\section{Continua}


Tabela 12 . Prevalência de diabetes segundo cobertura PSF e variáveis sociodemográficas.

Vila Nova Cachoeirinha e Vila Curuçá, São Paulo, 2001. (Conclusão)

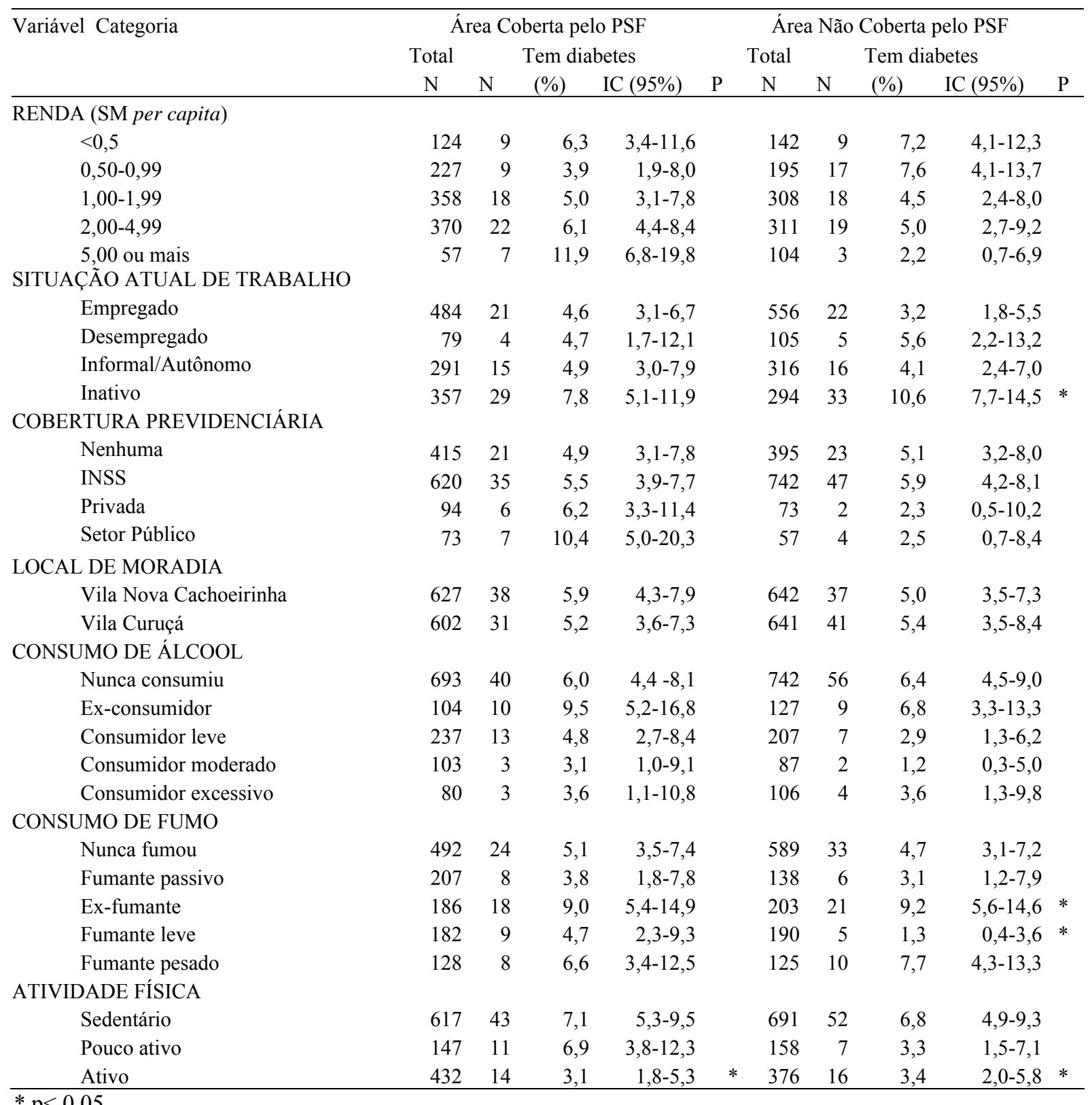

Para diabetes, mesmo recorrendo-se à tentativa de se utilizar da regressão logística, não foi possível fazer a análise multivariada de acordo com a cobertura do PSF, devido ao número relativamente pequeno de casos. 
Para Doença Isquêmica do Coração (DIC), soma das respostas nos questionários de infarto do miocárdio e doença coronária, observa-se prevalência significantemente maior nas seguintes categorias: sexo feminino, idade a partir dos 45 anos, casados e divorciados ou separados, sem nenhuma escolaridade, procedentes do interior de SP e outros estados, economicamente inativos, indivíduos da VNC e ex-consumidores de álcool. Prevalência significantemente menor encontra-se entre os consumidores leves de álcool e os ativos fisicamente (Tabela 13). Há tendência linear significativa para idade (diretamente proporcional) e escolaridade (inversamente proporcional).

Tabela 13. Distribuição da prevalência de doenças isquêmicas do coração segundo variáveis sociodemográficas. Vila Nova Cachoeirinha e Vila Curuçá, São Paulo, 2001.

\begin{tabular}{|c|c|c|c|c|c|c|}
\hline \multirow[t]{2}{*}{ VARIÁVEL } & \multirow[t]{2}{*}{ CATEGORIA } & \multicolumn{5}{|c|}{ Tem DIC } \\
\hline & & $\mathrm{N}$ Total & $\mathrm{N}$ & $\%$ & IC $95 \%$ & $\mathrm{P}$ \\
\hline \multicolumn{7}{|l|}{ SEXO } \\
\hline & Feminino & 1394 & 109 & 6,9 & $5,6-8,6$ & \\
\hline & Masculino & 1118 & 59 & 4,4 & $3,3-5,8$ & $*$ \\
\hline \multicolumn{7}{|c|}{ FAIXA ETÁRIA (anos) } \\
\hline & $15-29$ & 947 & 22 & 1,9 & $1,1-3,1$ & \\
\hline & $30-44$ & 805 & 33 & 3,2 & $2,2-4,8$ & \\
\hline & $45-59$ & 476 & 51 & 8,4 & $5,8-12,1$ & $*$ \\
\hline & 60 ou mais & 284 & 62 & 21,9 & $16,5-28,5$ & $*$ \\
\hline \multicolumn{7}{|c|}{ ESTADO CIVIL } \\
\hline & Solteiro & 907 & 33 & 3,3 & $2,3-4,8$ & \\
\hline & Casado & 938 & 71 & 5,8 & $4,3-8,2$ & $*$ \\
\hline & Divorciado ou separado & 62 & 7 & 11,4 & $5,1-23,8$ & $*$ \\
\hline & "Concubinato" & 67 & 6 & 6,5 & $2,7-14,7$ & \\
\hline & Viúvo & 377 & 22 & 4,6 & $2,7-7,8$ & \\
\hline \multicolumn{7}{|c|}{ ESCOLARIDADE } \\
\hline & Nenhuma & 131 & 27 & 19,1 & $12,3-28,4$ & \\
\hline & Ensino Fundamental $1^{\mathrm{a}}$ a $4^{\mathrm{a}}$ séries & 685 & 72 & 9,9 & $7,4-13,0$ & $*$ \\
\hline & Ensino Fundamental $5^{\mathrm{a}}$ a $8^{\mathrm{a}}$ séries & 772 & 37 & 4,5 & $3,1-6,4$ & $*$ \\
\hline & Ensino Médio completo ou incompleto & 750 & 28 & 2,7 & $1,8-4,1$ & $*$ \\
\hline & Superior completo ou incompleto & 158 & 3 & 1,3 & $0,4-4,1$ & $*$ \\
\hline \multicolumn{7}{|c|}{ PROCEDÊNCIA } \\
\hline & SP capital & 1207 & 53 & 3,7 & $2,7-5,0$ & \\
\hline & SP interior & 275 & 29 & 9,9 & $6,1-15,7$ & $*$ \\
\hline & Outros estados & 999 & 82 & 7,0 & $5,1-9,5$ & $*$ \\
\hline
\end{tabular}

Continua 
Tabela 13. Distribuição da prevalência de doenças isquêmicas do coração segundo variáveis sociodemográficas. Vila Nova Cachoeirinha e Vila Curuçá, São Paulo, 2001. (Conclusão)

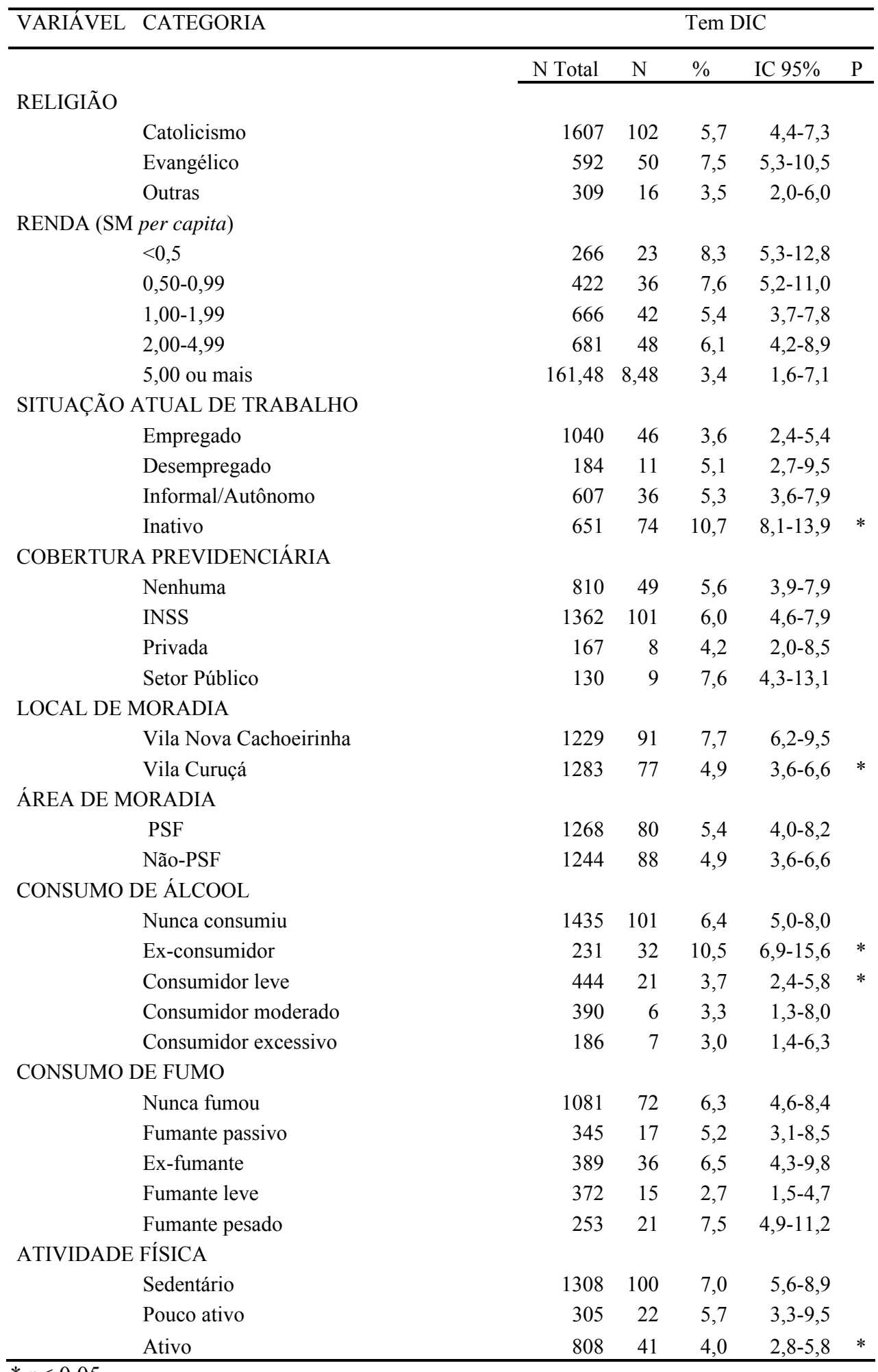

$* \mathrm{p}<0,05$ 
Aplicando-se a análise multivariada, verifica-se Razão de Prevalência entre os indivíduos que têm doenças isquêmicas do coração e os que não têm significantemente maior para as categorias faixa etária a partir dos 45 a 59 anos e menor, para as categorias masculino, curso superior completo ou incompleto e nos fumantes leves (Tabela 14). Não houve associação significativa com renda, consumo de álcool e atividade física.

Tabela 14. Análise multivariada da prevalência de doenças isquêmicas do coração. Vila Nova Cachoeirinha e Vila Curuçá, São Paulo, 2001.**

\begin{tabular}{|c|c|c|c|c|}
\hline Variável & Categorias & $\begin{array}{c}\text { Razão de } \\
\text { Prevalência }\end{array}$ & IC $95 \%$ & $\mathrm{P}$ \\
\hline \multicolumn{5}{|l|}{ Sexo } \\
\hline & Feminino & 1,00 & & \\
\hline & Masculino & 0,72 & $0,54-0,97$ & * \\
\hline \multicolumn{5}{|c|}{ Faixa etária (anos) } \\
\hline & $15-29$ & 1,00 & & \\
\hline & $30-44$ & 1,67 & $0,87-3,18$ & \\
\hline & $45-59$ & 3,73 & $1,97-7,07$ & * \\
\hline & 60 ou mais & 8,62 & $4,24-17,53$ & * \\
\hline \multicolumn{5}{|c|}{ Escolaridade } \\
\hline & Nenhuma & 1,00 & & \\
\hline & Ensino Fundamental $1^{\mathrm{a}}$ a $4^{\mathrm{a}}$ séries & 0,76 & $0,46-1,28$ & \\
\hline & Ensino Fundamental $5^{\mathrm{a}}$ a $8^{\mathrm{a}}$ séries & 0,72 & $0,36-1,44$ & \\
\hline & Ensino Médio completo ou incompleto & 0,52 & $0,24-1,13$ & \\
\hline & Superior completo ou incompleto & 0,25 & $0,07-0,90$ & * \\
\hline \multicolumn{5}{|c|}{ Consumo de fumo } \\
\hline & Nunca fumou & 1,00 & & \\
\hline & Fumante passivo & 1,09 & $0,63-1,87$ & \\
\hline & Ex-fumante & 0,79 & $0,48-1,32$ & \\
\hline & Fumante leve & 0,49 & $0,27-0,90$ & * \\
\hline & Fumante pesado & 1,38 & $0,82-2,33$ & \\
\hline
\end{tabular}

$* \mathrm{p}<0,05$

* resultados ajustados para as variáveis sexo, idade, estado civil, escolaridade, procedência, religião, renda, situação atual de trabalho e cobertura previdenciária, consumo de álcool, consumo de fumo e atividade física.

Em relação à cobertura PSF, nota-se prevalência significantemente menor no sexo masculino somente na área não coberta pelo PSF. Aumento de prevalência nos maiores de 45 anos e inativos ocorre em ambas as áreas. Diminuição de prevalência a partir da $5^{\mathrm{a}}$ à $8^{\mathrm{a}}$ 
série também ocorre em ambas. Maior prevalência entre os procedentes do interior de SP e de outros estados, quem nunca consumiu e ex-consumidores de álcool apenas na área de não-PSF. E menor prevalência entre os de $1^{\mathrm{a}}$ a $4^{\mathrm{a}}$ séries e fisicamente ativos apenas na área PSF (Tabela 15). Há tendência linear significativa para idade (diretamente proporcional) e escolaridade (inversamente proporcional) na área não-PSF, enquanto, na área PSF, há apenas em relação à idade.

Tabela 15. Prevalência de doenças isquêmicas do coração segundo cobertura PSF e variáveis sociodemográficas. Vila Nova Cachoeirinha e Vila Curuçá, São Paulo, 2001.

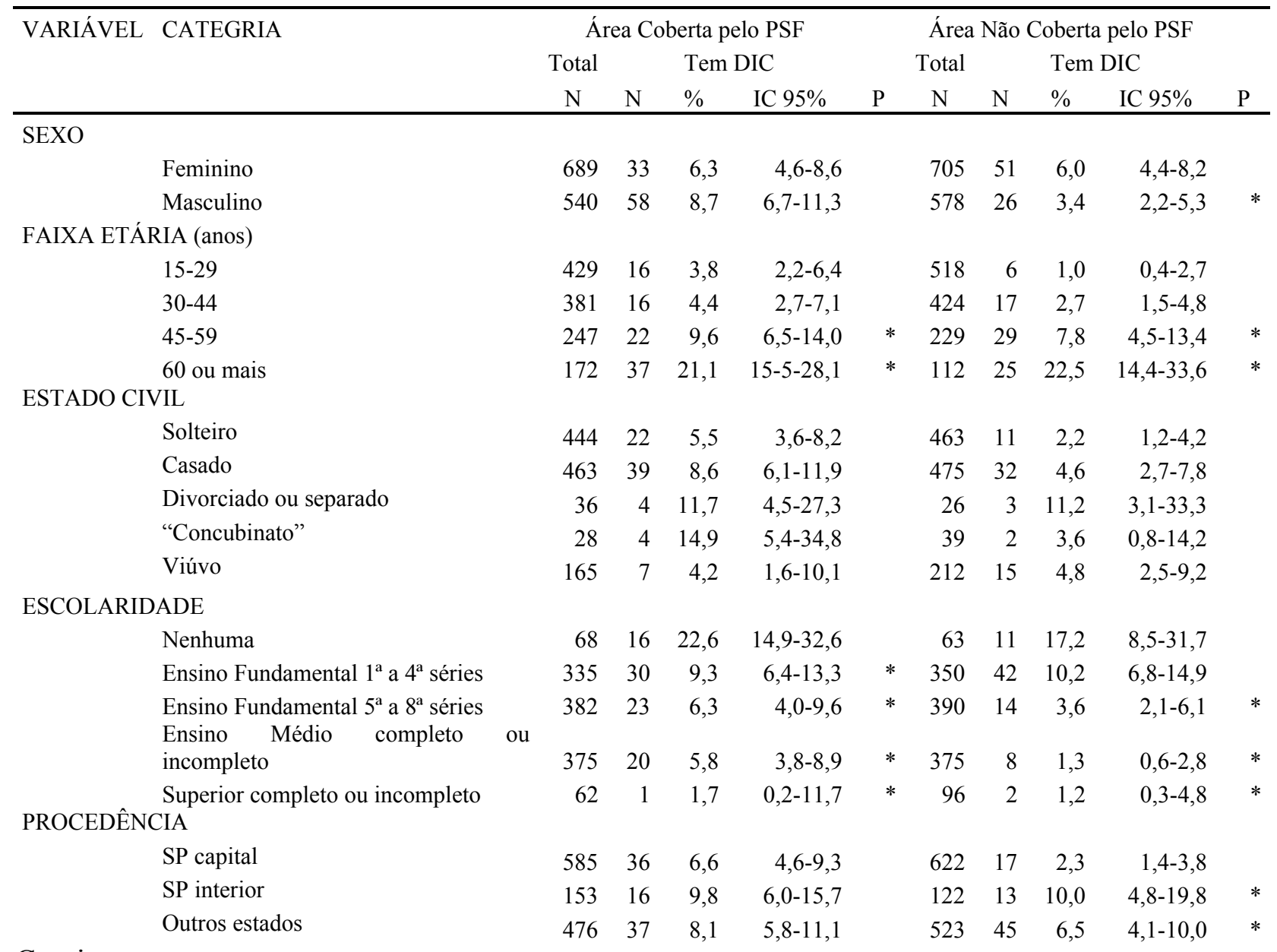

Continua 
Tabela 15. Prevalência de doenças isquêmicas do coração segundo cobertura PSF e variáveis sociodemográficas. Vila Nova Cachoeirinha e Vila Curuçá, São Paulo, 2001. (Conclusão)

\begin{tabular}{|c|c|c|c|c|c|c|c|c|c|c|c|}
\hline \multirow[t]{3}{*}{ VARIÁVEL } & \multirow[t]{3}{*}{ CATEGRIA } & \multicolumn{4}{|c|}{ Área Coberta pelo PSF } & \multicolumn{6}{|c|}{ Área Não Coberta pelo PSF } \\
\hline & & \multicolumn{2}{|c|}{ Total } & \multicolumn{2}{|c|}{ Tem DIC } & \multicolumn{3}{|c|}{ Total } & \multicolumn{2}{|c|}{ Tem DIC } & \multirow[b]{2}{*}{$\mathrm{P}$} \\
\hline & & $\mathrm{N}$ & $\mathrm{N}$ & $\%$ & IC $95 \%$ & $\mathrm{P}$ & $\mathrm{N}$ & $\mathrm{N}$ & $\%$ & IC $95 \%$ & \\
\hline \multicolumn{12}{|l|}{ RELIGIÃO } \\
\hline & Catolicismo & 795 & 61 & 7,9 & $6,1-10,2$ & & 812 & 41 & 4,6 & $3,1-6,8$ & \\
\hline & Evangélico & 296 & 21 & 7,4 & $4,6-11,8$ & & 296 & 29 & 7,6 & $4,7-11,9$ & \\
\hline & Outras & 138 & 9 & 6,8 & $3,8-11,9$ & & 171 & 7 & 2,2 & $0,9-5,5$ & \\
\hline \multicolumn{12}{|c|}{ RENDA (SM per capita) } \\
\hline & $<0,5$ & 124 & 15 & 12,2 & $6,8-20,9$ & & 142 & 8 & 6,4 & $3,3-12,1$ & \\
\hline & $0,50-0,99$ & 227 & 18 & 8,6 & $5,3-13,7$ & & 195 & 18 & 6,9 & $3,9-12,1$ & \\
\hline & $1,00-1,99$ & 358 & 24 & 6,8 & $4,5-10,3$ & & 308 & 18 & 4,5 & $2,4-8,2$ & \\
\hline & $2,00-4,99$ & 370 & 26 & 7,4 & $5,2-10,5$ & & 311 & 22 & 5,5 & $3,0-9,7$ & \\
\hline & 5,00 ou mais & 57 & 4 & 6,5 & $2,6-15,4$ & & 104 & 4 & 2,7 & $0,9-7,5$ & \\
\hline \multicolumn{12}{|c|}{ SITUAÇÃO ATUAL DE TRABALHO } \\
\hline & Empregado & 484 & 24 & 5,3 & $3,3-8,4$ & & 556 & 22 & 2,9 & $1,6-5,3$ & \\
\hline & Desempregado & 79 & 8 & 9,3 & $4,5-18,2$ & & 105 & 3 & 3,4 & $1,1-9,9$ & \\
\hline & Informal/Autônomo & 291 & 12 & 4,1 & $2,3-7,3$ & & 316 & 24 & 5,9 & $3,5-9,8$ & \\
\hline & Inativo & 357 & 47 & 13,6 & $9,9-18,5$ & * & 294 & 27 & 8,6 & $5,5-13,3$ & * \\
\hline \multicolumn{12}{|c|}{ COBERTURA PREVIDENCIÁRIA } \\
\hline & Nenhuma & 415 & 24 & 5,6 & $3,7-8,3$ & & 395 & 25 & 5,6 & $3,4-9,1$ & \\
\hline & INSS & 620 & 57 & 9,7 & $7,3-12,8$ & & 742 & 44 & 4,5 & $2,9-6,8$ & \\
\hline & Privada & 94 & 6 & 6,8 & $3,4-13,1$ & & 73 & 2 & 2,9 & $0,7-10,9$ & \\
\hline & Setor Público & 73 & 4 & 5,9 & $2,7-12,7$ & & 57 & 5 & 8,7 & $4,2-17,4$ & \\
\hline \multicolumn{12}{|c|}{ LOCAL DE MORADIA } \\
\hline & Vila Nova Cachoeirinha & 627 & 46 & 7,8 & $5,8-10,4$ & & 641 & 34 & 4,3 & $2,8-6,7$ & \\
\hline & Vila Curuçá & 602 & 45 & 7,5 & $5,5-10,3$ & & 642 & 43 & 5,8 & $3,8-8,7$ & \\
\hline \multicolumn{12}{|c|}{ CONSUMO DE ÁLCOOL } \\
\hline & Nunca consumiu & 693 & 54 & 8,1 & $6,2-10,6$ & & 742 & 47 & 5,5 & $3,9-7,8$ & \\
\hline & Ex-consumidor & 104 & 14 & 13,4 & $8,3-20,9$ & & 127 & 18 & 9,3 & $5,2-16,2$ & \\
\hline & Consumidor leve & 237 & 15 & 6,6 & $4,1-10,4$ & & 207 & 6 & 2,2 & $0,9-5,1$ & \\
\hline & Consumidor moderado & 103 & 4 & 4,1 & $1,5-10,3$ & & 87 & 2 & 2,8 & $0,6-11,9$ & \\
\hline & Consumidor excessivo & 80 & 3 & 4,1 & $1,4-44,8$ & & 106 & 4 & 2,5 & $0,9-7,0$ & \\
\hline \multicolumn{12}{|c|}{ CONSUMO DE FUMO } \\
\hline & Nunca fumou & 492 & 38 & 7,8 & $5,4-11,0$ & & 589 & 34 & 5,6 & $3,7-8,5$ & \\
\hline & Fumante passivo & 207 & 11 & 5,9 & $3,1-10,8$ & & 138 & 6 & 4,7 & $2,1-10,1$ & \\
\hline & Ex-fumante & 186 & 18 & 10,6 & $6,9-16,0$ & & 203 & 18 & 4,8 & $2,5-9,2$ & \\
\hline & Fumante leve & 182 & 9 & 4,9 & $2,5-9,5$ & & 190 & 6 & 1,5 & $0,5-4,3$ & \\
\hline & Fumante pesado & 128 & 11 & 8,7 & $5,1-14,5$ & & 125 & 10 & 6,8 & $3,7-12,2$ & \\
\hline \multicolumn{12}{|c|}{ ATIVIDADE FÍSICA } \\
\hline & Sedentário & 617 & 55 & 9,2 & $7,0-12,1$ & & 691 & 45 & 6,0 & $4,3-8,4$ & \\
\hline & Pouco ativo & 147 & 13 & 8,7 & $4,9-15,2$ & & 158 & 9 & 4,4 & $1,8-10,0$ & \\
\hline & Ativo & 432 & 20 & 4,9 & $3,2-7,5$ & * & 376 & 21 & 3,5 & $2,0-6,0$ & \\
\hline
\end{tabular}

$* \mathrm{p}<0,05$ 
Realizando-se a análise multivariada, a relação com o sexo masculino permanece apenas na área não-PSF, a maior prevalência a partir dos 45 anos apresenta-se para ambas as áreas, e a menor prevalência nas pessoas com Ensino Médio completo ou incompleto é observada apenas na área sem cobertura PSF (Tabela 16). Há tendência linear significativa para idade (diretamente proporcional) e escolaridade (inversamente proporcional) só na área não-coberta pelo PSF, enquanto, na área coberta, essa permanece apenas em relação à idade.

Tabela 16. Análise multivariada da prevalência de doenças isquêmicas do coração segundo cobertura PSF. Vila Nova Cachoeirinha e Vila Curuçá, São Paulo, 2001.**

\begin{tabular}{|c|c|c|c|c|c|c|c|}
\hline \multirow[t]{2}{*}{ Variável } & \multirow[t]{2}{*}{ Categorias } & \multicolumn{3}{|c|}{ Cobertura PSF } & \multicolumn{3}{|c|}{ Cobertura Não-PSF } \\
\hline & & $\begin{array}{c}\text { Razão de } \\
\text { prevalência }\end{array}$ & IC $95 \%$ & $\mathrm{P}$ & $\begin{array}{l}\text { Razão de } \\
\text { prevalência }\end{array}$ & IC $95 \%$ & $\mathrm{P}$ \\
\hline \multicolumn{8}{|l|}{ Sexo } \\
\hline & Feminino & 1,00 & & & 1,00 & & \\
\hline & Masculino & 0,77 & $0,52-1,14$ & & 0,66 & $0,43-0,99$ & * \\
\hline \multicolumn{8}{|c|}{ Faixa Etária (anos) } \\
\hline & $15-29$ & 1,00 & & & 1,00 & & \\
\hline & $30-44$ & 1,26 & $0,55-2,88$ & & 2,09 & $0,62-7,05$ & \\
\hline & $45-59$ & 2,74 & $1,23-6,09$ & * & 3,93 & $1,20-12,92$ & * \\
\hline & 60 ou mais & 5,95 & $2,73-12,97$ & $*$ & 10,02 & $2,62-38,37$ & $*$ \\
\hline \multicolumn{8}{|c|}{ Renda (SM per capita) } \\
\hline & $<0,5$ & 1,00 & & & 1,00 & & \\
\hline & $0,50-0,99$ & 0,94 & $0,48-1,85$ & & 1,12 & $0,47-2,71$ & \\
\hline & $1,00-1,99$ & 0,71 & $0,37-1,35$ & & 0,92 & $0,38-2,25$ & \\
\hline & $2,00-4,99$ & 0,73 & $0,36-1,47$ & & 1,16 & $0,53-2,56$ & \\
\hline & 5,00 ou mais & 0,76 & $0,26-2,19$ & & 0,80 & $0,22-2,84$ & \\
\hline \multicolumn{8}{|c|}{ Escolaridade } \\
\hline & Nenhuma & 1,00 & & & 1,00 & & \\
\hline & Ensino Fundamental $1^{\mathrm{a}}$ a $4^{\mathrm{a}}$ séries & 0,68 & $0,39-1,19$ & & 0,85 & $0,38-1,89$ & \\
\hline & Ensino Fundamental $5^{\mathrm{a}}$ a $8^{\mathrm{a}}$ séries & 0,82 & $0,41-1,64$ & & 0,62 & $0,19-1,98$ & \\
\hline & Ensino Médio completo ou incompleto & 0,89 & $0,39-2,03$ & & 0,21 & $0,05-0,89$ & * \\
\hline & Superior completo ou incompleto & 0,31 & $0,49-1,95$ & & 0,22 & $0,03-1,40$ & \\
\hline
\end{tabular}

$* \mathrm{p}<0,05$

**resultados ajustados para todas as variáveis constantes na tabela 
No que se refere à tuberculose, observa-se uma relação inversamente proporcional com o grau de escolaridade, embora o pequeno número de casos nas extremidades das categorias dessa variável exija cautela. Estatisticamente, há menor prevalência entre as pessoas com ensino superior completo ou incompleto em relação às pessoas sem nenhuma escolaridade. Quanto ao consumo de fumo, observa-se maior prevalência entre os fumantes leves comparados aos que nunca fumaram (Tabela 17). Há tendência linear significativa para escolaridade (inversamente proporcional).

Tabela 17. Distribuição da prevalência de tuberculose segundo variáveis sociodemográficas. Vila Nova Cachoeirinha e Vila Curuçá, São Paulo, 2001.

\begin{tabular}{|c|c|c|c|c|c|c|}
\hline \multirow[t]{2}{*}{ VARIÁVEL } & \multirow[t]{2}{*}{ CATEGORIA } & \multicolumn{5}{|c|}{ Tem Tuberculose } \\
\hline & & $\mathrm{N}$ Total & $\mathrm{N}$ & $\%$ & IC $95 \%$ & $\mathrm{P}$ \\
\hline \multicolumn{7}{|l|}{ SEXO } \\
\hline & Feminino & 1394 & 22 & 2,0 & $1,2-3,1$ & \\
\hline & Masculino & 1118 & 25 & 2,2 & $1,3-3,9$ & \\
\hline \multicolumn{7}{|c|}{ FAIXA ETÁRIA (anos) } \\
\hline & $15-29$ & 947 & 8 & 1,3 & $0,6-3,1$ & \\
\hline & $30-44$ & 805 & 17 & 2,1 & $1,2-3,5$ & \\
\hline & $45-59$ & 476 & 17 & 3,3 & $2,0-5,5$ & \\
\hline & 60 ou mais & 284 & 5 & 2,3 & $0,6-8,6$ & \\
\hline \multicolumn{7}{|c|}{ ESTADO CIVIL } \\
\hline & Solteiro & 907 & 15 & 2,2 & $1,2-4,2$ & \\
\hline & Casado & 938 & 19 & 1,9 & $1,1-3,4$ & \\
\hline & Divorciado ou separado & 62 & 2 & 3,1 & $0,7-12,5$ & \\
\hline & "Concubinato" & 67 & 0 & 0,0 & 0 & \\
\hline & Viúvo & 377 & 9 & 2,8 & $1,2-6,1$ & \\
\hline \multicolumn{7}{|c|}{ ESCOLARIDADE** } \\
\hline & Nenhuma & 131 & 3 & 3,0 & $0,9-9,6$ & \\
\hline & Ensino Fundamental $1^{\mathrm{a}}$ a $4^{\mathrm{a}}$ séries & 685 & 23 & 3,6 & $2,2-5,7$ & \\
\hline & Ensino Fundamental $5^{\mathrm{a}}$ a $8^{\mathrm{a}}$ séries & 772 & 13 & 2,1 & $1,1-3,7$ & \\
\hline & Ensino Médio completo ou incompleto & 750 & 7 & 1,2 & $0,5-2,8$ & \\
\hline & Superior completo ou incompleto & 158 & 1 & 0,4 & $0,0-3,0$ & \\
\hline \multicolumn{7}{|c|}{ PROCEDÊNCIA } \\
\hline & SP capital & 1207 & 20 & 1,7 & $1,0-2,9$ & \\
\hline & SP interior & 275 & 7 & 2,4 & $1,0-5,3$ & \\
\hline & Outros estados & 999 & 20 & 2,5 & $1,4-4,5$ & \\
\hline
\end{tabular}

Continua 
Tabela 17. Distribuição da prevalência de tuberculose segundo variáveis sociodemográficas. Vila Nova Cachoeirinha e Vila Curuçá, São Paulo, 2001. (Conclusão)

\begin{tabular}{|c|c|c|c|c|c|c|}
\hline \multirow{4}{*}{$\begin{array}{l}\text { VARIÁVEL } \\
\text { RELIGIÃO }\end{array}$} & \multirow[t]{2}{*}{ CATEGORIA } & \multicolumn{5}{|c|}{ Tem Tuberculose } \\
\hline & & \multirow[t]{2}{*}{ N Total } & \multirow[t]{2}{*}{$\mathrm{N}$} & \multirow[t]{2}{*}{$\%$} & \multirow[t]{2}{*}{ IC $95 \%$} & \multirow[t]{2}{*}{$\mathrm{P}$} \\
\hline & & & & & & \\
\hline & Catolicismo & 1607 & 32 & 2,1 & $1,2-3,6$ & \\
\hline & Evangélico & 592 & 9 & 2,1 & $1,1-4,2$ & \\
\hline & Outras & 309 & 6 & 1,8 & $0,8-4,4$ & \\
\hline \multicolumn{7}{|c|}{ RENDA (SM per capita) } \\
\hline & $<0,5$ & 266 & 6 & 3,2 & $1,0-9,3$ & \\
\hline & $0,50-0,99$ & 422 & 9 & 2,5 & $1,3-4,9$ & \\
\hline & $1,00-1,99$ & 666 & 13 & 2,5 & $1,3-4,8$ & \\
\hline & $2,00-4,99$ & 681 & 12 & 1,6 & $0,9-2,8$ & \\
\hline & 5,00 ou mais & 161 & 3 & 2,1 & $0,7-6,4$ & \\
\hline \multicolumn{7}{|c|}{ SITUAÇÃO ATUAL DE TRABALHO } \\
\hline & Empregado & 1040 & 18 & 2,2 & $1,3-3,6$ & \\
\hline & Desempregado & 184 & 3 & 2,6 & $0,4-13,7$ & \\
\hline & Informal/Autônomo & 607 & 12 & 2,0 & $0,9-4,4$ & \\
\hline & Inativo & 651 & 13 & 1,6 & $0,9-2,7$ & \\
\hline \multicolumn{7}{|c|}{ COBERTURA PREVIDENCIÁRIA } \\
\hline & Nenhuma & 810 & 13 & 1,6 & $0,8-3,2$ & \\
\hline & INSS & 1362 & 27 & 2,1 & $1,3-3,2$ & \\
\hline & Privada & 167 & 4 & 3,0 & $0,7-12,0$ & \\
\hline & Setor Público & 130 & 2 & 2,3 & $0,6-7,9$ & \\
\hline \multicolumn{7}{|c|}{ LOCAL DE MORADIA } \\
\hline & Vila Nova Cachoeirinha & 1268 & 30 & 2,6 & $1,5-4,2$ & \\
\hline & Vila Curuçá & 1244 & 17 & 1,3 & $0,8-2,2$ & \\
\hline \multicolumn{7}{|c|}{ ÁREA DE MORADIA } \\
\hline & PSF & 1229 & 23 & 2,1 & $1,4-3,0$ & \\
\hline & Não-PSF & 1283 & 24 & 2,1 & $1,2-3,7$ & \\
\hline \multicolumn{7}{|c|}{ CONSUMO DE ÁLCOOL } \\
\hline & Nunca consumiu & 1435 & 25 & 2,1 & $1,2-3,5$ & \\
\hline & Ex-consumidor & 231 & 6 & 2,9 & $1,2-6,8$ & \\
\hline & Consumidor leve & 444 & 5 & 1,2 & $0,5-3,1$ & \\
\hline & Consumidor moderado & 190 & 5 & 3,0 & $1,1-7,4$ & \\
\hline & Consumidor excessivo & 186 & 6 & 2,5 & $1,1-5,7$ & \\
\hline \multicolumn{7}{|c|}{ CONSUMO DE FUMO } \\
\hline & Nunca fumou & 1081 & 13 & 1,6 & $0,8-3,0$ & \\
\hline & Fumante passivo & 345 & 8 & 2,6 & $1,3-5,3$ & \\
\hline & Ex-fumante & 389 & 5 & 1,2 & $0,4-3,1$ & \\
\hline & Fumante leve & 372 & 15 & 4,7 & $2,7-7,1$ & * \\
\hline & Fumante pesado & 253 & 6 & 1,7 & $0,6-4,2$ & \\
\hline \multicolumn{7}{|c|}{ ATIVIDADE FÍSICA } \\
\hline & Sedentário & 1308 & 27 & 2,4 & $1,4-4,2$ & \\
\hline & Pouco ativo & 305 & 4 & 1,3 & $0,4-3,6$ & \\
\hline & Ativo & 808 & 16 & 2,1 & $1,1-1,4$ & \\
\hline
\end{tabular}

$\mathrm{p}<0,05$

** diferença significante entre as categorias ensino fundamental $1^{\mathrm{a}}$ a $4^{\mathrm{a}}$ séries e superior completo ou incompleto. 
Observando-se de acordo com a cobertura do PSF, na área do PSF notou-se aumento da prevalência para o sexo feminino e entre os fumantes, sejam os passivos, leves ou pesados . (Tabela 18)

Tabela 18. Prevalência de tuberculose segundo cobertura PSF e variáveis sociodemográficas. Vila Nova Cachoeirinha e Vila Curuçá, São Paulo, 2001.

\begin{tabular}{|c|c|c|c|c|c|c|c|c|c|c|}
\hline \multirow[t]{3}{*}{ VARIÁVEL } & \multicolumn{4}{|c|}{ Área Coberta pelo PSF } & \multicolumn{6}{|c|}{ Área Não Coberta pelo PSF } \\
\hline & \multirow{2}{*}{$\begin{array}{c}\text { Total } \\
\mathrm{N}\end{array}$} & \multicolumn{3}{|c|}{ Tem Tuberculose } & \multirow[b]{2}{*}{$\mathrm{P}$} & Total & \multicolumn{3}{|c|}{ Tem Tuberculose } & \multirow[b]{2}{*}{$\mathrm{P}$} \\
\hline & & $\mathrm{N}$ & $\%$ & IC $95 \%$ & & $\mathrm{~N}$ & $\mathrm{~N}$ & $\%$ & IC $95 \%$ & \\
\hline \multicolumn{10}{|l|}{ SEXO } & \\
\hline Feminino & 689 & 8 & 1,3 & $0,6-2,5$ & & 705 & 14 & 2,3 & $1,3-4,0$ & \\
\hline Masculino & 540 & 15 & 3,1 & $1,9-4,9$ & $*$ & 578 & 10 & 1,8 & $0,7-4,7$ & \\
\hline \multicolumn{11}{|l|}{ FAIXA ETÁRIA (anos) } \\
\hline $15-29$ & 429 & 3 & 0,7 & $0,2-2,3$ & & 518 & 5 & 1,6 & $0,6-4,3$ & \\
\hline $30-44$ & 381 & 10 & 3,1 & $1,7-5,4$ & & 424 & 7 & 1,6 & $0,7-3,8$ & \\
\hline $45-59$ & 247 & 7 & 3,0 & $1,3-6,5$ & & 229 & 10 & 3,5 & $1,8-6,8$ & \\
\hline 60 ou mais & 172 & 3 & 1,9 & $0,6-5,7$ & & 112 & 2 & 2,7 & $0,4-17,7$ & \\
\hline \multicolumn{11}{|l|}{ ESTADO CIVIL } \\
\hline Solteiro & 444 & 7 & 1,7 & $0,8-3,8$ & & 463 & 8 & 2,5 & $1,1-5,7$ & \\
\hline Casado & 463 & 11 & 2,7 & $1,6-4,7$ & & 475 & 8 & 1,6 & $0,6-3,9$ & \\
\hline Divorciado ou separado & 36 & 1 & 2,2 & $0,3-14,5$ & & 28 & 1 & 3,7 & $0,5-22,7$ & \\
\hline "Concubinato" & 28 & 0 & 0,0 & 0,0 & & 39 & 0 & 0,0 & 0,0 & \\
\hline Viúvo & 165 & 3 & 2,0 & $0,7-6,0$ & & 212 & 6 & 3,1 & $1,1-8,1$ & \\
\hline \multicolumn{11}{|l|}{ ESCOLARIDADE } \\
\hline Nenhuma & 68 & 1 & 1,5 & $0,2-9,3$ & & 63 & 2 & 3,9 & $0,9-14,7$ & \\
\hline Ensino Fundamental $1^{\mathrm{a}}$ a $4^{\mathrm{a}}$ séries & 335 & 11 & 3,9 & $2,4-6,5$ & & 350 & 12 & 3,4 & $1,6-6,9$ & \\
\hline Ensino Fundamental $5^{\mathrm{a}}$ a $8^{\mathrm{a}}$ séries & 382 & 7 & 1,9 & $0,9-3,9$ & & 390 & 6 & 2,2 & $1,0-4,8$ & \\
\hline Ensino Médio completo ou incompleto & 375 & 3 & 0,8 & $0,2-2,5$ & & 375 & 4 & 1,3 & $0,4-3,9$ & \\
\hline Superior completo ou incompleto & 62 & 1 & 1,9 & $0,3-12,2$ & & 96 & 0 & 0,0 & 0,0 & \\
\hline \multicolumn{10}{|l|}{ PROCEDÊNCIA } & \\
\hline SP capital & 585 & 8 & 1,4 & $0,7-2,7$ & & 622 & 12 & 1,9 & $0,9-3,7$ & \\
\hline SP interior & 153 & 5 & 3,6 & $1,5-8,3$ & & 122 & 2 & 1,6 & $0,3-7,6$ & \\
\hline Outros estados & 476 & 10 & 2,5 & $1,4-4,5$ & & 523 & 10 & 2,5 & $1,1-5,8$ & \\
\hline \multicolumn{10}{|l|}{ RELIGIÃO } & \\
\hline Catolicismo & 795 & 16 & 2,2 & $1,4-3,5$ & & 812 & 16 & 2,0 & $0,9-4,5$ & \\
\hline Evangélico & 296 & 3 & 1,0 & $0,3-3,1$ & & 296 & 6 & 2,7 & $1,2-6,1$ & \\
\hline Outras & 138 & 4 & 3,4 & $1,2-8,7$ & & 171 & 2 & 1,3 & $0,3-5,4$ & \\
\hline \multicolumn{11}{|l|}{ RENDA (SM per capita) } \\
\hline$<0,5$ & 124 & 3 & 2,3 & $0,8-6,7$ & & 142 & 3 & 3,6 & $0,8-14,0$ & \\
\hline $0,50-0,99$ & 227 & 5 & 2,7 & $1,2-5,9$ & & 195 & 4 & 2,4 & $0,9-6,5$ & \\
\hline $1,00-1,99$ & 358 & 6 & 1,8 & $0,8-4,1$ & & 308 & 7 & 3,0 & $1,3-6,7$ & \\
\hline $2,00-4,99$ & 370 & 7 & 2,3 & $1,1-4,5$ & & 311 & 5 & 1,2 & $0,5-3,1$ & \\
\hline 5,00 ou mais & 57 & 0 & 0,0 & 0,0 & & 104 & 3 & 2,5 & $0,8-7,8$ & \\
\hline
\end{tabular}

\section{Continua}


Tabela 18. Prevalência de tuberculose segundo cobertura PSF e variáveis sociodemográficas. Vila Nova Cachoeirinha e Vila Curuçá, São Paulo, 2001. (Conclusão)

\begin{tabular}{|c|c|c|c|c|c|c|c|c|c|c|}
\hline \multirow[t]{3}{*}{ VARIÁVEL } & \multicolumn{4}{|c|}{ Área Coberta pelo PSF } & \multicolumn{6}{|c|}{ Área Não Coberta pelo PSF } \\
\hline & \multirow{2}{*}{$\begin{array}{c}\text { Total } \\
\mathrm{N}\end{array}$} & \multicolumn{3}{|c|}{ Tem Tuberculose } & \multirow[b]{2}{*}{$\mathrm{P}$} & Total & \multicolumn{3}{|c|}{ Tem Tuberculose } & \multirow[b]{2}{*}{$\mathrm{P}$} \\
\hline & & $\mathrm{N}$ & $\%$ & IC $95 \%$ & & $\mathrm{~N}$ & $\mathrm{~N}$ & $\%$ & IC $95 \%$ & \\
\hline \multicolumn{11}{|c|}{ SITUAÇÃO ATUAL DE TRABALHO } \\
\hline Empregado & 484 & 7 & 1,7 & $0,8-3,4$ & & 556 & 11 & 2,4 & $1,2-4,5$ & \\
\hline Desempregado & 79 & 1 & 1,0 & $0,1-7,3$ & & 105 & 2 & 3,3 & $0,4-20,2$ & \\
\hline Informal/Autônomo & 291 & 7 & 2,6 & $1,2-5,7$ & & 316 & 5 & 1,7 & $0,4-6,0$ & \\
\hline Inativo & 357 & 8 & 2,5 & $1,3-4,6$ & & 294 & 5 & 1,0 & $0,4-2,6$ & \\
\hline \multicolumn{11}{|l|}{ COBERTURA PREVIDENCIÁRIA } \\
\hline Nenhuma & 415 & 7 & 1,7 & $0,8-1,8$ & & 395 & 6 & 1,6 & $0,6-4,2$ & \\
\hline INSS & 620 & 14 & 2,6 & $1,7-4,1$ & & 742 & 13 & 1,9 & $1,0-3,6$ & \\
\hline Privada & 94 & 1 & 1,2 & $0,2-7,9$ & & 73 & 3 & 3,8 & $0,7-19,0$ & \\
\hline Setor Público & 73 & 1 & 1,5 & $0,2-10,1$ & & 57 & 1 & 2,8 & $0,6-12,0$ & \\
\hline \multicolumn{11}{|l|}{ LOCAL DE MORADIA } \\
\hline Vila Nova Cachoeirinha & 627 & 15 & 2,6 & $1,7-3,8$ & & 641 & 15 & 2,5 & $1,2-5,2$ & \\
\hline Vila Curuçá & 602 & 8 & 1,4 & $0,6-3,1$ & & 642 & 9 & 1,3 & $0,7-2,5$ & \\
\hline \multicolumn{11}{|l|}{ CONSUMO DE ÁLCOOL } \\
\hline Nunca consumiu & 693 & 9 & 1,4 & $0,7-2,7$ & & 742 & 16 & 2,4 & $1,2-4,5$ & \\
\hline Ex-consumidor & 104 & 4 & 4,0 & $1,5-10,0$ & & 127 & 2 & 2,5 & $0,6-8,8$ & \\
\hline Consumidor leve & 237 & 4 & 2,1 & $0,8-5,4$ & & 207 & 1 & 0,7 & $0,0-5,0$ & \\
\hline Consumidor moderado & 103 & 3 & 3,5 & $1,2-9,9$ & & 87 & 2 & 2,6 & $0,6-10,9$ & \\
\hline Consumidor excessivo & 80 & 3 & 4,2 & $1,4-11,7$ & & 106 & 3 & 1,9 & $0,6-6,3$ & \\
\hline \multicolumn{11}{|l|}{ CONSUMO DE FUMO } \\
\hline Nunca fumou & 492 & 3 & 0,6 & $0,2-1,8$ & & 589 & 10 & 2,0 & $0,9-4,1$ & \\
\hline Fumante passivo & 207 & 5 & 2,9 & $1,2-6,5$ & * & 138 & 3 & 2,5 & $0,8-7,3$ & \\
\hline Ex-fumante & 186 & 2 & 1,1 & $0,2-4,4$ & & 203 & 3 & 1,3 & $0,4-4,2$ & \\
\hline Fumante leve & 182 & 9 & 5,6 & $3,0-10,1$ & * & 190 & 6 & 4,2 & $1,8-9,6$ & \\
\hline Fumante pesado & 128 & 4 & 3,3 & $1,1-9,4$ & * & 125 & 2 & 0,8 & $0,1-4,3$ & \\
\hline \multicolumn{11}{|l|}{ ATIVIDADE FÍSICA } \\
\hline Sedentário & 617 & 11 & 2,1 & $1,2-3,5$ & & 691 & 16 & 2,6 & $1,2-5,5$ & \\
\hline Pouco ativo & 147 & 2 & 1,2 & $0,3-5,0$ & & 158 & 2 & 1,3 & $0,3-5,1$ & \\
\hline Ativo & 432 & 10 & 2,5 & $1,3-4,9$ & & 376 & 6 & 1,9 & $0,6-5,4$ & \\
\hline
\end{tabular}
$* \mathrm{p}<0,05$

Não foi possível realizar a análise multivariada devido ao pequeno número de casos. 


\subsection{Estilo de vida}

\subsubsection{Fumo}

Observa-se na tabela 19 que fumar é um estilo de vida associado ao sexo masculino, menos prevalente na faixa etária dos 15 aos 29 anos, menos prevalente nos solteiros e com diminuição progressiva dos que já fumaram com o aumento da escolaridade. Há menos pessoas que já fumaram na população procedente de SP capital, assim como entre os evangélicos.

Tabela 19. Distribuição da prevalência de consumo de fumo segundo variáveis sociodemográficas. Vila Nova Cachoeirinha e Vila Curuçá, São Paulo, 2001.

\begin{tabular}{|c|c|c|c|c|c|c|}
\hline \multirow{2}{*}{\multicolumn{2}{|c|}{ VARIÁVEL CATEGORIA }} & \multicolumn{5}{|c|}{ Já fumou } \\
\hline & & N Total & $\mathrm{N}$ & $\%$ & IC $95 \%$ & $\mathrm{p}$ \\
\hline \multicolumn{6}{|l|}{ SEXO } & $*$ \\
\hline & $\mathrm{F}$ & 1374 & 497 & 36,1 & $33,0-39,2$ & \\
\hline & M & 1106 & 536 & 49,4 & $46,2-52,7$ & \\
\hline \multicolumn{7}{|c|}{ FAIXA ETÁRIA (anos) } \\
\hline & $15-29$ & 928 & 244 & 26,4 & $22,6-30,6$ & \\
\hline & $30-44$ & 799 & 427 & 51,9 & $47,0-56,6$ & * \\
\hline & $45-59$ & 471 & 245 & 54,3 & $49,2-59,3$ & * \\
\hline & 60 ou mais & 282 & 117 & 42,5 & $36,8-48,5$ & * \\
\hline \multicolumn{7}{|c|}{ ESTADO CIVIL } \\
\hline & Solteiro & 887 & 260 & 28,5 & $24,7-32,7$ & \\
\hline & Casado & 930 & 416 & 45,5 & $41,6-49,5$ & * \\
\hline & Divorciado ou separado & 59 & 36 & 66,4 & $51,6-78,5$ & * \\
\hline & "Concubinato" & 68 & 46 & 74,0 & $59,7-84,5$ & * \\
\hline & Viúvo & 376 & 211 & 55,3 & $50,5-60,0$ & * \\
\hline \multicolumn{7}{|c|}{ ESCOLARIDADE } \\
\hline & Nenhuma & 134 & 68 & 53,1 & $40,9-64,9$ & \\
\hline & Ensino Fundamental $1^{\mathrm{a}}$ a $4^{\mathrm{a}}$ séries & 674 & 340 & 50,2 & $45,9-54,6$ & \\
\hline & Ensino Fundamental $5^{\mathrm{a}}$ a $8^{\mathrm{a}}$ séries & 768 & 349 & 45,5 & $41,5-49,5$ & \\
\hline & Ensino Médio completo ou incompleto & 735 & 225 & 32,2 & $27,8-36,7$ & * \\
\hline & Superior completo ou incompleto & 155 & 45 & 33,0 & $24,7-42,5$ & * \\
\hline
\end{tabular}

\section{Continua}


Tabela 19. Distribuição da prevalência de consumo de fumo segundo variáveis sociodemográficas. Vila Nova Cachoeirinha e Vila Curuçá, São Paulo, 2001. (Conclusão)

\begin{tabular}{|c|c|c|c|c|c|c|}
\hline \multirow{2}{*}{ VARIÁVEL } & \multirow{2}{*}{ CATEGORIA } & \multicolumn{5}{|c|}{ Já fumou } \\
\hline & & N Total & $\mathrm{N}$ & $\%$ & IC 95\% & $\mathrm{p}$ \\
\hline \multicolumn{7}{|c|}{ PROCEDÊNCIA } \\
\hline & SP capital & 1181 & 432 & 36,3 & $32,6-40,0$ & \\
\hline & SP interior & 274 & 122 & 45,6 & $40,0-51,3$ & * \\
\hline & Outros estados & 993 & 470 & 48,7 & $44,5-52,9$ & * \\
\hline \multicolumn{7}{|l|}{ RELIGIÃO } \\
\hline & Catolicismo & 1607 & 700 & 43,1 & $40,0-46,1$ & \\
\hline & Evangélico & 573 & 193 & 34,3 & $28,5-40,7$ & * \\
\hline & Outras & 296 & 138 & 49,6 & $41,3-58,0$ & \\
\hline \multicolumn{7}{|c|}{ RENDA (SM per capita) } \\
\hline & $<0,5$ & 264 & 129 & 49,4 & $39,2-59,6$ & \\
\hline & $0,50-0,99$ & 420 & 184 & 41,8 & $36,6-47,3$ & \\
\hline & $1,00-1,99$ & 659 & 270 & 43,3 & $38,9-47,7$ & \\
\hline & $2,00-4,99$ & 679 & 245 & 38,7 & $34,3-43,3$ & \\
\hline & 5,00 ou mais & 161 & 65 & 38,8 & $30,4-48,0$ & \\
\hline \multicolumn{7}{|c|}{ SITUAÇÃO ATUAL DE TRABALHO } \\
\hline & Empregado & 1038 & 401 & 40,8 & $36,5-45,3$ & \\
\hline & Desempregado & 177 & 88 & 45,5 & $35,5-55,9$ & \\
\hline & Informal/Autônomo & 588 & 274 & 47,3 & $43,2-51,3$ & \\
\hline & Inativo & 648 & 256 & 38,5 & $34,5-42,7$ & \\
\hline \multicolumn{7}{|c|}{ COBERTURA PREVIDENCIÁRIA } \\
\hline & Nenhuma & 791 & 364 & 47,7 & $43,2-52,2$ & \\
\hline & INSS & 1355 & 546 & 39,8 & $36,2-43,5$ & \\
\hline & Privada & 164 & 60 & 39,6 & $30,1-50,0$ & \\
\hline & Setor Público & 128 & 46 & 38,3 & $28,9-48,8$ & \\
\hline \multicolumn{7}{|c|}{ LOCAL DE MORADIA } \\
\hline & Vila Nova Cachoeirinha & 1260 & 531 & 42,6 & $39,2-46,1$ & \\
\hline & Vila Curuçá & 1220 & 502 & 41,0 & $37,8-44,3$ & \\
\hline \multicolumn{7}{|c|}{ ÁREA DE MORADIA } \\
\hline & PSF & 1216 & 508 & 41,7 & $38,7-44,9$ & \\
\hline & Não-PSF & 1264 & 525 & 42,1 & $38,8-45,5$ & \\
\hline
\end{tabular}

$* \mathrm{p}<0,05$

Utilizando-se da análise multivariada, verifica-se Razão de Prevalência, de acordo com o consumo de fumo, significantemente maior para as categorias masculino, faixa etária a partir dos 30 aos 44 anos, casado, divorciado ou separado, vivendo em "concubinato" ou viúvo e com consumo de álcool, atual ou anterior; e menor, para a categoria pouco ativo fisicamente (Tabela 20). Não houve associação significativa com renda e escolaridade. 
Tabela 20. Análise multivariada da prevalência do consumo atual ou anterior de fumo. Vila Nova Cachoeirinha e Vila Curuçá, São Paulo, 2001.**

\begin{tabular}{|c|c|c|c|c|}
\hline Variável & Categorias & $\begin{array}{c}\text { Razão de } \\
\text { prevalência }\end{array}$ & IC 95\% & $\mathrm{p}$ \\
\hline \multicolumn{5}{|l|}{ Sexo } \\
\hline & Feminino & 1,00 & & \\
\hline & Masculino & 1,13 & $1,01-1,26$ & * \\
\hline \multicolumn{5}{|c|}{ Faixa etária (anos) } \\
\hline & $15-29$ & 1,00 & & \\
\hline & $30-44$ & 1,69 & $1,43-1,99$ & $*$ \\
\hline & $45-59$ & 1,73 & $1,42-2,11$ & * \\
\hline & 60 ou mais & 1,48 & $1,22-1,80$ & * \\
\hline \multicolumn{5}{|c|}{ Estado civil } \\
\hline & Solteiro & 1,00 & & \\
\hline & Casado & 1,15 & $1,00-1,32$ & * \\
\hline & Divorciado ou separado & 1,66 & $1,27-2,17$ & * \\
\hline & "Concubinato" & 1,85 & $1,47-2,33$ & $*$ \\
\hline & Viúvo & 1,48 & $1,30-1,68$ & * \\
\hline \multicolumn{5}{|c|}{ Consumo de álcool } \\
\hline & Nunca consumiu & 1,00 & & \\
\hline & Ex-consumidor & 1,90 & $1,64-2,21$ & * \\
\hline & Consumidor leve & 1,72 & $1,46-2,02$ & $*$ \\
\hline & Consumidor moderado & 1,67 & $1,40-1,99$ & $*$ \\
\hline & Consumidor excessivo & 2,26 & $1,91-2,66$ & $*$ \\
\hline \multicolumn{5}{|c|}{ Atividade física } \\
\hline & Sedentário & 1,00 & & \\
\hline & Pouco ativo & 0,83 & $0,68-0,99$ & * \\
\hline & Ativo & 0,98 & $0,87-1,11$ & \\
\hline
\end{tabular}

$* \mathrm{p}<0,05$

**resultados ajustados para as variáveis sexo, idade, estado civil, escolaridade, procedência, religião, renda, situação atual de trabalho e cobertura previdenciária, consumo de álcool, consumo de fumo e atividade física.

Observando-se o consumo atual ou anterior de fumo de acordo com a cobertura PSF, nota-se que se mantém a relação com o sexo masculino em ambas as áreas, assim como com a idade (com prevalência maior entre os idosos apenas na área não-PSF), estado civil e escolaridade(com prevalência menor entre os com ensino médio completo ou incompleto apenas na área não-PSF). Ressalte-se a menor prevalência de tabagismo entre os idosos na área do PSF em relação à área não-PSF (33,2 vs 49,7\%). Já a maior prevalência de fumantes em indivíduos de outros estados, com indivíduos do interior de SP ocupando uma 
posição intermediária, só foi significante na área não-PSF. Embora continue a haver menor prevalência de fumantes entre os evangélicos em ambas as áreas, apenas na área do PSF manteve-se a significância estatística. Há diminuição estatisticamente significante do consumo de fumo na faixa de 2,00 a 4,99 SM, apenas na área do PSF. Há menor prevalência de fumo entre os que têm o INNS como cobertura previdenciária apenas na área não-PSF. Em relação ao álcool, em ambas as áreas houve associação com o tabagismo, com aumento do consumo entre os ex-consumidores e os consumidores leves. Já em relação à atividade física, só houve associação estatisticamente significante na área do PSF, com menor número de fumantes entre os pouco ativos (Tabela 21).

Tabela 21. Prevalência de consumo atual ou anterior de fumo segundo cobertura PSF e variáveis sócio-demográficas. Vila Nova Cachoeirinha e Vila Curuçá, São Paulo, 2001.

\begin{tabular}{|c|c|c|c|c|c|c|c|c|c|c|c|}
\hline \multirow[t]{3}{*}{ VARIÁVEL } & \multirow[t]{3}{*}{ CATEGRIA } & \multicolumn{4}{|c|}{ Área coberta pelo PSF } & \multicolumn{6}{|c|}{ Área não coberta pelo PSF } \\
\hline & & \multicolumn{2}{|c|}{ Total } & \multicolumn{2}{|c|}{ Já fumou } & \multicolumn{3}{|c|}{ Total } & \multicolumn{3}{|c|}{ Já fumou } \\
\hline & & $\mathrm{N}$ & $\mathrm{N}$ & $\%$ & IC $95 \%$ & $\mathrm{P}$ & $\mathrm{N}$ & $\mathrm{N}$ & $\%$ & IC $95 \%$ & $\mathrm{P}$ \\
\hline \multicolumn{12}{|l|}{ SEXO } \\
\hline & Feminino & 677 & 242 & 35,0 & $31,1-39,2$ & & 697 & 255 & 36,5 & $32,4-40,8$ & \\
\hline & Masculino & 539 & 266 & 50,1 & $45,7-54,6$ & $*$ & 567 & 270 & 49,0 & $44,7-53,4$ & $*$ \\
\hline \multicolumn{12}{|c|}{ FAIXA ETÁRIA (anos) } \\
\hline & $15-29$ & 421 & 112 & 27,0 & $23,3-31,0$ & & 507 & 132 & 26,2 & $21,0-32,1$ & \\
\hline & $30-44$ & 382 & 208 & 54,8 & $49,2-60,2$ & $*$ & 417 & 219 & 50,5 & $43,9-57,1$ & $*$ \\
\hline & $45-59$ & 243 & 129 & 52,6 & $46,1-59,0$ & $*$ & 228 & 116 & 55,1 & $48,1-61,9$ & * \\
\hline & 60 ou mais & 170 & 59 & 33,2 & $25,9-41,2$ & & 112 & 58 & 49,7 & $41,7-57,8$ & $*$ \\
\hline \multicolumn{12}{|c|}{ ESTADO CIVIL } \\
\hline & Solteiro & 437 & 137 & 31,5 & $26,6-36,8$ & & 450 & 123 & 27,0 & $21,9-32,8$ & \\
\hline & Casado & 460 & 204 & 44,8 & $40,1-49,6$ & $*$ & 470 & 212 & 45,8 & $40,4-51,3$ & $*$ \\
\hline & Divorciado ou separado & 35 & 21 & 59,9 & $42,0-75,6$ & $*$ & 24 & 15 & 71,5 & $49,5-86,5$ & * \\
\hline & "Concubinato" & 29 & 18 & 63,0 & $45,3-77,9$ & $*$ & 39 & 28 & 77,9 & $59,0-89,6$ & * \\
\hline & Viúvo & 163 & 92 & 56,7 & $49,3-65,5$ & $*$ & 213 & 119 & 54,7 & $49,1-60,3$ & $*$ \\
\hline \multicolumn{12}{|c|}{ ESCOLARIDADE } \\
\hline & Nenhuma & 70 & 30 & 42,5 & $31,4-54,4$ & & 64 & 38 & 59,2 & $41,0-75,2$ & \\
\hline & Ensino Fundamental $1^{\mathrm{a}}$ a $4^{\mathrm{a}}$ séries & 328 & 159 & 47,2 & $41,3-53,2$ & & 346 & 181 & 51,9 & $45,8-57,9$ & \\
\hline & Ensino Fundamental $5^{\mathrm{a}}$ a $8^{\mathrm{a}}$ séries & 379 & 183 & 49,4 & $43,2-53,6$ & & 389 & 166 & 44,0 & $38,7-49,5$ & \\
\hline & $\begin{array}{l}\text { Ensino Médio completo ou } \\
\text { incompleto }\end{array}$ & 371 & 218 & 33,2 & $28,3-38,6$ & & 364 & 107 & 31,6 & $25,9-38,0$ & $*$ \\
\hline & Superior completo ou incompleto & 61 & 15 & 24,4 & $15,3-36,7$ & $*$ & 94 & 30 & 35,5 & $25,4-47,1$ & * \\
\hline
\end{tabular}

Continua 
Tabela 21. Prevalência de consumo atual ou anterior de fumo segundo cobertura PSF e variáveis sócio-demográficas. Vila Nova Cachoeirinha e Vila Curuçá, São Paulo, 2001. (Conclusão)

\begin{tabular}{|c|c|c|c|c|c|c|c|c|c|c|c|}
\hline \multirow[t]{3}{*}{ VARIÁVEL } & \multirow[t]{3}{*}{ CATEGRIA } & \multicolumn{4}{|c|}{ Área coberta pelo PSF } & \multicolumn{6}{|c|}{ Área não coberta pelo PSF } \\
\hline & & \multicolumn{2}{|c|}{ Total } & \multicolumn{2}{|c|}{ Já fumou } & \multicolumn{3}{|c|}{ Total } & \multicolumn{3}{|c|}{ Já fumou } \\
\hline & & $\mathrm{N}$ & $\mathrm{N}$ & $\%$ & IC $95 \%$ & $\mathrm{P}$ & $\mathrm{N}$ & $\mathrm{N}$ & $\%$ & IC $95 \%$ & $\mathrm{P}$ \\
\hline \multicolumn{12}{|c|}{ PROCEDÊNCIA } \\
\hline & SP capital & 580 & 224 & 38,9 & $34,8-43,0$ & & 601 & 208 & 35,0 & $30,0-40,4$ & \\
\hline & SP interior & 147 & 68 & 47,0 & $38,9-55,2$ & & 127 & 54 & 44,7 & $37,1-52,5$ & * \\
\hline & Outros estados & 473 & 211 & 44,2 & $39,5-59,1$ & & 520 & 259 & 50,7 & $45,0-56,4$ & * \\
\hline \multicolumn{12}{|l|}{ RELIGIÃO } \\
\hline & Catolicismo & 791 & 352 & 44,6 & $41,2-48,1$ & & 816 & 348 & 42,3 & $38,1-46,7$ & \\
\hline & Evangélico & 290 & 93 & 31,3 & $25,6-37,7$ & * & 283 & 100 & 36,0 & $27,7-45,3$ & \\
\hline & Outras & 135 & 63 & 47,0 & $38,4-55,8$ & & 161 & 75 & 50,7 & $39,3-61,9$ & \\
\hline \multicolumn{12}{|c|}{ RENDA (SM per capita) } \\
\hline & $<0,5$ & 122 & 63 & 50,0 & $40,3-59,7$ & & 142 & 66 & 49,1 & $34,8-63,6$ & \\
\hline & $0,50-0,99$ & 228 & 109 & 47,7 & $40,6-54,8$ & & 192 & 75 & 38,1 & $30,8-45,9$ & \\
\hline & $1,00-1,99$ & 353 & 145 & 41,9 & $37,1-46,9$ & & 306 & 125 & 44,0 & $37,7-50,5$ & \\
\hline & $2,00-4,99$ & 370 & 127 & 35,4 & $30,0-41,1$ & * & 309 & 118 & 40,4 & $34,5-46,7$ & \\
\hline & 5,00 ou mais & 57 & 24 & 40,2 & $36,7-55,3$ & & 104 & 41 & 38,6 & $28,7-49,5$ & \\
\hline \multicolumn{12}{|c|}{ SITUAÇÃO ATUAL DE TRABALHO } \\
\hline & Empregado & 482 & 185 & 39,5 & $34,1-45,1$ & & 556 & 216 & 41,3 & $35,7-47,3$ & \\
\hline & Desempregado & 75 & 39 & 49,7 & $36,8-62,5$ & & 102 & 49 & 43,9 & $31,1-57,6$ & \\
\hline & Informal/Autônomo & 286 & 131 & 45,8 & $39,9-51,8$ & & 302 & 143 & 48,0 & $42,7-53,4$ & \\
\hline & Inativo & 355 & 144 & 39,6 & $34,6-44,8$ & & 293 & 112 & 37,8 & $32,1-43,8$ & \\
\hline \multicolumn{12}{|c|}{ COBERTURA PREVIDENCIÁRIA } \\
\hline & Nenhuma & 406 & 176 & 42,9 & $37,3-48,6$ & & 385 & 188 & 50,4 & $44,4-56,4$ & \\
\hline & INSS & 618 & 261 & 42,5 & $38,5-46,6$ & & 737 & 285 & 38,6 & $33,7-43,8$ & * \\
\hline & Privada & 91 & 37 & 41,1 & $30,6-52,3$ & & 73 & 23 & 38,9 & $25,9-53,7$ & \\
\hline & Setor Público & 74 & 23 & 31,3 & $18,8-47,2$ & & 54 & 23 & 43,3 & $30,7-56,9$ & \\
\hline \multicolumn{12}{|c|}{ LOCAL DE MORADIA } \\
\hline & Vila Nova Cachoeirinha & 623 & 254 & 40,6 & $36,2-45,2$ & & 637 & 277 & 43,6 & $39,0-48,3$ & \\
\hline & Vila Curuçá & 593 & 254 & 43,4 & $39,5-47,3$ & & 627 & 248 & 39,8 & $35,2-44,6$ & \\
\hline \multicolumn{12}{|c|}{ CONSUMO DE ÁLCOOL } \\
\hline & Nunca consumiu & 684 & 195 & 28,3 & $24,7-32,1$ & & 746 & 202 & 29,2 & $24,8-33,9$ & \\
\hline & Ex-consumidor & 105 & 70 & 67,2 & $56,2-76,5$ & * & 127 & 87 & 62,3 & $53,8-70,2$ & * \\
\hline & Consumidor leve & 230 & 126 & 54,8 & $48,0-61,4$ & * & 185 & 98 & 50,7 & $42,9-58,5$ & * \\
\hline & Consumidor moderado & 104 & 53 & 50,1 & $40,9-59,4$ & & 84 & 51 & 58,5 & $45,1-70,8$ & \\
\hline & Consumidor excessivo & 81 & 59 & 74,3 & $62,0-83,7$ & & 108 & 74 & 71,4 & $58,4-81,6$ & \\
\hline \multicolumn{12}{|c|}{ ATIVIDADE FÍSICA } \\
\hline & Sedentário & 613 & 268 & 44,1 & $39,9-48,5$ & & 698 & 290 & 41,5 & $36,6-46,7$ & \\
\hline & Pouco ativo & 146 & 45 & 30,6 & $22,7-39,8$ & * & 158 & 56 & 38,2 & $30,1-47,1$ & \\
\hline & Ativo & 434 & 182 & 41,5 & $37,0-46,1$ & & 374 & 160 & 45,1 & $38,4-52,1$ & \\
\hline
\end{tabular}

$* \mathrm{p}<0,05$ 


\subsection{2 Álcool}

Observa-se na tabela 22, que o consumo de álcool está associado ao sexo masculino, assim como há menor consumo entre os evangélicos.

Tabela 22. Distribuição da prevalência de consumo de álcool segundo variáveis sociodemográficas. Vila Nova Cachoeirinha e Vila Curuçá, São Paulo, 2001.

\begin{tabular}{|c|c|c|c|c|c|c|}
\hline \multirow{2}{*}{\multicolumn{2}{|c|}{ Variável Categorias }} & \multicolumn{4}{|c|}{ Já consumiu } & \multirow[b]{2}{*}{$\mathrm{P}$} \\
\hline & & N Total & $\mathrm{N}$ & $\%$ & IC 95\% & \\
\hline \multicolumn{7}{|l|}{ SEXO } \\
\hline & Feminino & 1474 & 454 & 31,0 & $27,6-34,6$ & \\
\hline & Masculino & 1264 & 829 & 65,8 & $61,1-70,2$ & $*$ \\
\hline \multicolumn{7}{|c|}{ FAIXA ETÁRIA (anos) } \\
\hline & $15-29$ & 1063 & 466 & 46,0 & $42,3-49,7$ & \\
\hline & $30-44$ & 845 & 439 & 49,0 & $43,5-54,6$ & \\
\hline & $45-59$ & 524 & 255 & 49,6 & $43,9-55,2$ & \\
\hline & 60 ou mais & 306 & 123 & 41,3 & $32,9-50,3$ & \\
\hline \multicolumn{7}{|c|}{ ESTADO CIVIL } \\
\hline & Solteiro & 1011 & 452 & 45,6 & $41,6-49,7$ & \\
\hline & Casado & 997 & 482 & 47,7 & $43,2-52,1$ & \\
\hline & Divorciado ou separado & 65 & 37 & 52,9 & $40,0-65,4$ & \\
\hline & "Concubinato" & 71 & 29 & 46,5 & $32,5-61,1$ & \\
\hline & Viúvo & 419 & 232 & 55,7 & $47,7-63,4$ & \\
\hline \multicolumn{7}{|c|}{ ESCOLARIDADE } \\
\hline & Nenhuma & 138 & 55 & 42,3 & $30,6-55,0$ & \\
\hline & Ensino Fundamental $1^{\mathrm{a}}$ a $4^{\mathrm{a}}$ séries & 747 & 366 & 50,3 & $46,4-54,3$ & \\
\hline & Ensino Fundamental $5^{\mathrm{a}}$ a $8^{\mathrm{a}}$ séries & 837 & 425 & 48,8 & $44,0-53,7$ & \\
\hline & Ensino Médio completo ou incompleto & 807 & 338 & 43,3 & $38,0-48,8$ & \\
\hline & Superior completo ou incompleto & 172 & 71 & 42,7 & $32,3-53,8$ & \\
\hline \multicolumn{7}{|c|}{ PROCEDÊNCIA } \\
\hline & SP capital & 1306 & 598 & 45,9 & $41,8-50,1$ & \\
\hline & SP interior & 300 & 143 & 48,1 & $40,9-55,4$ & \\
\hline & Outros estados & 1087 & 516 & 48,0 & $43,6-50,4$ & \\
\hline \multicolumn{7}{|c|}{ RELIGIÃO } \\
\hline & Catolicismo & 1746 & 864 & 49,4 & $45,5-53,3$ & \\
\hline & Evangélico & 637 & 227 & 36,0 & $31,6-40,7$ & $*$ \\
\hline & Outras & 338 & 177 & 52,4 & $44,2-60,5$ & \\
\hline
\end{tabular}

\section{Continua}


Tabela 22. Distribuição da prevalência de consumo de álcool segundo variáveis sociodemográficas. Vila Nova Cachoeirinha e Vila Curuçá, São Paulo, 2001. (Conclusão)

\begin{tabular}{|c|c|c|c|c|c|}
\hline \multirow[t]{2}{*}{ Variável Categorias } & \multicolumn{4}{|c|}{ Já consumiu } & \multirow[b]{2}{*}{$\bar{P}$} \\
\hline & N Total & $\mathrm{N}$ & $\%$ & IC 95\% & \\
\hline \multicolumn{6}{|l|}{ RENDA (SM per capita) } \\
\hline$<0,5$ & 271 & 114 & 43,1 & $36,9-49,5$ & \\
\hline $0,50-0,99$ & 424 & 171 & 37,8 & $32,0-43,9$ & \\
\hline $1,00-1,99$ & 662 & 254 & 40,4 & $36,2-44,8$ & \\
\hline $2,00-4,99$ & 683 & 306 & 45,4 & $38,4-52,5$ & \\
\hline 5,00 ou mais & 161 & 63 & 40,1 & $30,9-50,0$ & \\
\hline \multicolumn{6}{|l|}{ SITUAÇÃO ATUAL DE TRABALHO } \\
\hline Empregado & 1120 & 485 & 45,2 & $40,1-50,4$ & \\
\hline Desempregado & 200 & 102 & 49,5 & $40,6-58,5$ & \\
\hline Informal/Autônomo & 679 & 370 & 52,2 & $46,1-58,1$ & \\
\hline Inativo & 702 & 307 & 47,1 & $43,7-50,5$ & \\
\hline \multicolumn{6}{|l|}{ COBERTURA PREVIDENCIÁRIA } \\
\hline Nenhuma & 882 & 450 & 49,8 & $44,8-54,7$ & \\
\hline INSS & 1473 & 668 & 46,2 & $42,4-50,0$ & \\
\hline Privada & 181 & 72 & 40,0 & $27,9-53,4$ & \\
\hline Setor Público & 147 & 60 & 48,8 & $37,5-60,2$ & \\
\hline \multicolumn{6}{|l|}{ LOCAL DE MORADIA } \\
\hline Vila Nova Cachoeirinha & 1376 & 640 & 46,6 & $41,4-51,9$ & \\
\hline Vila Curuçá & 1362 & 643 & 47,9 & $44,7-51,1$ & \\
\hline \multicolumn{6}{|l|}{ ÁREA DE MORADIA } \\
\hline PSF & 1324 & 622 & 47,1 & $43,4-50,8$ & \\
\hline Não-PSF & 1414 & 661 & 47,2 & $42,5-51,9$ & \\
\hline
\end{tabular}

* $\mathrm{p}<0,05$

Realizando-se a análise multivariada, verifica-se Razão de Prevalência, de acordo com o consumo de álcool, significantemente maior para as categorias masculino, renda per capita de 1,00 a 1,99 SM, consumo ativo de fumo, atual ou anterior e pouco ativo fisicamente; e menor, para a categoria evangélico (Tabela 23). Não houve associação com escolaridade. 
Tabela 23. Análise multivariada da prevalência de consumo atual ou anterior de álcool. Vila Nova Cachoeirinha e Vila Curuçá, São Paulo, 2001.**

\begin{tabular}{|c|c|c|c|c|}
\hline Variável & Categorias & $\begin{array}{l}\text { Razão de } \\
\text { prevalência }\end{array}$ & IC 95\% & $\mathrm{P}$ \\
\hline \multicolumn{5}{|l|}{ Sexo } \\
\hline & Feminino & 1,00 & & \\
\hline & Masculino & 1,99 & $1,78-2,23$ & * \\
\hline \multicolumn{5}{|l|}{ Religião } \\
\hline & Catolicismo & 1,00 & & \\
\hline & Evangélico & 0,76 & $0,63-0,93$ & * \\
\hline & Islamismo & 1,14 & $0,98-1,33$ & \\
\hline & Outras & 0,72 & $0,51-1,02$ & \\
\hline \multicolumn{5}{|c|}{ Renda (SM per capita) } \\
\hline & $<0,5$ & 1,00 & & \\
\hline & $0,50-0,99$ & 0,90 & $0,75-1,07$ & \\
\hline & $1,00-1,99$ & 0,90 & $0,76-1,07$ & * \\
\hline & $2,00-4,99$ & 1,00 & $0,83-1,22$ & \\
\hline & 5,00 ou mais & 0,84 & $0,63-1,12$ & \\
\hline \multicolumn{5}{|c|}{ Consumo de fumo } \\
\hline & Nunca fumou & 1,00 & & \\
\hline & Fumante passivo & 1,19 & $0,95-1,49$ & \\
\hline & Ex-fumante & 1,97 & $1,67-2,31$ & $*$ \\
\hline & Fumante leve & 1,97 & $1,70-2,28$ & $*$ \\
\hline & Fumante pesado & 1,98 & $1,59-2,47$ & $*$ \\
\hline \multicolumn{5}{|c|}{ Atividade física } \\
\hline & Sedentário & 1,00 & & \\
\hline & Pouco ativo & 1,21 & $1,01-1,45$ & $*$ \\
\hline & Ativo & 1,09 & $0,96-1,25$ & \\
\hline
\end{tabular}

$* \mathrm{p}<0,05$

**resultados ajustados para as variáveis sexo, idade, estado civil, escolaridade, procedência, religião, renda, situação atual de trabalho e cobertura previdenciária, consumo de álcool, consumo de fumo e atividade física.

Avaliando-se de acordo com a cobertura do PSF, mantém-se a associação com o sexo masculino em ambas as áreas. Relação com faixa etária apenas no PSF, com pico na faixa de 30 a 44 anos, assim como com escolaridade, com a maior prevalência estatisticamente significante naqueles que cursaram o ensino fundamental. No quesito religião, evangélicos apresentaram menor consumo em ambas as áreas. Associação com o fumo também surgiu em ambas as áreas, sendo que na área do PSF com aumento da prevalência já a partir do fumante passivo. Em relação à atividade física, na área do PSF há significância estatística 
na diminuição do consumo de fumo entre os ativos, enquanto, na área não-PSF, há diferença entre consumo e qualquer nível de atividade física (tabela 24).

Tabela 24. Prevalência de consumo atual ou anterior de álcool segundo cobertura PSF e variáveis sócio-demográficas. Vila Nova Cachoeirinha e Vila Curuçá, São Paulo, 2001.

\begin{tabular}{|c|c|c|c|c|c|c|c|c|c|c|c|}
\hline \multirow[t]{3}{*}{ VARIÁVEL } & \multirow[t]{3}{*}{ CATEGRIA } & \multicolumn{4}{|c|}{ Área Coberta pelo PSF } & \multicolumn{6}{|c|}{ Área Não Coberta pelo PSF } \\
\hline & & \multirow{2}{*}{$\begin{array}{c}\text { Total } \\
\mathrm{N}\end{array}$} & \multicolumn{3}{|c|}{ Já consumiu álcool } & \multirow[b]{2}{*}{$\mathrm{P}$} & Total & \multicolumn{3}{|c|}{ Já consumiu álcool } & \multirow[b]{2}{*}{$\mathrm{P}$} \\
\hline & & & $\mathrm{N}$ & $\%$ & IC $95 \%$ & & $\mathrm{~N}$ & $\mathrm{~N}$ & $\%$ & IC $95 \%$ & \\
\hline \multicolumn{12}{|l|}{ SEXO } \\
\hline & Feminino & 717 & 227 & 31,7 & $27-6-36,1$ & & 757 & 227 & 30,7 & $26,0-35,7$ & \\
\hline & Masculino & 607 & 395 & 65,3 & $60,7-69,6$ & $*$ & 657 & 434 & 66,1 & $\begin{array}{r}59,3- \\
72,27\end{array}$ & $*$ \\
\hline \multicolumn{12}{|c|}{ FAIXA ETÁRIA (anos) } \\
\hline & $15-29$ & 470 & 203 & 44,0 & $38,7-49,5$ & & 593 & 263 & 46,8 & $41,9-51,7$ & \\
\hline & $30-44$ & 398 & 218 & 54,8 & $49,6-59,8$ & * & 447 & 221 & 46,5 & $38,9-54,3$ & \\
\hline & $45-59$ & 271 & 130 & 46,8 & $39,6-54,1$ & & 253 & 125 & 51,0 & $43,2-58,7$ & \\
\hline & 60 ou mais & 185 & 71 & 39,2 & $32,1-46,8$ & & 121 & 52 & 42,9 & $29,2-57,8$ & \\
\hline \multicolumn{12}{|c|}{ ESTADO CIVIL } \\
\hline & Solteiro & 487 & 226 & 47,4 & $41,5-53,3$ & & 524 & 226 & 44,7 & $39,4-50,2$ & \\
\hline & Casado & 487 & 235 & 47,6 & $42,5-52,7$ & & 510 & 247 & 47,7 & $41,6-53,8$ & \\
\hline & Divorciado ou separado & 39 & 25 & 64,7 & $48,4-78,2$ & & 26 & 12 & 43,1 & $25,4-62,7$ & \\
\hline & "Concubinato" & 32 & 12 & 37,3 & $22,6-54,9$ & & 39 & 17 & 50,1 & $31,6-68,6$ & \\
\hline & Viúvo & 178 & 99 & 56,3 & $48,4-64,0$ & & 241 & 133 & 55,4 & $44,6-65,8$ & \\
\hline \multicolumn{12}{|c|}{ ESCOLARIDADE } \\
\hline & Nenhuma & 72 & 27 & 36,4 & $25,2-49,2$ & & 66 & 28 & 45,8 & $28,9-63,8$ & \\
\hline & Ensino Fundamental $1^{\mathrm{a}}$ a $4^{\mathrm{a}}$ séries & 363 & 182 & 50,5 & $44,7-56,3$ & $*$ & 384 & 184 & 50,2 & $44,9-55,5$ & \\
\hline & Ensino Fundamental $5^{\mathrm{a}}$ a $8^{\mathrm{a}}$ séries & 410 & 213 & 52,4 & $47,4-57,4$ & * & 428 & 212 & 47,1 & $40,6-53,8$ & \\
\hline & $\begin{array}{l}\text { Ensino Médio completo ou } \\
\text { incompleto }\end{array}$ & 395 & 159 & 40,5 & $35,7-45,3$ & & 412 & 179 & 44,7 & $37,2-52,5$ & \\
\hline & Superior completo ou incompleto & 68 & 30 & 44,2 & $30,3-59,1$ & & 104 & 41 & 42,3 & $29,4-56,2$ & \\
\hline \multicolumn{12}{|c|}{ PROCEDÊNCIA } \\
\hline & SP capital & 633 & 296 & 46,7 & $41,6-51,9$ & & 673 & 302 & 45,6 & $39,9-51,3$ & \\
\hline & SP interior & 165 & 79 & 48,1 & $39,8-56,4$ & & 135 & 64 & 48,2 & $37,6-58,9$ & \\
\hline & Outros estados & 504 & 234 & 46,9 & $42,2-51,7$ & & 583 & 282 & 48,5 & $41,9-55,1$ & \\
\hline \multicolumn{12}{|l|}{ RELIGIÃO } \\
\hline & Catolicismo & 849 & 435 & 51,2 & $46,5-55,8$ & & 897 & 429 & 48,6 & $43,2-53,9$ & \\
\hline & Evangélico & 319 & 104 & 33,0 & $27,7-38,7$ & $*$ & 318 & 123 & 37,7 & $31,5-44,3$ & $*$ \\
\hline & Outras & 151 & 78 & 51,8 & $43,2-60,2$ & & 187 & 99 & 52,7 & $41,6-63,5$ & \\
\hline \multicolumn{12}{|c|}{ RENDA (SM per capita) } \\
\hline & $<0,5$ & 129 & 63 & 49,0 & $37,6-60,6$ & & 142 & 51 & 40,1 & $32,7-48,0$ & \\
\hline & $0,50-0,99$ & 230 & 107 & 46,7 & $39,6-53,8$ & & 194 & 64 & 32,0 & $24,4-40,7$ & \\
\hline & $1,00-1,99$ & 355 & 140 & 40,6 & $34,8-46,6$ & & 307 & 114 & 40,3 & $34,6-46,4$ & \\
\hline & $2,00-4,99$ & 370 & 157 & 42,0 & $36,5-47,8$ & & 313 & 149 & 47,1 & $36,8-57,7$ & \\
\hline & 5,00 ou mais & 57 & 19 & 34,0 & $20,8-50,3$ & & 104 & 44 & 41,3 & $30,6-53,0$ & \\
\hline
\end{tabular}

\section{Continua}


Tabela 24. Prevalência de consumo atual ou anterior de álcool segundo cobertura PSF e variáveis sócio-demográficas. Vila Nova Cachoeirinha e Vila Curuçá, São Paulo, 2001. (Conclusão)

\begin{tabular}{|c|c|c|c|c|c|c|c|c|c|c|c|}
\hline \multirow[t]{3}{*}{ VARIÁVEL } & \multirow[t]{3}{*}{ CATEGRIA } & \multicolumn{4}{|c|}{ Área Coberta pelo PSF } & \multicolumn{6}{|c|}{ Área Não Coberta pelo PSF } \\
\hline & & \multirow{2}{*}{$\begin{array}{c}\text { Total } \\
\mathrm{N}\end{array}$} & \multicolumn{3}{|c|}{ Já consumiu álcool } & \multicolumn{2}{|r|}{ Total } & \multicolumn{3}{|c|}{ Já consumiu álcool } & \multirow[b]{2}{*}{$\mathrm{P}$} \\
\hline & & & $\mathrm{N}$ & $\%$ & IC $95 \%$ & $\mathrm{P}$ & $\mathrm{N}$ & $\mathrm{N}$ & $\%$ & IC $95 \%$ & \\
\hline \multicolumn{12}{|c|}{ SITUAÇÃO ATUAL DE TRABALHO } \\
\hline & Empregado & 512 & 220 & 44,0 & $38,4-49,9$ & & 608 & 265 & 45,7 & $38,8-52,7$ & \\
\hline & Desempregado & 87 & 48 & 53,8 & $41,9-65,4$ & & 113 & 54 & 47,7 & $36,1-59,5$ & \\
\hline & Informal/Autônomo & 317 & 174 & 54,6 & $46,5-62,3$ & & 362 & 196 & 51,0 & $43,0-59,0$ & \\
\hline & Inativo & 385 & 170 & 43,8 & $37,6-50,3$ & & 317 & 137 & 45,5 & $39,3-51,9$ & \\
\hline \multicolumn{12}{|c|}{ COBERTURA PREVIDENCIÁRIA } \\
\hline & Nenhuma & 444 & 232 & 52,3 & $45,8-58,7$ & & 438 & 218 & 48,4 & $41,7-55,2$ & \\
\hline & INSS & 659 & 304 & 46,4 & $41,9-50,9$ & & 814 & 364 & 46,1 & $41,1-51,2$ & \\
\hline & Privada & 100 & 37 & 36,2 & $25,3-48,7$ & & 81 & 35 & 41,9 & $25,0-60,9$ & \\
\hline & Setor Público & 85 & 29 & 36,6 & $21,8-54,5$ & & 62 & 31 & 57,4 & $42,6-71,0$ & \\
\hline \multicolumn{12}{|c|}{ LOCAL DE MORADIA } \\
\hline & Vila Nova Cachoeirinha & 672 & 315 & 47,3 & $42,0-52,5$ & & 704 & 325 & 46,3 & $39,1-53,7$ & \\
\hline & Vila Curuçá & 652 & 307 & 46,9 & $41,9-51,9$ & & 710 & 336 & 48,4 & $44,2-52,7$ & \\
\hline \multicolumn{12}{|c|}{ CONSUMO DE FUMO } \\
\hline & Nunca fumou & 497 & 131 & 26,1 & $22,0-30,7$ & & 596 & 149 & 28,6 & $22,6-35,6$ & \\
\hline & Fumante passivo & 204 & 8 & 39,6 & $32,4-47,3$ & $*$ & 142 & 45 & 29,9 & $21,7-39,7$ & \\
\hline & Ex-fumante & 188 & 112 & 60,2 & $52,9-67,1$ & $*$ & 205 & 123 & 58,4 & $48,8-67,4$ & * \\
\hline & Fumante leve & 186 & 112 & 60,1 & $51,6-68,1$ & * & 186 & 106 & 57,4 & $45,7-68,3$ & * \\
\hline & Fumante pesado & 129 & 84 & 65,7 & $56,3-74,0$ & * & 121 & 81 & 63,0 & $51,7-73,0$ & * \\
\hline \multicolumn{12}{|c|}{ ATIVIDADE FÍSICA } \\
\hline & Inativo & 619 & 239 & 38,4 & $33,9-43,2$ & & 698 & 237 & 35,5 & $29,4-42,0$ & \\
\hline & Pouco ativo & 148 & 62 & 43,0 & $35,0-51,4$ & & 159 & 77 & 48,7 & $35,7-61,8$ & * \\
\hline & Ativo & 437 & 212 & 48,6 & $43,3-53,9$ & * & 375 & 177 & 47,2 & $40,7-53,8$ & * \\
\hline
\end{tabular}

\subsubsection{Atividade física}

Na tabela 25, vemos a associação de atividade física com o sexo masculino, entre os mais jovens e entre solteiros, viúvos e separados. Há uma tendência de aumento com a escolaridade e maior prevalência em SP capital e outros estados. Há uma tendência a aumento da atividade física com o aumento de renda, embora a maior percentagem de pouco ativos e ativos estejam na faixa salarial de meio a um salário mínimo per capita. 
Também há menor prevalência de inativos entre os informais e autônomos. Há tendência linear significativa para idade (inversamente proporcional).

Tabela 25. Distribuição da prevalência de atividade física segundo variáveis sociodemográficas. Vila Nova Cachoeirinha e Vila Curuçá, São Paulo, 2001.

\begin{tabular}{|c|c|c|c|c|c|c|c|c|c|c|c|}
\hline Variável & Categorias & & Sedent & ário & & ouco & ativo & & Ati & & \\
\hline & & $\mathrm{N}$ & $\%$ & IC (95\%) & $\mathrm{N}$ & $\%$ & IC (95\%) & $\mathrm{N}$ & $\%$ & IC (95\%) & $\mathrm{P}$ \\
\hline SEXO & & & & & & & & & & & \\
\hline & Feminino & 864 & 62,6 & $59,7-65,5$ & 152 & 12,2 & $10,5-14,5$ & 355 & 25,2 & $22,4-28,2$ & \\
\hline & Masculino & 467 & 41,3 & $36,1-46,6$ & 157 & 15,6 & $12,9-18,7$ & 464 & 43,1 & $38,1-48,3$ & \\
\hline FAIXA E & TÁRIA (anos) & & & & & & & & & & \\
\hline & $15-29$ & 426 & 44,6 & $38,5-50,9$ & 128 & 14,2 & $11,3-17,5$ & 368 & 41,2 & $35,4-47,3$ & \\
\hline & $30-44$ & 439 & 54,9 & $49,6-60,1$ & 95 & 14,6 & $11,3-18,6$ & 251 & 30,5 & $26,7-34,5$ & \\
\hline & $45-59$ & 265 & 54,4 & $48,6-60,0$ & 53 & 12,3 & $8,5-17,3$ & 156 & 33,3 & $28,4-38,7$ & \\
\hline & 60 ou mais & 201 & 74,4 & $66,1-81,3$ & 33 & 12,2 & $7,5-19,2$ & 44 & 13,4 & $9,7-18,3$ & \\
\hline ESTADC & CIVIL & & & & & & & & & & \\
\hline & Solteiro & 421 & 46,8 & $41,7-51,9$ & 127 & 15,2 & $12,2-18,8$ & 333 & 38,0 & $33,9-42,3$ & \\
\hline & Casado & 516 & 54,7 & $50,0-59,4$ & 127 & 15,8 & $12,7-19,4$ & 274 & 29,5 & $25,7-33,5$ & \\
\hline & Divorciado ou separado & 35 & 55,0 & $40,8-68,4$ & 7 & 9,7 & $4,5-19,7$ & 18 & 35,3 & $22,7-50,2$ & \\
\hline & "Concubinato" & 41 & 64,9 & $50,7-76,9$ & 6 & 6,6 & $2,8-14,8$ & 19 & 28,5 & $17,1-43,6$ & \\
\hline & Viúvo & 203 & 52,5 & $45,3-59,5$ & 25 & 8,6 & $5,7-12,9$ & 145 & 38,9 & $32,8-45,4$ & \\
\hline ESCOLA & RIDADE & & & & & & & & & & \\
\hline & Nenhuma & 93 & 70,8 & $59,7-79,8$ & 10 & 6,3 & $3,3-11,7$ & 28 & 22,9 & $14,9-33,6$ & \\
\hline & $\begin{array}{l}\text { Ensino Fundamental } 1^{\mathrm{a}} \text { a } 4^{\mathrm{a}} \\
\text { séries }\end{array}$ & 406 & 60,2 & $55,2-64,9$ & 64 & 11,0 & $8,3-14,5$ & 201 & 28,8 & $24,9-33,1$ & \\
\hline & $\begin{array}{l}\text { Ensino Fundamental } 5^{\mathrm{a}} \text { a } 8^{\mathrm{a}} \\
\text { séries }\end{array}$ & 374 & 48,9 & $44,4-53,5$ & 96 & 12,3 & $9,7-15,4$ & 293 & 38,7 & $33,3-44,5$ & \\
\hline & $\begin{array}{l}\text { Ensino Médio completo ou } \\
\text { incompleto }\end{array}$ & 368 & 49,1 & $44,2-54,0$ & 104 & 15,5 & $12,5-19,2$ & 255 & 35,4 & $31,2-39,8$ & \\
\hline & $\begin{array}{l}\text { Superior completo ou } \\
\text { incompleto }\end{array}$ & 81 & 50,3 & $41,9-58,6$ & 34 & 25,3 & $17,3-35,5$ & 40 & 24,4 & $15,8-35,8$ & \\
\hline PROCE & ÊNCIA & & & & & & & & & & \\
\hline & SP capital & 603 & 49,9 & $45,6-54,2$ & 168 & 15,7 & $13,4-18,4$ & 403 & 34,4 & $30,9-38,0$ & \\
\hline & SP interior & 174 & 63,0 & $55,1-70,2$ & 31 & 11,8 & $7,4-18,3$ & 72 & 25,2 & $19,5-31,8$ & \\
\hline & Outros estados & 536 & 53,8 & $49,4-58,2$ & 107 & 11,8 & $9,8-14,3$ & 335 & 34,4 & $30,8-38,2$ & \\
\hline RELIGI $\tilde{A}$ & & & & & & & & & & & \\
\hline & Catolicismo & 865 & 53,5 & $49,3-57,7$ & 191 & 12,5 & $10,6-14,7$ & 541 & 33,9 & $30,3-37,8$ & \\
\hline & Evangélico & 313 & 54,2 & $48,7-59,6$ & 72 & 14,3 & $11,2-18,0$ & 178 & 31,5 & $27,0-36,3$ & \\
\hline & Outras & 257 & 49,4 & $42,6-56,2$ & 79 & 9,8 & $5,7-16,4$ & 164 & 40,8 & $33,6-48,4$ & \\
\hline RENDA & (SM per capita) & & & & & & & & & & \\
\hline & $<0,5$ & 158 & 58,7 & $51,7-65,4$ & 33 & 11,1 & $7,4-16,1$ & 78 & 30,2 & $23,4-38,0$ & \\
\hline & $0,50-0,99$ & 220 & 51,0 & $44,5-57,5$ & 45 & 10,4 & $7,2-14,8$ & 155 & 38,6 & $32,1-45,4$ & \\
\hline & $1,00-1,99$ & 372 & 57,1 & $52,6-61,5$ & 71 & 11,5 & $8,4-15,6$ & 215 & 31,4 & $27,6-35,3$ & \\
\hline & $2,00-4,99$ & 341 & 49,6 & $44,1-55,3$ & 101 & 16,1 & $12,1-21,1$ & 235 & 34,2 & $30,1-38,6$ & \\
\hline & 5,00 ou mais & 64 & 40,9 & $30,9-51,6$ & 36 & 24,7 & $17,7-33,2$ & 59 & 34,5 & $27,3-46,3$ & \\
\hline
\end{tabular}

\section{Continua}


Tabela 25. Distribuição da prevalência de atividade física segundo variáveis sociodemográficas. Vila Nova Cachoeirinha e Vila Curuçá, São Paulo, 2001. (Conclusão)

\begin{tabular}{|c|c|c|c|c|c|c|c|c|c|}
\hline \multirow[t]{2}{*}{ Variável Categorias } & \multicolumn{3}{|c|}{ Sedentário } & \multicolumn{3}{|c|}{ Pouco ativo } & \multicolumn{3}{|c|}{ Ativo } \\
\hline & $\mathrm{N}$ & $\%$ & $\mathrm{IC}(95 \%)$ & $\mathrm{N}$ & $\%$ & $\mathrm{IC}(95 \%)$ & $\mathrm{N}$ & $\%$ & $\mathrm{IC}(95 \%)$ \\
\hline SITUAÇÃO ATUAL DE TRABALHO & & & & & & & & & $*$ \\
\hline Empregado & 546 & 51,9 & $47,3-56,5$ & 136 & 14,8 & $11,7-18,4$ & 341 & 33,3 & $29,7-37,2$ \\
\hline Desempregado & 107 & 62,8 & $53,8-71,1$ & 17 & 9,1 & $5,3-15,1$ & 52 & 28,1 & $20,5-37,1$ \\
\hline Informal/Autônomo & 273 & 46,4 & $41,1-51,7$ & 77 & 14,0 & $11,3-17,2$ & 233 & 39,6 & $34,0-45,4$ \\
\hline Inativo & 390 & 59,1 & $54,6-63,4$ & 75 & 12,7 & $9,8-16,3$ & 182 & 28,2 & $24,4-32,3$ \\
\hline \multicolumn{10}{|l|}{ COBERTURA PREVIDENCIÁRIA } \\
\hline Nenhuma & 397 & 50,2 & $45,3-55,0$ & 95 & 12,1 & $9,5-15,3$ & 289 & 37,7 & $33,5-42,2$ \\
\hline INSS & 746 & 53,8 & $50,1-57,5$ & 178 & 14,6 & $11,9-17,7$ & 422 & 31,6 & $28,2-35,2$ \\
\hline Privada & 91 & 56,1 & $44,0-67,4$ & 19 & 14,6 & $9,1-22,5$ & 53 & 29,3 & $18,9-42,5$ \\
\hline Setor Público & 73 & 58,6 & $47,2-69,1$ & 13 & 12,8 & $6,2-24,3$ & 40 & 28,7 & $21,8-36,6$ \\
\hline \multicolumn{10}{|l|}{ LOCAL DE MORADIA } \\
\hline Vila Nova Cachoeirinha & 659 & 52,7 & $48,0-57,4$ & 166 & 14,2 & $11,8-17,0$ & 419 & 33,0 & $29,5-36,8$ \\
\hline Vila Curuçá & 672 & 53,8 & $49,8-57,7$ & 143 & 12,9 & $10,8-15,3$ & 400 & 33,3 & $29,5-37,4$ \\
\hline \multicolumn{10}{|l|}{ ÁREA DE MORADIA } \\
\hline PSF & 627 & 50,9 & $47,2-54,5$ & 149 & 12,6 & $10,6-14,8$ & 419 & 36,6 & $33,3-40,0$ \\
\hline Não-PSF & 704 & 54,3 & $49,7-58,7$ & 160 & 14,3 & $11,9-16,9$ & 400 & 31,5 & $27,9-35,3$ \\
\hline
\end{tabular}

$* \mathrm{p}<0,05$

Aplicando-se a análise multivariada, verifica-se Razão de Prevalência, de acordo com o nível de atividade física, significantemente maior para as categorias faixa etária a partir dos 30 aos 44 anos; e menor, para as categorias masculino, profissionais desempregados, informais e autônomos e consumo moderado de álcool (Tabela 26). Não houve associação significativa com escolaridade e consumo de fumo. 
Tabela 26. Análise multivariada da prevalência de sedentarismo. Vila Nova Cachoeirinha e Vila Curuçá, São Paulo, 2001.*

\begin{tabular}{|c|c|c|c|c|}
\hline Variável & Categorias & $\begin{array}{c}\text { Razão de } \\
\text { prevalência }\end{array}$ & IC 95\% & $\mathrm{P}$ \\
\hline \multicolumn{5}{|l|}{ Sexo } \\
\hline & Feminino & 1,00 & & \\
\hline & Masculino & 0,69 & $0,60-0,78$ & $*$ \\
\hline \multicolumn{5}{|c|}{ Faixa etária (anos) } \\
\hline & $15-29$ & 1,00 & & \\
\hline & $30-44$ & 1,23 & $1,03-1,47$ & $*$ \\
\hline & $45-59$ & 1,20 & $1,06-1,35$ & $*$ \\
\hline & 60 ou mais & 1,59 & $1,32-1,89$ & $*$ \\
\hline \multicolumn{5}{|c|}{ Situação atual de trabalho } \\
\hline & Empregado & 1,00 & & \\
\hline & Desempregado & 1,17 & $1,03-1,33$ & $*$ \\
\hline & Informal/Autônomo & 0,87 & $0,77-0,99$ & $*$ \\
\hline & Inativo & 0,99 & $0,89-1,11$ & \\
\hline \multicolumn{5}{|c|}{ Consumo de álcool } \\
\hline & Nunca consumiu & 1,00 & & \\
\hline & Ex-consumidor & 1,03 & $0,90-1,18$ & \\
\hline & Consumidor leve & 0,92 & $0,78-1,07$ & \\
\hline & Consumidor moderado & 0,76 & $0,61-0,94$ & $*$ \\
\hline & Consumidor excessivo & 0,93 & $0,73-1,19$ & \\
\hline
\end{tabular}

$* \mathrm{p}<0,05$

**resultados ajustados para as variáveis sexo, idade, estado civil, escolaridade, procedência, religião, renda, situação atual de trabalho e cobertura previdenciária, consumo de álcool, consumo de fumo e atividade física.

Avaliando-se de acordo com a cobertura do PSF (tabela 27), vê-se que o sedentarismo continua associado ao sexo feminino em ambas as áreas, assim como em relação à faixa etária (já a partir dos 30 anos no PSF). Já menor nível de sedentarismo entre os solteiros em relação aos casados só é estatisticamente significante na área do PSF. Em relação à escolaridade, em ambas as áreas, há diminuição do sedentarismo com o aumento da escolaridade, embora com signifância estatística diversa entre as categorias em relação a nenhuma escolaridade, quando comparamos PSF e não-PSF. No quesito procedência, só na área não-PSF ocorre aumento do sedentarismo naqueles provenientes do interior de SP. A 
relação com renda ocorre apenas na área não-PSF, com a diminuição do sedentarismo nas duas maiores faixas de renda. A associação de atividade física com a categoria profissional também só ocorre com significância estatística na área não-PSF, com maior sedentarismo entre os desempregados. A associação de atividade física com consumo de álcool surge nas duas áreas, com menor nível de sedentarismo nas categorias de consumo leve, moderado e excessivo (área PSF), moderado e excessivo (área não-PSF).

Tabela 27. Prevalência de sedentarismo segundo cobertura PSF e variáveis sóciodemográficas. Vila Nova Cachoeirinha e Vila Curuçá, São Paulo, 2001.

\begin{tabular}{|c|c|c|c|c|c|c|c|c|c|c|c|}
\hline \multirow[t]{3}{*}{ VARIÁVEL } & \multirow[t]{3}{*}{ CATEGORIA } & \multicolumn{4}{|c|}{ Área coberta pelo PSF } & \multicolumn{6}{|c|}{ Área não coberta pelo PSF } \\
\hline & & \multirow{2}{*}{$\begin{array}{r}\text { Total } \\
\mathrm{N}\end{array}$} & \multicolumn{3}{|c|}{ Sedentário } & \multicolumn{3}{|c|}{ Total } & \multicolumn{3}{|c|}{ Sedentário } \\
\hline & & & $\mathrm{N}$ & $\%$ & IC $95 \%$ & $\mathrm{P}$ & $\mathrm{N}$ & $\mathrm{N}$ & $\%$ & IC $95 \%$ & $\mathrm{P}$ \\
\hline \multicolumn{12}{|l|}{ SEXO } \\
\hline & Feminino & 680 & 398 & 58,1 & $53,4-62,6$ & & 691 & 466 & 64,9 & $61,1-68,5$ & \\
\hline & Masculino & 536 & 229 & 41,7 & $36,8-46,9$ & $*$ & 552 & 238 & 41,0 & $33,8-48,7$ & * \\
\hline \multicolumn{12}{|c|}{ FAIXA ETÁRIA (anos) } \\
\hline & $15-29$ & 423 & 175 & 40,2 & $34,9-45,7$ & & 499 & 251 & 46,6 & $37,9-55,5$ & \\
\hline & $30-44$ & 377 & 201 & 53,2 & $48,1-58,2$ & * & 408 & 238 & 55,7 & $48,2-63,0$ & \\
\hline & $45-59$ & 245 & 132 & 53,0 & $45,5-60,5$ & * & 229 & 133 & 55,0 & $47,1-62,7$ & * \\
\hline & 60 ou mais & 171 & 119 & 68,2 & $61,2-74,5$ & * & 107 & 82 & 79,4 & $64,2-89,3$ & * \\
\hline \multicolumn{12}{|c|}{ ESTADO CIVIL } \\
\hline & Solteiro & 438 & 191 & 42,9 & $37,1-48,9$ & & 230 & 443 & 48,8 & $41,5-56,2$ & \\
\hline & Casado & 457 & 252 & 54,0 & $48,8-59,1$ & * & 264 & 460 & 55,1 & $48,6-61,5$ & \\
\hline & Divorciado ou separado & 36 & 20 & 56,4 & $41,6-70,1$ & & 15 & 24 & 53,8 & $31,6-74,6$ & \\
\hline & "Concubinato" & 29 & 16 & 53,1 & $33,5-71,8$ & & 25 & 37 & 69,2 & $50,6-83,2$ & \\
\hline & Viúvo & 162 & 82 & 50,3 & $42,5-58,0$ & & 121 & 211 & 53,4 & $43,5-62,9$ & \\
\hline \multicolumn{12}{|c|}{ ESCOLARIDADE } \\
\hline & Nenhuma & 70 & 51 & 71,3 & $59,8-80,6$ & & 61 & 42 & 70,4 & $53,4-83,2$ & \\
\hline & Ensino Fundamental $1^{\mathrm{a}}$ a $4^{\mathrm{a}}$ séries & 333 & 196 & 58,0 & $52,4-63,5$ & & 338 & 210 & 61,4 & $54,2-68,1$ & * \\
\hline & Ensino Fundamental $5^{\mathrm{a}}$ a $8^{\mathrm{a}}$ séries & 377 & 165 & 43,7 & $38,2-49,3$ & * & 386 & 209 & 51,5 & $45,0-57,9$ & \\
\hline & $\begin{array}{l}\text { Ensino Médio completo ou } \\
\text { incompleto }\end{array}$ & 369 & 177 & 46,8 & $41,1-52,5$ & * & 358 & 191 & 50,2 & $43,3-57,1$ & * \\
\hline & Superior completo ou incompleto & 60 & 34 & 55,8 & $41,2-69,5$ & * & 95 & 47 & 48,7 & $38,7-58,8$ & \\
\hline \multicolumn{12}{|c|}{ PROCEDÊNCIA } \\
\hline & SP capital & 578 & 287 & 49,3 & $44,2-54,4$ & & 596 & 316 & 50,1 & $44,2-56,1$ & \\
\hline & SP interior & 151 & 89 & 58,6 & $49,7-67,1$ & & 126 & 85 & 65,7 & $53,9-75,8$ & * \\
\hline & Outros estados & 471 & 243 & 50,3 & $45,7-54,8$ & & 507 & 293 & 55,5 & $49,2-61,6$ & \\
\hline
\end{tabular}

Continua 
Tabela 27. Prevalência de sedentarismo segundo cobertura PSF e variáveis sóciodemográficas. Vila Nova Cachoeirinha e Vila Curuçá, São Paulo, 2001.

\begin{tabular}{|c|c|c|c|c|c|c|c|c|c|c|c|}
\hline \multirow[t]{3}{*}{ VARIÁVEL } & \multirow[t]{3}{*}{ CATEGORIA } & \multicolumn{4}{|c|}{ Área coberta pelo PSF } & \multicolumn{6}{|c|}{ Área não coberta pelo PSF } \\
\hline & & \multicolumn{2}{|c|}{ Total } & \multicolumn{2}{|c|}{ Sedentário } & \multicolumn{3}{|c|}{ Total } & \multicolumn{3}{|c|}{ Sedentário } \\
\hline & & $\mathrm{N}$ & $\mathrm{N}$ & $\%$ & IC $95 \%$ & $\mathrm{P}$ & $\mathrm{N}$ & $\mathrm{N}$ & $\%$ & IC $95 \%$ & $\mathrm{P}$ \\
\hline \multicolumn{12}{|l|}{ RELIGIÃO } \\
\hline & Catolicismo & 791 & 406 & 51,0 & $46,6-55,4$ & & 806 & 459 & 54,8 & $48,7-60,7$ & \\
\hline & Evangélico & 288 & 153 & 52,0 & $45,3-58,7$ & & 275 & 160 & 55,4 & $47,6-63,0$ & \\
\hline & Outras & 44 & 68 & 47,7 & $39,0-56,6$ & & 52 & 85 & 50,1 & $41,2-59,0$ & \\
\hline \multicolumn{12}{|c|}{ RENDA (SM per capita) } \\
\hline & $<0,5$ & 130 & 70 & 53,0 & $42,1-63,6$ & & 139 & 88 & 61,6 & $52,6-69,9$ & \\
\hline & $0,50-0,99$ & 227 & 111 & 47,7 & $40,6-54,8$ & & 193 & 109 & 53,2 & $43,4-62,8$ & \\
\hline & $1,00-1,99$ & 353 & 184 & 51,8 & $47,4-56,2$ & & 305 & 188 & 60,3 & $53,6-66,5$ & \\
\hline & $2,00-4,99$ & 369 & 191 & 50,6 & $43,7-57,5$ & & 308 & 150 & 49,1 & $41,4-56,9$ & * \\
\hline & 5,00 ou mais & 56 & 26 & 49,1 & $34,4-64,0$ & & 103 & 38 & 39,1 & $27,4-52,2$ & * \\
\hline \multicolumn{12}{|c|}{ SITUAÇÃO ATUAL DE TRABALHO } \\
\hline & Empregado & 475 & 243 & 50,6 & $46,1-55,1$ & & 548 & 303 & 52,4 & $46,2-58,6$ & \\
\hline & Desempregado & 78 & 41 & 50,6 & $37,6-63,6$ & & 98 & 66 & 68,2 & $56,6-77,8$ & * \\
\hline & Informal/Autônomo & 286 & 127 & 43,8 & $36,--51,0$ & & 297 & 146 & 47,7 & $40,5-55,1$ & \\
\hline & Inativo & 358 & 206 & 56,7 & $49,9-63,2$ & & 289 & 184 & 60,8 & $54,8-66,5$ & \\
\hline \multicolumn{12}{|c|}{ COBERTURA PREVIDENCIÁRIA } \\
\hline & Nenhuma & 408 & 190 & 45,2 & $39,1-51,4$ & & 373 & 207 & 53,0 & $45,7-60,2$ & \\
\hline & INSS & 614 & 328 & 53,3 & $48,8-57,7$ & & 732 & 418 & 54,1 & $49,0-59,0$ & \\
\hline & Privada & 92 & 51 & 52,7 & $38,5-66,4$ & & 72 & 41 & 57,7 & $41,1-72,8$ & \\
\hline & Setor Público & 74 & 43 & 58,2 & $45,8-69,6$ & & 52 & 30 & 58,9 & $41,3-74,4$ & \\
\hline \multicolumn{12}{|c|}{ LOCAL DE MORADIA } \\
\hline & Vila Nova Cachoeirinha & 517 & 299 & 48,2 & $43,2-53,2$ & & 627 & 360 & 54,8 & $48,2-61,3$ & \\
\hline & Vila Curuçá & 599 & 328 & 54,6 & $49,2-60,0$ & & 616 & 344 & 53,4 & $47,9-58,7$ & \\
\hline \multicolumn{12}{|c|}{ CONSUMO DE ÁLCOOL } \\
\hline & Nunca consumiu & 691 & 380 & 54,5 & $49,8-59,2$ & & 741 & 461 & 59,5 & $53,7-65,1$ & \\
\hline & Ex-consumidor & 103 & 54 & 51,0 & $41,6-60,3$ & & 125 & 73 & 59,1 & $48,1-69,3$ & \\
\hline & Consumidor leve & 227 & 105 & 45,9 & $40,4-51,5$ & * & 173 & 84 & 49,0 & $39,8-58,4$ & \\
\hline & Consumidor moderado & 102 & 45 & 42,7 & $32,6-53,6$ & * & 86 & 32 & 32,7 & $22,6-44,7$ & * \\
\hline & Consumidor excessivo & 81 & 35 & 41,7 & $30,7-53,6$ & $*$ & 107 & 48 & 41,3 & $29,2-54,5$ & * \\
\hline \multicolumn{12}{|c|}{ CONSUMODE DE FUMO } \\
\hline & Nunca fumou & 492 & 257 & 51,0 & $45,4-56,6$ & & 584 & 341 & 56,8 & $49,8-63,5$ & \\
\hline & Fumante passivo & 206 & 88 & 42,3 & $34,8-50,2$ & & 140 & 67 & 49,3 & $40,9-57,8$ & \\
\hline & Ex-fumante & 179 & 100 & 54,7 & $46,5-62,7$ & & 199 & 117 & 52,9 & $45,2-60,4$ & \\
\hline & Fumante leve & 187 & 98 & 53,1 & $46,6-59,4$ & & 186 & 101 & 54,6 & $43,7-65,1$ & \\
\hline & Fumante pesado & 129 & 70 & 54,2 & $43,1-64,9$ & & 121 & 72 & 53,8 & $43,7-63,7$ & \\
\hline
\end{tabular}

$* \mathrm{p}<0,05$ 


\section{DISCUSSÃO.}

A ESF vem firmando-se no país e dando origem a um debate que tende a substituir as questões conceituais e filosóficas iniciais por uma análise mais objetiva das diversas facetas produzidas por esse modelo de atenção básica. A importância que tem sido atribuída a ela gera também uma razoável quantidade de mudanças tanto na formação profissional no país, quanto no surgimento de análises de seu desempenho. Em contrapartida, os diversos outros modelos de atenção primária no país, mormente os das principais capitais (onde o atendimento médico era geralmente realizado por um clínico, um pediatra e um ginecologista-obstetra), vêm sendo abandonados no tocante a investimentos públicos ou buscas de tecnologias leves que permitam incrementar ou potencializar as eventuais vantagens dessas outras conformações.

De qualquer forma, tenta-se dissecar aqui aspectos de alguma relevância no início da história do PSF na cidade de São Paulo, reconhecendo, entretanto, algumas limitações do trabalho realizado. As duas primeiras limitações relacionam-se aos procedimentos metodológicos. A primeira delas diz respeito ao aspecto transversal da realização do inquérito domiciliar, não permitindo que se possam determinar relações de causa e efeito das associações encontradas, conseguindo-se, quando muito, oferecer hipóteses que eventualmente venham a explicar o achado. A segunda refere-se ao fato de estarmos trabalhando com morbidade referida. Haapanen et al. (1997) mostraram boa correlação entre morbidade referida e prontuários médicos, especificamente para doenças cardiovasculares como um grupo (aí incluídas a HAS, angina pectoris, Infarto Agudo do Miocárdio - IAM - e DM), ao menos entre finlandeses de ambos os sexos entre 45 e 73 anos. Vargas et al. (1997), nos EUA, também validaram o uso da morbidade referida para 
HAS nas populações de brancos não hispânicos, mulheres negras não hispânicas e nas pessoas com uma visita médica no último ano. Com metodologia diferente, Beckett et al. (2000) chegaram à mesma conclusão para HAS e DM (com menos precisão para o infarto) em idosos americanos e chineses de Taipé. Wu et al. (2000) consideraram as doenças do coração como inadequadas para serem estudadas por morbidade referida, novamente focando em idosos de Taipé. Sen (2002), referindo-se a dados de diversos locais, questiona a qualidade do resultado das pesquisas com morbidade referida. Na cidade de São Paulo, Goldenberg et al. (2003) mostraram que a prevalência de diabetes praticamente dobrava entre os homens e aumentava em pouco mais de $1 / 3$ entre as mulheres quando se procedia à análise da glicemia de jejum e curva glicêmica com $75 \mathrm{~g}$ de glicose entre os indivíduos de 30 a 65 anos de idade.

Uma restrição que se aplica à discussão que se segue envolve a comparação dos nossos resultados com outros autores nacionais ou estrangeiros: a grande variação, principalmente entre os estudiosos dos estilos de vida aqui apresentados, em relação à metodologia e aos conceitos utilizados para caracterizar a exposição ao risco. Portanto, há que se acautelar frente a essas comparações.

Em contrapartida, como pontos positivos no presente estudo, ressaltem-se o cuidadoso processo de amostragem que se utilizou para evitar os vieses de seleção, o expressivo número de respondentes incluídos na pesquisa, o fato de não usarmos, regra geral, a informação que não viesse do respondente propriamente dito e a taxa de recusa bastante aceitável. A utilização da análise multivariada permite também contornar os vieses de confusão.

No aspecto mais abrangente, devem-se ressaltar as limitações de um inquérito domiciliar como instrumento de análise de uma estratégia de atenção primária, com toda a 
sua complexidade, como é o caso do PSF. O instrumento impõe-se, porém, como possibilidade para se conhecerem eventuais resultados advindos da ação da ESF, embora 3 a 5 anos seja considerado o tempo mínimo para se avaliar o impacto de qualquer intervenção dada por programas de saúde (Habicht et al., 1999).

Há que se considerar também um dado da realidade no momento da realização do estudo. Na descrição dos resultados, observa-se que há relativa baixa procura do PSF nas áreas do PSF, tanto na VNC quanto na VC, associada a uma procura "paralela" de outras instâncias do SUS. O encontro de pequeno percentual de atendimento pelo PSF nas áreas não-PSF também completa o quadro, possivelmente refletindo o atendimento realizado por meio do "acolhimento" das unidades de saúde do modelo PSF atuando nas áreas próximas. O fenômeno está possivelmente associado à cultura histórica de nossas populações de buscar atendimento diretamente nos Prontos Socorros ou Prontos Atendimentos (aqui colocados na categoria SUS). Segundo a PNAD de 2003 (Brasil, 2005), 5,8\% das pessoas (vs 4,8\% em 1998) referiam usar Pronto Socorro ou Emergência como serviço de saúde regular.

Essa realidade observada impõe reconhecer-se que abordagens que apresentam uma certa característica ecológica (haja vista que os indivíduos pesquisados residem em uma área coberta pela ESF, não necessariamente cada um deles sendo usuário da Unidade de Saúde da Família) limitam a amplitude da associação entre os resultados encontrados e o papel do PSF. 


\subsection{Características sociodemográficas.}

Observamos que a área não coberta pelo PSF na VNC é de ocupação mais recente, com população mais jovem, maior procedência de outros estados e condições de moradia com instalações mais precárias, evidenciadas pelas ligações clandestinas utilizadas para se conectar nas redes de luz, água e esgoto, além da residência em favelas. Já, na VC, praticamente não há diferenças entre as áreas. Quando juntamos as populações cobertas pelo PSF em ambas as áreas e as comparamos com as não cobertas, vemos que as diferenças sociodemográficas entre elas são discretas, facilitando a comparação da morbidade e estilo de vida.

O PSF está historicamente ligado a áreas mais carentes, tendo inicialmente sido implantado, no Brasil, em áreas vulneráveis apontadas pelo Mapa da Fome, do IPEA Instituto de Pesquisas Econômicas Aplicadas - (Bousquat et al., 2005), assim como foi utilizado o IDH em São Paulo para a definição das áreas prioritárias para iniciar o programa. Porém, uma vez definido o bairro ou o distrito, há uma dificuldade muito maior para se escolherem e terem disponíveis indicadores sociais para a escolha das áreas a serem cobertas pelo programa dentro daquele distrito. Escasseiam, na literatura, dados de caráter microrregional para essas escolhas. Principalmente nas grandes cidades, é legítimo supor que o gestor, ao introduzir a estratégia em áreas carentes, muitas vezes optou por realizar a territorialização das equipes do PSF a partir de UBS's já existentes, facilitando a viabilização da estratégia, isso em comparação à solução mais custosa de se construir uma nova unidade nas áreas mais afastadas dessas UBS's. Em áreas com menor densidade de unidades, a tendência foi manter o atendimento pelo modelo tradicional, às vezes em unidades mistas (PSF e modelo tradicional na mesma unidade), que não requerem, 
obrigatoriamente, uma relação "adequada" de médicos por habitante, como é o caso do PSF, com limites bem estabelecidos de pessoas por equipe. Esse "mosaico" persiste na cidade de São Paulo, sendo atualmente o distrito administrativo da Vila Curuçá o único completamente coberto pelo PSF.

\subsection{Morbidade}

\subsubsection{Morbidade aguda}

A prevalência de doenças nos 15 dias anteriores à entrevista varia bastante nos diversos inquéritos de saúde. Carvalho e al. (1988) encontraram, em cinco áreas distintas na Bahia, taxas que variaram de $19,2 \%$ a $37,9 \%$, sem que "apontassem claramente para um padrão de morbidade referida relacionado com as características de urbanização/industrialização". Já Cesar e Tanaka (1996) encontraram taxas de cerca de 30\% de morbidade aguda. Cesar et al. (2005), estudando quatro áreas do Estado de São Paulo, encontraram taxas variando de 17\% (Campinas) a 35\% (Grande São Paulo).

Schulpen e Swinkels (1980), em um área rural do Quênia, encontraram 25\% de morbidade aguda, utilizando-se de período recordatório de duas semanas.

Lebrão et al. (1991), em Botucatu, com período recordatório médio de três semanas, encontraram taxas de $45 \%$ entre os homens e $55 \%$ entre as mulheres, corroborando a imensa maioria dos estudos de morbidade aguda que apontam a maior prevalência de queixas entre as mulheres.

Em Souselas (Portugal), Cardoso e Ramalheira (2001) encontraram 40\% entre as mulheres e $30 \%$ entre os homens, valores superiores aos da região Centro portuguesa (36 e 
$28 \%$, respectivamente) e aos do país como um todo (34\% e $24 \%$, respectivamente), ambos utilizados como termo de comparação nesse estudo.

As taxas de 20,4 e 13,4\% de morbidade aguda relatadas neste presente estudo (tabela 2), respectivamente entre mulheres e homens, encontram-se de acordo com a literatura revisitada, lembrando que a população deste estudo restringe-se à faixa etária de 15 anos ou mais.

Observa-se também aumento da morbidade aguda com a idade, o que reproduz os relatos de Carvalho et al. (1988) e o estudo de Botucatu (esse, a partir dos 50 anos). Essa associação dá-se naturalmente pelas características próprias do aumento da idade.

A associação de maior morbidade com menor escolaridade do presente trabalho também reproduz o que ocorreu no estudo de Botucatu.

Gomes e Tanaka (2003), apesar de estudarem morbidade aguda apenas entre as mulheres, ressaltam a perspectiva de gênero, relacionando essa maior prevalência com o processo de globalização e o tipo de inserção da mulher no mercado de trabalho, responsáveis pelas maiores taxas de morbidade aguda entre as mulheres com atividade remunerada, encontradas na região Sul do município de São Paulo.

A presença de associação de variáveis relacionadas com a situação atual de trabalho e cobertura previdenciária (menor morbidade aguda para trabalho informal ou autônomo e cobertura previdenciária privada) reforça a relação de morbidade com papel social e relação de trabalho, condizente com o trabalho de Gomes e Tanaka (2003).

Comparando-se a área coberta pelo PSF e a área não coberta, observa-se que a associação com faixa etária tem um perfil discretamente diferente entre as áreas (tabela 5), com maior prevalência de morbidades agudas, na área do PSF, já a partir dos 45 anos de idade, sugerindo que o PSF possa estar tendo algum papel na percepção de doença dessa 
população, numa idade mais precoce. Mais especificamente, ações de promoção de saúde na área PSF podem estar tendo impacto positivo já a partir dos 45 anos. O sistema de atenção à saúde é reconhecido como sendo um dos determinantes do estado de saúde de uma população (Castellanos, citado por Barros, 2005), podendo a mudança de estratégia do antigo modelo para o PSF ter um papel nesse aspecto.

\subsubsection{Morbidade crônica}

As prevalências de HAS encontradas $(28,6 \%$ entre as mulheres e $20,0 \%$ entre os homens) são semelhantes à maioria das estimativas habitualmente encontradas no nosso meio.

Observando os estudos brasileiros, Rego et al. (1990), no município de São Paulo, com população entre 15 e 59 anos de idade, utilizando-se de duas medidas da pressão arterial na visita domiciliar e calculando a média entre elas, encontraram prevalências que variavam de 15,8 a $31,0 \%$ entre os homens e de 7,8 a $14,4 \%$ entre as mulheres, de acordo com os critérios da OMS e do "Joint National Committee (JNC)" americano, versão de 1984, respectivamente. Lebrão et al. (1991), com informação das últimas três semanas, encontraram 5,3\% no total de queixas referidas. As próprias autoras afirmam que, posteriormente, utilizando-se da medida da pressão arterial (PA) nessa mesma população, chegaram a uma taxa de $12,3 \%$ de hipertensos com idade maior que 16 anos. Em Porto Alegre, Duncan et al. (1993) encontraram 15\% de prevalência, tanto em homens quanto em mulheres. Sousa (1999), em município da região metropolitana de São Paulo, encontrou 
prevalência de $18,0 \%$ entre maiores de 20 anos. Ainda na década de 90 , estudo realizado pela Secretaria de Saúde do Rio Grande do Sul (RGS, 2001), com pessoas de 20 anos ou mais de idade, nos municípios-sede das 19 Coordenadorias Regionais de Saúde, encontrou prevalência de $32,2 \%$ entre os homens e $30,8 \%$ entre as mulheres, usando duas aferições na visita e registrando a última delas. Castanho et al. (2001), apesar de método de seleção discutível (voluntários em quatro locais de Campinas), encontraram cerca de $20 \%$ de HAS, maior nas mulheres, sendo a diferença entre sexos mais evidente nas mais jovens. Gomes e Tanaka (2003), estudando mulheres de 10 a 49 anos de idade, encontraram taxa de 4,0\% de hipertensão referida no Sul do município de São Paulo. Compilação realizada pelo CEInfo (Coordenação de Epidemiologia e Informação da Secretaria Municipal de Saúde de São Paulo) com os dados de pesquisa do INCA (Instituto Nacional de Câncer) realizada entre 2002 e 2005 em 15 capitais do Brasil e no Distrito Federal, mostrou prevalência de HAS de $24 \%$ entre os homens e de $28 \%$ entre as mulheres no município de São Paulo (São Paulo, 2004). Masson et al. (2005), estudando mulheres em São Leopoldo (RS), encontraram 22,7\% de prevalência. Cesar et al. (2005) encontraram prevalência média de 20,0\% entre homens e mulheres das quatro regiões estudadas do Estado de São Paulo, com maior prevalência entre as mulheres. Utilizando-se de pesquisa por telefone, rara no nosso meio, Monteiro et al. (2005) encontraram 18,2\% entre os homens e 25,0\% entre as mulheres no município de São Paulo. Szwarcwald et al. (2006), avaliando a atenção básica em quatro municípios do estado do Rio de Janeiro, encontraram prevalências entre 22,5 e 27,9\%, em população com 18 anos ou mais (por intermédio de questionário). No estudo da Universidade Federal de Pelotas, conduzido por Facchini et al. (2006), encontraram prevalências de HAS em adultos, nas populações de UBS's tradicionais e de PSF, da ordem de 26,2 a 29,3\% na região Sul e de 26,7 a 28,8\% na região Nordeste, respectivamente. 
Nos EUA, Sturm e Gresenz (2002), em pesquisa realizada por telefone entre adultos de 60 áreas metropolitanas, encontraram hipertensão em 11,5 a 25,0\% da população. Em Atenas, Grécia, Pitsavos et al. (2003) encontraram, no bojo do "estudo Attica", 37\% de hipertensão entre os homens e $25 \%$ entre as mulheres.

Aumento da prevalência de HAS com o aumento da idade, assim como encontrado no presente estudo, foi também descrito por Castanho et al. (2001) e Cesar et. al. (2005), embora esse aspecto seja inerente a essa doença, assim como às doenças crônicas em geral. Já como parte dos Estudos de Linha de Base (ELB) do Projeto de Expansão e Consolidação do Saúde da Família (PROESF) e conduzido pela Universidade Federal de Pelotas, Piccini et al. (2006) encontraram prevalências de 58 a $64 \%$ na região Sul e de 64 a $65 \%$ na região Nordeste, entre idosos (65 anos ou mais). Esses valores são bastante semelhantes aos encontrados na nossa pesquisa, com $63,3 \%$ de prevalência de HAS entre aqueles com 60 anos ou mais de idade (dado não apresentado). A justificativa apresentada pelos autores do Sul para essa prevalência, também maior do que em outros trabalhos nacionais, vale igualmente para os nossos números: o fato de a população estudada ser adstrita a UBS's da periferia, áreas "menos privilegiadas e com piores indicadores sociais, demográficos e de morbidade, sendo portanto previsível encontrar prevalências maiores deste problema crônico."

Em relação ao possível papel da ESF referente à HAS, notamos uma maior prevalência na área coberta, em ambos os sexos, assim como Facchini et al. (2006). Já Piccini et al. (2006), nos maiores de 65 anos, encontraram maior prevalência de HAS, estatisticamente significativa, nas unidades de PSF em relação às tradicionais na região Sul, mas não na região Nordeste. 
Sturm e Gresenz (2002) observaram aumento de prevalência da HAS com a diminuição de renda. No estudo aqui apresentado, isso só foi observado na área não-PSF, mesmo assim somente a partir de 2 SM (Tabela 9). Pode-se sugerir que o maior acesso ao serviço de saúde e, portanto, ao diagnóstico da patologia, mesmo entre faixas de renda mais altas, o que poderia estar ocorrendo no PSF, aumente a prevalência dessa doença nesse segmento. Ressalte-se que, se essa hipótese estiver correta, o PSF não estaria atuando no sentido de maior eqüidade nessa população, mas, sim, no sentido de universalizar o acesso ao diagnóstico na sua área. Mesmo que haja associação inversa de HAS e renda, o subdiagnóstico na área não-PSF poderia ser mais expressivo.

As diferenças de prevalência das doenças crônicas, relacionadas aos diversos indicadores socioeconômicos, nem sempre se evidenciam nos trabalhos da literatura. No nosso meio, Cesar et al. (2005) encontraram aumento da escolaridade do chefe de família associado à diminuição da prevalência de HAS. Já Sturm e Gresenz (2002), ao tentarem utilizar um indicador mais complexo (o coeficiente de Gini) para medir a relação entre diferenças socioeconômicas e doenças crônicas, não conseguiram mostrar correlação. No entanto, Glover et al. (2004), na Austrália, encontraram expressivas associações entre iniqüidade (medida por intermédio de diversos indicadores socioeconômicos) e diversas doenças crônicas e fatores de risco, incluindo HAS e DM.

Em relação ao diabetes, os valores de prevalência de 6,2\% entre as mulheres e 4,2\% entre os homens são semelhantes a outros estudos nacionais. Estudo realizado em nove capitais brasileiras entre 1984-86 mostrou uma prevalência de 7,6\% entre as mulheres, com 9,7\% na cidade de São Paulo. Dados do INCA (São Paulo, 2004) mostram prevalência de 7\% no município de São Paulo. A Pesquisa Mundial de Saúde (PMS), realizada no Brasil em 2003, em indivíduos com 18 anos ou mais, encontrou 7,0\% entre os homens e 5,2\% 
entre as mulheres (Theme-Filha et al., 2005). Masson et al. (2005), em mulheres de 20 a 60 anos da região urbana de São Leopoldo (RS), encontraram 3,7\% de prevalência. Cesar et al. (2005), em quatro regiões do Estado de São Paulo, encontraram 4,4\% de prevalência média entre homens e mulheres com 20 anos ou mais, com maior prevalência no sexo feminino. Monteiro et al. (2005) encontraram 5,0\% entre os homens e 5,8\% entre as mulheres. Facchini et al. (2006) encontraram prevalências de 6,2\% a 7,6\% no Sul e de $7,0 \%$ a $6,0 \%$ no Nordeste, respectivamente entre famílias adstritas a unidades de PSF e tradicionais, na população adulta. Entre os idosos (65 anos ou mais), houve 22,0\% a 17,8\% $(\mathrm{p}<0,05)$ e $19,0 \%$ e $18,4 \%$, referentes a populações do Sul de do Nordeste, PSF e UBS tradicional, respectivamente. No nosso trabalho, encontramos $18,7 \%$ de diabetes naqueles com 60 ou mais anos de idade. Na PMS, no inquérito do INCA e no de Cesar et al., assim como no inquérito aqui apresentado, houve aumento da prevalência com a idade.

Nos EUA, Sturm e Gresenz (2002) encontraram prevalências variando de 2,3\% a $10,3 \%$, inversamente correlacionadas com o aumento de renda dos indivíduos. Na Grécia (Pitsavos et al., 2003), encontraram-se 8\% dos homens e 6\% das mulheres com história de DM. No Canadá, Chauhan (2003), utilizando-se dos dados do "National Population Health Surveys" e do "Canadian Community Health Surveys", aponta um aumento na prevalência de DM em ambos os sexos. Os homens teriam passado de 3,4\% em 1994/95 para 4,8\% em 2000/01, enquanto as mulheres teriam aumentado de 3,3\% para 4,2\% no mesmo período, mantendo-se o aumento da prevalência relacionado à idade. Lipscombe e Hux (2007), avaliando dados da província de Ontário, Canadá, entre 1995 e 2005, mostram um aumento de $69 \%$ na prevalência ajustada para sexo e idade, tendo passado de 5,2\% para $8,8 \%$ (acima dos vinte anos). E dão dois destaques: que esse ritmo de crescimento ultrapassa a previsão de crescimento da Organização Mundial de Saúde (WHO, 2005a) e que, 
proporcionalmente, o aumento foi maior nos menores de 50 anos. Estudo realizado por Gikas et al. (2004), na cidade de Salamis (Grécia), encontrou prevalência de 8,2\% entre homens e mulheres de 20 a 94 anos de idade, utilizando-se de morbidade referida. Nesse mesmo trabalho, análise multivariada com regressão logística encontrou, entre outros fatores independentes de risco: aumento com a idade, sexo masculino, hipertensão e, entre as mulheres, associação com baixo nível educacional. Associação com a escolaridade do chefe de família foi encontrada por Cesar et al. (2005). Tanto no presente trabalho quanto na pesquisa de Chauhan (2003), não houve encontro de associação independente com escolaridade, tendo essa variável, no nosso estudo, perdido seu valor explicativo quando se corrige para outros fatores. Também não encontramos associação com renda, ao contrário do estudo de Sturm e Gresenz (2002).

Encontramos associação independente com o consumo moderado de álcool e diminuição da prevalência de diabetes, assim como aumento da prevalência com o hábito de fumar mais do que 20 cigarros por dia. Em relação ao álcool, contrariamente ao aqui apresentado, Passos et al. (2005) mostraram-no como fator de risco para os idosos. Já em relação ao fumo, Gulliford et al. (2003), estudando os diabéticos da região central de Londres, afirmam que, “em diabetes mellitus, fumar está associado com aumento do risco de mortalidade cardiovascular e complicações microvasculares."

Quando observamos a possível atuação do PSF, vemos que, só na área não coberta por ele, há predominância do sexo feminino. Esse fato poderia indicar um maior acesso dos homens com diabetes ao seu diagnóstico na área do PSF. Observa-se aumento da prevalência entre os homens na área PSF comparada com a área não coberta, embora não haja diferença estatisticamente significativa. Goldenberg et al. (2003) mostraram que a busca ativa leva a um aumento do diagnóstico entre os homens, reduzindo substancialmente 
a diferença entre os sexos. As diferenças em relação a idade e escolaridade sugerem diagnóstico mais precoce e em pessoas com menor escolaridade no PSF. A diferença na prevalência de DM na faixa de maior renda poderia indicar mais diagnósticos feitos pelo PSF também nessa categoria, tendo Goldenberg et al. (2003) observado que, entre os homens, há aumento da prevalência da doença associado a um aumento do nível socioeconômico, ou seja, aumento do diagnóstico no grupo masculino está associado a um aumento no diagnóstico nas faixas de renda mais elevadas.

Em relação às doenças isquêmicas do coração (infarto do miocárdio e doença coronária), encontrou-se, no nosso trabalho, prevalência de $6,9 \%$ entre as mulheres e de 4,4\%, entre os homens. Cesar et al. (2005) também encontraram maior prevalência entre as mulheres $(4,1 \%$ contra $2,9 \%$ nos homens entre 20 e 59 anos, $17,5 \%$ contra $14,1 \%$ nos homens com 60 anos ou mais). Chama a atenção, neste trabalho, o fato de essa maior prevalência entre as mulheres ocorrer também naquelas com menos de 50 anos de idade, quando o esperado, particularmente nessa faixa etária, seria o inverso. Destaque-se que o Brasil é um dos países do mundo com menor diferença na taxa de mortalidade por doenças coronárias entre homens e mulheres (Castanho et al., 2001), embora a mortalidade ainda seja maior no sexo masculino. Pitsavos et al. (2003) encontraram, na Grande Atenas, 5\% e $3 \%$ de prevalência, respectivamente entre homens e mulheres.

Aumento da prevalência com a idade foi observado no presente trabalho e igualmente apresentado por Cesar et al. (2005). Encontrou-se também diminuição da prevalência de DIC com a maior faixa de escolaridade. Cesar et al. (2005) também encontraram menor prevalência com a maior escolaridade do chefe de família.

Em relação ao PSF, se assumirmos que, na nossa população em geral, assim como no resto do mundo, há mais homens do que mulheres com doença isquêmica do coração, 
teremos que o PSF pode ter promovido maior acesso à população masculina, desfazendo o viés surgido na área não-PSF (onde a prevalência feminina é maior). Corrobora-se, assim, a hipótese de o programa produzir maior acesso da população à atenção primária, já apresentada em relação à HAS e o DM.

As elevadas prevalências de tuberculose $(2,0 \%$ e $2,2 \%$, respectivamente, entre homens e mulheres) devem-se, muito provavelmente, a um grande número de indivíduos que já tiveram a doença no passado. Cesar et al. (2005) encontraram 0,05\%, em ambos os sexos, identificando apenas a doença no momento, já que o valor é muito próximo da prevalência no Brasil: 47/100.000 hab (Brasil, 2007b), embora não haja dúvida de que exista subnotificação. Prevalência maior no sexo masculino em relação ao feminino e associação com o hábito de fumar na área do PSF (menor número de casos entre os não-fumantes), sugerem, novamente, um eventual acesso mais amplo da população masculina, restabelecendo-se, talvez, a realidade da associação com o fumo. Porém, o baixo número de casos em ambas as áreas relativizam essas suposições.

\subsection{Estilo de vida}

\subsubsection{Fumo}

Há cinqüenta anos, o fumo tem sido relacionado a diversos problemas de saúde, de forma inequívoca. Está particularmente envolvido na etiologia das doenças cardiovasculares, calculando-se que "o risco de um ataque cardíaco fatal para um fumante é de duas a três vezes maior do que para um não-fumante” (Simpson, 1984), sendo proporcional à quantidade de cigarros fumados. Analogamente, prossegue o autor, " $90 \%$ 
das mortes por câncer de pulmão e $75 \%$ das mortes por bronquite e enfisema, no Reino Unido, são atribuídos ao ato de fumar”.

A prevalência do tabagismo no nosso estudo $(29,1$ e $22.1 \%$, respectivamente, entre homens e mulheres) está em concordância com a literatura deste início de século, que tem apontado valores entre 23 e $38 \%$ para homens e 18 a 30\%, para as mulheres (Rio Grande do Sul, 2001; São Paulo, 2004; Monteiro et al., 2005; Cesar et al. 2005; Szwarcwald et al., 2006). Esses valores são bastante mais baixos do que os apresentados pelos homens na década anterior, que se situavam entre 40 e $52 \%$. Entre as mulheres, a queda foi mais discreta, pois, na década anterior, encontrávamos prevalências entre 22 e 36\% (Rego, 1990; Pohlmann et al., 1991; Chaieb et al., 1993; Duncan et al., 1993; Lolio et al., 1993 Moreira et al., 1995; Chaieb et al., 1995; Martins et al., 1995; Costa e Silva e Koifman,1998).

A maior prevalência de tabagismo entre os homens é uma unanimidade nas pesquisas nacionais já referidas nesse texto. Cesar et al. (2005), embora tenham encontrado maior prevalência entre os homens, só observaram diferença estatisticamente significativa no município de Botucatu (o mesmo não tendo ocorrido na região Sudoeste da Grande São Paulo, distrito do Butantã - São Paulo - e em Campinas). Essa prevalência entre os homens é o padrão de toda a América, com exceção do Canadá (Costa e Silva e Koifman , 1998).

Em relação à associação com idade, manteve-se, no nosso estudo, prevalência aumentada acima dos 30 anos, mesmo corrigindo para outros fatores. Pohlman et al. (1991) encontraram predomínio na faixa etária dos 25 a 54 anos. Lolio et al. (1993) encontraram valores mais baixos para os menores de 25 anos e na faixa etária dos 45 aos 54 anos. Moreira et al. (1995) encontraram razão de prevalência bruta significantemente aumentada para as faixas etárias de 30 a 39 anos e 40 a 49 anos, quando comparadas com a faixa dos 
18 aos 29 anos. O inquérito do INCA (São Paulo, 2004) mostrou 14\% de prevalência entre as pessoas de 15 aos 24 anos e $22 \%$ entre os de 25 anos ou mais. Cesar et al. (2005) encontraram prevalências crescentes até os 40 a 59 anos, decrescendo a partir dos 60 . Pode-se dizer, portanto, que o consumo de tabaco é um hábito mais prevalente no "homem maduro", embora com prevalências nada desprezíveis entre os idosos. Marinho (2006) relata prevalência de 28,9\% entre os homens e de 13,6\%, entre as mulheres maiores de 60 anos, constatadas em inquérito realizado em Porto Alegre em 1995.

Em relação ao estado civil, nossa pesquisa mostrou aumento do risco para todas as categorias, em relação ao solteiro. Cesar et al. (2005) encontraram prevalência mais elevada "nas pessoas separadas e nas unidas quando comparadas às casadas", mesmo ajustado para a idade. Situação inversa, com o risco surgindo entre os solteiros, foi mostrada, em idosos, por Marinho (2006).

Relação com o álcool, como observada no nosso estudo, é consistente com o achado de diversos outros autores (Moreira et al., 1995; Chaieb e Castellarin, 1998; Barros e Nahas, 2001; Costa et al., 2004; Cesar et al., 2005). Já em relação à atividade física, houve associação de menor consumo de fumo entre os "pouco ativos". Barros e Nahas (2001) encontraram maior proporção de fumantes do sexo masculino entre os inativos $(26,3 \%)$ do que entre os ativos e pouco ativos (cerca de 20\%). Hallal et al. (2003) não obtiveram resultados estatisticamente significativos para a associação entre fumo e atividade física.

Não encontramos associação com nível de renda. Associação com escolaridade e com religião não se mantiveram quando controlamos para outros fatores. Lolio et al. (1993) encontraram maior prevalência do hábito de fumar nas camadas de mais baixa renda, assim como, apenas entre os homens, diminuição do tabagismo com o aumento da escolaridade. Moreira et al. (1995) também encontraram maior prevalência com a diminuição de 
escolaridade mas não encontraram associação com a renda. Martins et al. (1995) encontraram associação de fumo e mulheres de classes socioeconômicas mais elevadas, padrão que não ocorreu entre os homens. Segundo os dados do INCA (São Paulo, 2004), havia $22 \%$ de fumantes com ensino fundamental incompleto na capital de São Paulo, em contraposição a $18 \%$ entre aqueles com ensino fundamental completo ou mais. Cesar et al. (2005) não encontraram associação do tabagismo em adolescentes com a escolaridade do chefe de família. Relatam, porém, associação com a religião, sendo os evangélicos os que fumam menos (também encontrada na nossa população).

Em relação à cobertura do PSF, há dois aspectos que nos permitem levantar hipóteses. O primeiro, em relação à menor prevalência de fumo entre os idosos na área do PSF: poderse-ia sugerir um maior acesso dessa população à orientação antitabágica, embora Souza et al. (2002), avaliando prontuários do QUALIS-Santa Marcelina, tenham encontrado referência ao tabagismo em apenas $39,5 \%$ dos prontuários familiares pesquisados, sem distinção de idade. Também contrariamente a essa hipótese, Szwarcwald et al. (2006) encontraram a menor prevalência do hábito de fumar $(16,1 \%)$, entre os quatro municípios fluminenses estudados, exatamente naquele com a menor cobertura de PSF $(11,1 \%$ de domicílios cadastrados), embora esse município tivesse a segunda maior taxa de domicílios $(73,7 \%)$ que receberam orientações sobre comportamentos saudáveis (incluindo não fumar).

O outro aspecto, em relação à menor prevalência de tabagismo entre aqueles "pouco ativos", poderia estar mostrando o impacto de possíveis orientações sobre o fumo entre grupos de caminhadas eventualmente realizados pelas USF's, assumindo-se que seus integrantes, em geral, não praticam atividade física suficiente para serem classificados como ativos. Szwarcwald et al. (2006) sugerem a relação entre PSF e promoção de saúde: 
entre os municípios fluminenses estudados, aquele com menor cobertura de PSF possuía a menor taxa de indivíduos que não realizam atividade física por lazer ou condicionamento físico $(48,3 \%)$.

\subsection{2 Álcool}

Diferentemente do fumo, em que há um claro aumento do risco de adoecer com o aumento do consumo, o álcool apresenta um padrão peculiar. Ao menos em relação à mortalidade (White et al., 2002) e à doença coronariana (Wells et al., 2004), a relação do álcool com a variável desfecho em questão (morte ou doença coronariana) forma uma curva em $\mathrm{U}$, ou seja, incidência elevada para os extremos de consumo, funcionando como um fator de proteção com o consumo moderado, particularmente acima dos 35-40 anos de idade (quando aumentaria o risco de doença coronariana).

A prevalência de consumo excessivo de álcool no nosso estudo $(13,5 \%$ entre os homens e 2,1\% entre as mulheres - dados não apresentados) está de acordo com o que foi encontrado por outros autores, apesar da ampla variação decorrente das diversas metodologias utilizadas e possíveis circunstâncias locais. Nos últimos quinze anos, pesquisas nacionais apontam "dependência" (ou "abuso", ou "consumo de alto risco", ou "consumo diário ou quase diário") variando de 4,9\% a 29,2\% entre os homens e de 0,6\% a 4,0\% entre as mulheres (Almeida e Coutinho, 1993; Moreira et al., 1996; Chaieb e Castellarin, 1998; Galduróz et al., 2003; Almeida-Filho et al., 2004; Costa et al., 2004; Monteiro et al., 2005; Cesar et al., 2005). Em relação ao uso atual de álcool, o achado do presente trabalho $(54,5 \%$ entre os homens e $23,8 \%$ entre as mulheres, dados não apresentados) é algo inferior ao apresentado por outros autores, que encontraram 
prevalências que variavam de $63,9 \%$ a $71,0 \%$ em homens a $42,4 \%$ a $44 \%$, entre as mulheres (Almeida e Coutinho, 1993; Almeida-Filho et al., 2004). Nos EUA, Grant (1997), baseado na "National Institute on Alcohol Abuse and Alcoholism's National Longitudinal Alcohol Epidemiologic Survey (NLAES)", com amostra representativa de toda a população americana, encontrou consumo, no último ano, em 55,8\% dos homens e 33,9\% das mulheres, com história de dependência alcoólica em 18,6\% dos homens e 8,4\% das mulheres.

O predomínio da maior prevalência de consumo e abuso do uso de álcool em homens é praticamente uniforme na literatura. Relação com religião também já foi descrita. Na amostra deste trabalho, houve abstinência entre os evangélicos da ordem de $34,2 \%$ entre os homens e 69,0\% entre as mulheres. Almeida e Coutinho (1993) também relataram associação de menor uso de álcool e religião protestante tanto na análise univariada como no modelo logístico ajustado por outras variáveis.

Em relação à renda, Santana et al. (1989) encontraram maior prevalência de alcoolismo na faixa até $1 \mathrm{SM}$, embora não tenham usado nenhum método estatístico para demonstrar diferença estatisticamente significativa com as outras faixas. Almeida e Coutinho (1993) demonstraram associação de uso de álcool (mas não alcoolismo) e renda familiar até 3 SM. Moreira et al. (1996) encontraram, apenas entre os homens, maior dependência com a diminuição da renda per capita na análise univariada, variável que perdeu a sua significância estatística na análise multivariada. Chaieb e Castellarin (1998) encontraram que "a renda familiar é significativamente maior entre os não-alcoolistas e é um fator independentemente associado com o alcoolismo". Barros e Nahas (2001) encontraram associação de abuso de álcool com classes econômicas A e B, tanto para homens quanto para mulheres, na análise univariada. Almeida-Filho et al. (2004) 
encontraram associação de "consumo de alto risco" com classe social alta, permanecendo após o ajuste do modelo. Costa et al. (2004) encontraram associação inversa de consumo abusivo de álcool com nível socioeconômico, porém, sem significância estatística. Grant (1997) refere maior consumo de álcool nos indivíduos provenientes das famílias com o maior nível de renda, sendo, porém, maior a dependência de álcool nas famílias de menor poder aquisitivo.

Em relação à atividade física, a associação sugere que, havendo ou não etiologia comum a ambos os estilos de vida ou relação "causal" entre um e outro, os eventuais benefícios de proteção cardiovascular conferidos pelo consumo do álcool poderiam estar potencializados pelo menor nível de sedentarismo dessa parcela da população. Naturalmente, essa correlação precisa ser mais bem estudada. Curiosamente, diversos autores que estudam estilos de vida colhem dados sobre essas duas variáveis sem porém correlacioná-las, ao menos na literatura a que tivemos acesso. Barros e Nahas (2001) referem abuso de álcool (mais do que 14 drinques ou doses/semana ou mais de 5 drinques/doses em uma mesma ocasião) e diminuição da atividade física, contrariamente ao nosso achado de menor prevalência de sedentarismo entre os consumidores moderados de álcool. No estudo citado, entre os homens que abusavam de bebidas alcoólicas, havia $53,9 \%$ de insuficientemente ativos, contra $62,4 \%$ "dentre os que não bebem ou o fazem com moderação. Entre as mulheres que ingerem muito álcool, 75,5\% foram consideradas insuficientemente ativas contra $83,5 \%$ entre as que bebem com moderação ou são abstêmias." Costa et al. (2004) não encontraram associação de consumo abusivo de álcool e atividade física.

Associação de maior prevalência de alcoolismo com menor escolaridade foi mostrada por Santana et al. (1989), Moreira et al. (1996) e Grant (1997). Cesar et al. (2005) 
mostraram esse perfil apenas para os homens. Almeida e Coutinho (1993), Chaieb e Castellarin (1998), Almeida-Filho et al. (2004) e Costa et al. (2004) não demonstraram tal associação. Barros e Nahas (2001) mostraram aumento do abuso com o aumento da escolaridade. Já Cesar et al. (2005) mostraram padrão semelhante entre as mulheres. Dentro desse panorama, não parece ter nenhum significado especial o fato de haver maior consumo de álcool nas faixas intermediárias de escolaridade apenas nas áreas de PSF. A mesma falta de poder explicativo pode ser estendida para o encontro de associação entre faixa etária e consumo de álcool apenas na área do PSF. Em suma, pode-se dizer que o QUALIS, até o momento do estudo, não parece ter produzido impacto mensurável, pelo nosso instrumento, no padrão de consumo de álcool desta população.

\subsubsection{Atividade física}

Nas décadas de 80 e 90, avolumaram-se os artigos citando diversos benefícios da atividade física para a saúde. Pate et al. (1995) escreveram um artigo sobre "Atividade Física e Saúde Pública - uma recomendação do Centro de Prevenção e Controle de Doenças e do Colégio Americano de Medicina Esportiva”, que, até muito recentemente, era a base para as recomendações de atividade física em quase todo o mundo. Nesse artigo, são citados os benefícios da prática de atividade física para a doença coronariana (Oldridge, 1982; Leon et al., 1987), hipertensão (Pereira et al., 1999), diabetes mellitus não-insulino dependente (Helmrich et al., 1991), osteoporose, câncer de cólon, ansiedade e depressão. Naturalmente, estudos mostrando diminuição de mortalidade com atividade física são também encontrados (Paffenbarger Jr et al., 1986; Blair et al., 
1989; Kaplan et al., 1996; Kujala et al., 1998). Recentemente, essas diretrizes foram atualizadas (Haskell et al, 2007).

Nessa atualização, o nível de atividade física proposto para um adulto é de 30 minutos de atividade moderada durante cinco dias na semana ou atividade física intensa, 20 minutos por dia, durante três dias na semana e oito a dez exercícios de força muscular, com 8 a 12 repetições de cada exercício, duas vezes na semana. A antiga recomendação era de 30 minutos de atividade física moderada na maioria dos dias da semana, de preferência todos os dias. Ou seja, além de especificar-se melhor a freqüência na semana, incorpora-se o conceito de "equivalente metabólico" (dispêndio energético das atividades) para permitir tempo menor com atividade mais intensa, além de propor-se explicitamente a atividade de força muscular. Uma novidade das recentes recomendações é a proposta para os maiores de 65 anos ou adultos com 50-64 anos, com problemas crônicos de saúde. Nesse grupo, além do proposto para o adulto saudável, recomenda-se planejamento dessas atividades e exercícios para melhorar o equilíbrio, para as pessoas com risco de sofrer quedas.

Com o entendimento que predominou até agora, passou-se a, idealmente, medir-se o nível de atividade física em quatro situações: no trabalho, no transporte (para a escola, trabalho, etc), durante atividades domésticas e nas atividades de lazer, reconhecidas pela própria OMS como os momentos oportunos para a prática de atividade física (WHO, 2005b).

A prevalência de atividade física encontrada neste estudo não diferiu muito em relação a outros estudos nacionais, considerando-se as importantes limitações para compará-los. Na nossa pesquisa, mediu-se atividade física no lazer e trabalho, sem inclusão de atividades 
domésticas e transporte. A inclusão ou exclusão de qualquer desses tópicos vai alterar bastante as prevalências encontradas nos diversos artigos.

Encontramos 41,3 e $62,6 \%$ de sedentarismo, respectivamente entre homens e mulheres. Duncan et al. (1993), em Porto Alegre, encontraram 38\% entre os homens e $58 \%$ entre as mulheres. No Rio de Janeiro, Gomes et al. (2001), medindo sedentarismo no lazer, encontraram 59,8 e 77,8\% respectivamente entre homens e mulheres. No Rio Grande do Sul (RGS, 2001), encontraram-se 71,4\% de sedentarismo entre os homens e 71,3\% entre as mulheres. Barros e Nahas (2001) encontraram, em uma amostra representativa dos cerca de 300 mil trabalhadores da indústria de Santa Catarina, 34,8\% de inatividade entre os homens e 67,0\% entre as mulheres. Matsudo et al. (2002), no ano de 2002 no Estado de São Paulo, encontraram sedentarismo (não-realização de nenhuma atividade física por pelo menos 10 minutos contínuos durante a semana) em 9,7\% dos homens e 8,0\% das mulheres, utilizando-se do QIAF (Questionário Internacional de Atividade Física - IPAC, em inglês). Por sua vez, um grupo composto em parte pelos mesmos pesquisadores (Monteiro et al., 2003), avaliando a PPV (Pesquisa sobre Padrão de Vida) de 1996-97, realizada no Nordeste e Sudeste do Brasil, encontrou apenas 18,2\% e 8,2\%, respectivamente, entre homens e mulheres, de atividade física no lazer, de ao menos 30 minutos de qualquer atividade ou esporte em ao menos um dia da semana. No trabalho aqui apresentado, encontramos 43,1\% e $25,2 \%$, respectivamente entre homens e mulheres, como ativos, incluindo o trabalho. Os dados do INCA (São Paulo, 2004) mostraram 29\% de insuficientemente ativos entre os homens e $41 \%$, entre as mulheres, sempre na cidade de São Paulo. Monteiro et al. (2005) encontraram sedentarismo em 33,9\% dos homens e 57,9\% das mulheres. Cesar et al. (2005), utilizando-se do QIAF, encontraram 68,6\% de ativos entre os homens e 79,0\%, entre as mulheres, possivelmente as maiores prevalências já encontradas no nosso meio, 
embora os autores concedam que as atividades domésticas foram possivelmente superestimadas na sua amostra. Hallal et al. (2003), em Pelotas, também com o uso do QIAF, encontraram 41,1\% de inatividade (menos de 150 minutos de atividade física por semana), sem diferença significativa entre homens e mulheres. Hallal et al. (2005) comparando seus dados de Pelotas com o estudo de Matsudo no Estado de São Paulo, encontrou prevalência três vezes maior de estilo de vida sedentário em Pelotas. Em São Leopoldo, Masson et al. (2005) encontraram 37\% de inatividade entre as mulheres (nenhuma atividade física de lazer ou atividades de baixa intensidade não mais do que uma vez por semana). Pesquisa do Datafolha (Collucci, 2007), encomendada pela Sociedade Brasileira de Cardiologia, mostrou $40 \%$ de sedentarismo entre os homens e $59 \%$, entre as mulheres.

$\mathrm{Na}$ Europa, a presença de alguma atividade física de lazer varia de 40,7\% em Portugal a 91,9\% na Finlândia (Gonzalez, 2001). Atenas, na Grécia, encontra-se em uma posição intermediária, com $42 \%$ dos homens e $40 \%$ das mulheres considerados ativos fisicamente (Skoumas et al, 2003). A OMS (WHO, 2005b) afirma que "pelo menos 60\% da população global não atinge a recomendação mínima de 30 minutos diários de atividade física moderada".

Como se percebe, a maioria dos autores encontra maior prevalência de sedentarismo entre as mulheres, embora a mensuração das atividades físicas no trabalho doméstico levem a uma prevalência praticamente igual entre os sexos (Hallal et al, 2005).

Aumento do sedentarismo com a idade, assim como visto nos nossos dados, é encontrado pela maioria dos autores e pesquisas (Gomes et al, 2001; Barros e Nahas; 2001; Monteiro et al, 2003; Hallal et al, 2003; São Paulo, 2004; Cesar et al., 2005; FSP, 2007), embora nem todos o tenham encontrado (Matsudo et al, 2002; Masson et al, 2005). 
Matsudo et al. (2002) encontraram aumento do sedentarismo nas classes A e B, encontro semelhante ao de Hallal et al. (2003). Por sua vez, Martins et al. (1995) encontraram menos sedentarismo nas mulheres de nível socioeconômico mais elevado. Barros e Nahas (2001) encontraram associação entre menor nível econômico e maior proporção de insuficientemente ativos no lazer. Masson et al. (2005) referem que "as mulheres das classes C, D e E apresentavam quase $10,0 \%$ a mais de probabilidade de serem classificadas como insuficientemente ativas quando comparadas com as da classe A", embora não tenham mostrado associação com renda no mesmo trabalho. Monteiro et al. (2003) encontraram aumento da atividade física no lazer com o aumento da renda. Cauley (1991) não mostrou associação do nível socioeconômico com o nível de atividade física como um todo, estando esse nível relacionado a atividades específicas (por exemplo, "participação em esportes foi referida mais freqüentemente em homens e mulheres de alto nível (socioeconômico)." A associação, no nosso estudo, após controle para variáveis de confusão, com renda intermediária, talvez esteja mostrando o resultado final da realização de atividades físicas diversas por pessoas com níveis de renda diferentes, sem um significado específico para essa associação.

Em relação à ocupação, Burton e Turrell (2000) mostraram que trabalhadores com ocupações de "colarinho azul" (em contraposição aos de "colarinho branco") tinham "50\% mais de chances de serem classificados como insuficientemente ativos (no lazer)", embora esse achado não estivesse correlacionado com o total de horas trabalhadas. A hipótese para justificar que profissionais autônomos e informais façam mais atividade física seria, portanto, não o fato de possuírem mais tempo livre (o que por si já é duvidoso), e sim pela melhor possibilidade de gerenciarem o seu tempo, sempre acreditando que a atividade física no lazer é que fez a diferença. 
Em relação ao PSF, podemos sugerir que um maior acesso a recomendações de estímulo à prática de atividade física poderia estar beneficiando alguns subgrupos, como os solteiros, procedentes de outros estados e interior de SP, os de baixa renda e os de outras categorias profissionais que não os autônomos ou informais, todos eles com menor nível de sedentarismo do que os da área não-PSF. Facchini et al. (2006) encontraram diferença estatisticamente significativa a favor do PSF para "recomendação médica de atividade física na UBS alguma vez na vida", nas faixas etárias de 30 a 64 anos e 65 anos ou mais, tanto no Sul como no Nordeste, nos 41 municípios com população acima de 100 mil habitantes das duas regiões.

\subsection{Considerações finais.}

O Programa de Saúde da Família, após ter tido uma enorme expansão inicial, parece ter encontrado uma certa estabilização, no tocante ao aumento do número de equipes, dentro do país. Inúmeras razões devem estar contribuindo para isso, como a falta de profissionais médicos com formação e perfil para essa função, críticas ao próprio desenho da equipe (há quem avalie como desnecessária a presença dos ACS's), limitações orçamentárias (particularmente enquanto não se aprova a regulamentação da Emenda Constitucional 29), a dificuldade em expandir o programa nos grandes centros urbanos (divergências de opiniões em relação à proposta, significativo número de profissionais de outras especialidades atuando na atenção primária). Ainda, constata-se uma certa expectativa quanto aos resultados das avaliações que o programa/estratégia começa a sofrer. É legítimo que, particularmente, o gestor queira assegurar-se de que os esforços 
envolvidos numa mudança de razoável magnitude na atenção primária esteja trazendo real impacto na saúde da população.

Deve-se considerar que o crescimento extremamente rápido da estratégia fez surgirem não um, mas diversos PSF's. Inicia-se aí um dos desafios para a avaliação do programa: a dificuldade de generalização de eventuais resultados encontrados, ou seja, a possibilidade de haver uma boa validação externa nas pesquisas de avaliação. Sob esse aspecto, nossa análise do QUALIS também sofre essa restrição. No entanto, o fato de se terem encontrado resultados que sugerem "mudanças" (no sentido de reconhecê-las) no perfil de morbidade de uma população em função do tipo de estratégia em que está organizada a atenção primária é interessante. Primeiro, pelo fato de que o achado parece corroborado por outros autores, o que parece sustentar o potencial de mudança intrínseco a essa estratégia. Segundo, porque, em se "confirmando" os sentidos da mudança nesse perfil, está-se diante de um marco histórico na atenção à saúde de nossa população: a possibilidade de se atuar não somente no sentido de universalizar o acesso da população a um bem constitucionalmente garantido mas também intervir em favor de uma maior eqüidade do sistema. Esse objetivo é hoje prioridade na agenda de todos os países desenvolvidos, incluindo aqueles com sistemas de saúde paradigmáticos e que têm tradição de décadas de cuidados com a saúde de seu povo.

Há ainda bastante para se avançar tanto no que diz respeito à melhoria dos processos de trabalho dentro da estratégia, quanto na possibilidade de se criarem avaliações engenhosas que permitam "medir" essa atenção assumida como mais "qualificada" dentro do PSF. Embutido nesse termo, ressalte-se a ampla gama de aspectos de difícil mensuração, que são, de uma maneira ou de outra, influenciados por uma estratégia tão singular como é o PSF, e que possivelmente estariam contribuindo para os resultados já 
encontrados. Referimo-nos à presença dos ACS's nas residências de forma rotineira; à maior disseminação de informações proporcionada pelas visitas domiciliares, grupos e possíveis consultas mais prolongadas; perfil diferenciado de boa parte dos profissionais envolvidos com a estratégia. São avaliações de processo que ainda merecem ser realizadas se se quer dar robustez aos eventuais achados de pesquisas de resultado.

Por outro lado, deve-se notar que o fato de que, após uma década de apoio e incentivo à ESF, sem que o mesmo tenha ocorrido com outras modalidades de atenção primária, cria uma situação algo injusta na comparação da nova estratégia com os "antigos” modelos.

É necessária também a ampliação de estudos envolvendo os pacientes que são alvos prioritários da estratégia, como os hipertensos, diabéticos, gestantes, crianças pequenas e portadores de tuberculose e hanseníase. Contínua avaliação do possível impacto da estratégia nos estilos de vida da população também é mister. Ainda, parece oportuna a realização de estudos do tipo custo-efetividade, já que os resultados da maior parte das avaliações que comparam o modelo tradicional com o PSF, ao menos nesse momento, parecem pender de forma apenas discreta ou moderada para esse último, embora o custo seja supostamente bastante mais elevado.

Na pesquisa aqui apresentada, o fato de haver semelhança entre os valores de prevalência encontrados com os publicados no país, inclusive em relação a tendências, como é o caso do fumo, reforça a qualidade da metodologia utilizada no processo amostral, na condução do trabalho de campo e na análise dos dados.

Sendo o objetivo final desta pesquisa a análise do impacto do QUALIS na prevalência de morbidades e no estilo de vida das populações de sua área de cobertura, o encontro de diferenças entre as áreas permitiu vislumbrar uma possível participação dessa estratégia na mudança. Embora as diferenças possam ser descritas como relativamente discretas e sutis, 
parecem consolidar um certo eixo explicativo, o que dá coerência às hipóteses aqui levantadas. Como explicação geral, parece que a estratégia permite um maior acesso da população às ações empreendidas pela rede de atenção primária seja no tocante a cuidados específicos, aqui representados pela maior possibilidade de os indivíduos terem suas eventuais patologias reconhecidas, seja em relação às ações de promoção de saúde, permitindo possíveis mudanças de estilo de vida, aqui, quando muito, incipientes. Mesmo esse impacto de amplitudes diversas é absolutamente coerente com a maneira como se dá a interação de uma população ou indivíduos com o sistema de saúde. Em outras palavras, é muito mais fácil e factível no curto prazo que, em se promovendo um maior acesso a cuidados de saúde, as pessoas possam ser diagnosticadas com essa ou aquela patologia, permitindo a elas que declarem esse seu novo "estado" de saúde. Muito mais difícil e ambicioso é encontrar caminhos para que essas pessoas modifiquem o seu estilo de vida, deixando, por exemplo, de fumar ou intensificando a sua atividade física. Nesse sentido, após relativo curto prazo de atuação, poder-se-ia esperar do QUALIS impacto no primeiro aspecto, mas, menos provavelmente, no segundo. Um outro "efeito colateral" desse maior acesso a diagnósticos seria o de aproximar o dado da morbidade referida em inquéritos da real situação da população estudada. O encontro de apenas metade dos casos de diabetes, em inquéritos de morbidade referida, como sugerem alguns estudos no nosso meio, exemplifica, entre outras, as enormes barreiras de acesso a atendimento de saúde que ainda persistem. E, desnecessário dizer, o diagnóstico de uma patologia complexa como o diabetes, do ponto de vista da necessidade de se alterarem hábitos diversos, uso de diferentes medicações, necessidades de exames regulares e necessidade do aporte de especialistas logo no início do quadro (para a realização de fundo de olho) é apenas o primeiro passo dessa longa cadeia de cuidados. Ou seja: só o acesso não é suficiente para 
que consigamos garantir o direito constitucional do cidadão brasileiro à saúde. Mas ele é condição sine qua non. Ao mesmo tempo em que se procura garanti-lo por meio de determinada estratégia, há que se proporem e avaliarem mecanismos que garantam a continuidade da cadeia de cuidados.

Uma outra questão refere-se à qualificação desse maior acesso. Como se discutiu em relação à HAS, onde houve aumento da morbidade referida na população de maior renda na área do PSF, a ampliação do acesso parece ter-se dado principalmente em relação ao primeiro princípio fundamental do SUS, o da universalização. Isso demonstra como ainda temos muito para avançar no sentido de garantir esse aspecto essencial no nosso sistema, mesmo na cidade mais rica do país. Mas a estratégia não parece se limitar a esse processo, havendo indícios, como no caso da maior prevalência de diabetes na área do PSF, entre indivíduos de menor idade e menor escolaridade, de agir também em prol de uma maior eqüidade do sistema. Esse "favorecimento" de grupos relativamente mais excluídos do sistema é particularmente bem-vindo, haja vista a reconhecida maior dificuldade em se atuar nesse aspecto. Ressalte-se aqui o caráter imprescindível de se construir um sistema universal a priori, sob pena de as ações que procurem minimizar possíveis iniqüidades funcionarem como medidas perversas ou equivocadas. Mas, confirmada a possibilidade de a estratégia funcionar em ambos os princípios, estaremos avançando na construção do SUS.

Vale ressaltar também um aspecto interessante em relação a um possível maior acesso da população masculina por intermédio da ESF, como parece ter ocorrido nos casos de pacientes com diabetes e tuberculose. A despeito de as mulheres serem, regra geral, consideradas como grupo mais vulnerável, especificamente no tocante ao acesso à rede primária de atenção temos, historicamente, muito mais mulheres em contato com os serviços. Não deixa, portanto, de ser um achado o fato de uma proposta de atenção 
primária estar favorecendo, de certa maneira, o acesso masculino, mesmo não trazendo nenhuma mudança no horário de funcionamento das unidades, sendo essa uma das principais razões apontadas para o fato de termos sempre poucos homens nos serviços. Ou seja, há potencial para se atrair essa população para a atenção primária com ações outras que não a óbvia possibilidade de atendimentos em horários que não coincidam com o horário habitual de trabalho.

A partir dos resultados aqui encontrados, podem-se sugerir outros estudos específicos, procurando-se compreender se é o processo de trabalho ou o tipo de profissional da ESF que está contribuindo para estes resultados. É efetivamente a figura do agente comunitário de saúde que, por intermédio da busca ativa de casos, promove esse maior acesso? Poderia esse aspecto ser potencializado, definindo-se critérios de risco que ensejariam visitas domiciliares por parte desse profissional, ao invés das rotineiras visitas mensais indiscriminadas? Junta-se a isso a definição de uma relação quantitativa de pessoas por equipe de saúde da família (e, por conseguinte, por médico), que, embora não seja considerada ideal (atualmente uma equipe para 3 a 4 mil pessoas), já produz um limite razoável, não existente no modelo tradicional? Ou a atuação mais direta da enfermagem, bastante fortalecida no novo modelo, é que tem papel preponderante nesses achados? E qual a preponderância do papel da formação desses profissionais? Ou, se todos esses fatores contribuem, será que conseguimos estudá-los e entender quais os mais relevantes, se atuam sinergicamente ou apenas de forma aditiva? Isso nos permitiria desenhos de equipes mais flexíveis, aspecto particularmente importante nas grandes cidades devido ao grande número de profissionais de saúde já atuando, hoje freqüentemente a reboque de uma proposta que tem muita dificuldade em integrá-los. Colocá-los em equipes de suporte à ESF, em uma espécie de espaço virtual entre a atenção primária e a secundária, como é o 
modelo dos Núcleos de Atenção à Saúde da Família (NASF), que estão sendo propostos, é uma medida interessante, porém com importante impacto no custo do programa.

Portanto, segue sendo imprescindível que pesquisadores busquem conhecer não só possíveis outros impactos da ESF na saúde da população, assim como eventualmente em outras áreas, mas também dissecar o modelo e extrair dele as suas potencialidades e armadilhas. E, como sói acontecer, responder o mais rapidamente possível a mudanças de rumo que ocorrem a partir das decisões dos gestores, tentando demonstrar os eventuais benefícios dessas mudanças. Pois diferentes formas de gestão de uma estratégia supostamente única podem trazer importantes contribuições (ou retumbantes fracassos) nos seus resultados, ofuscando outros mecanismos intrínsecos da estratégia propriamente dita. E, assim, pode-se vislumbrar trabalho para toda uma geração de pesquisadores. 


\section{REFERÊNCIAS}

Almeida LM, Coutinho ESF. Prevalência de consumo de bebidas alcoólicas e de alcoolismo em região metropolitana do Brasil. Rev Saude Publica. 1993;27(1):23-9.

Almeida-Filho N, Lessa I, Magalhães L, Araújo MJ, Aquino E, Kawachi I, James SA. Determinantes sociais e padrões de consumo de álcool na Bahia, Brasil. Rev Saude Publica. 2004;38(1):45-54.

Alves Sobrinho EJM, Gouvêa IGC, Batista KBC, Sucupira ACSL, Capucci PF, Sousa MF, Andrade LOM, Schneider DA. Município de São Paulo: implantando o PSF. São Paulo, 2001. (mimeo.)

Barros MBA. Introdução. In: Cesar CLG, Carandina L, Alves MCGP, Barros MBA, Goldbaum M. Saúde e condição de vida em São Paulo. Inquérito multicêntrico de saúde no Estado de São Paulo. São Paulo: Imprensa Oficial;2005, p.11-34.

Barros MVG, Nahas MV. Comportamentos de risco, auto-avalição do nível de saúde e percepção de estresse entre trabalhadores da indústria. Rev Saude Publica. 2001;35(6): 554-63.

Beckett M, Weinstein M, Goldman N, Yu-Hsuan L. Do health interview surveys yield reliable data on chronic illness among older respondents? Am J Epidemiol. 2000;151(3):315-23. 
Bertoncini JH. Da intenção ao gesto: análise da implantação do Programa Saúde da Família em Blumenau [dissertação]. Florianópolis: Universidade Federal de Santa Catarina, Centro de Ciências da Saúde; 2000.

Blair SN, Kohl III HW, Paffenbarger RS Jr, Clark DG, Cooper KH, Gibbons LW. Physical fitness and all-cause mortality - a prospective study of healthy men and women. JAMA. 1989;262 (17):2395-401.

Blaxter M. Health and lifestyles. Nova York: Routledge Inc.; 1990.

Bousquat A, Cohn A, Elias PE. O PSF e a dinâmica urbana das grandes cidades. In: Viana ALd'A, Elias PEM, Ibañez N, organizadores. Proteção social: dilemas e desafios. São Paulo: Hucitec; 2005. p.244-65.

Brasil. Ministério da Saúde. Secretaria de Políticas de Saúde. Brasília: Ministério da Saúde;2000a.

Brasil. Ministério da Saúde. Secretaria de Assistência à Saúde. Coordenação de Atenção Básica. Avaliação da implantação e funcionamento do Programa de Saúde da Família PSF. Brasília: Ministério da Saúde;2000b.

Brasil. Ministério da Saúde. Secretaria de Políticas de Saúde. Departamento de Atenção Básica. Avaliação da implementação do Programa Saúde da Família em dez grandes centros urbanos. Brasília: Ministério da Saúde;2002. 
Brasil. Instituto Brasileiro de Geografia e Estatística (IBGE). Coordenação de Trabalho e Rendimento. Acesso e utilização de serviços de saúde. Rio de Janeiro: IBGE;2005.

Brasil. Ministério da Saúde. Secretaria de Atenção Básica. Departamento de Atenção Básica. Política Nacional de Atenção Básica. Brasília: Ministério da Saúde;2006.

Brasil. Ministério da Saúde. Secretaria de Atenção Básica. Departamento de Atenção Básica. [on line] [citado em 06/04/2007]. Disponível em: http://dtr2004.saude.gov.br/dab/abnumeros.php\#consolidado.

Brasil. Ministério da Saúde. Secretaria da Vigilância em Saúde. Vigilância Epidemiológica. [on line] [citado em 01/05/2007]. Disponível em: http://portal.saude.gov.br/portal/saude/visualizar_texto.cfm?idtxt=21445.

Burton NW, Turrel G. Occupation, hours worked, and leisure-time physical activity. Preventive Medicine. 2000;31:673-81.

Campos CEA. Os inquéritos de saúde sob a perspectiva do planejamento. Cad Saude Publica. 1993 9(2):190-200.

Carandina L, Sanches O, Carvalheiro JR. Análise das condições de saúde e de vida da população urbana de Botucatu, SP. I - Descrição do plano amostral e avaliação da amostra. Rev Saude Publica. 1986;20(6):465-74. 
Cardoso SM, Ramalheira C. Inquérito ao Estado de Saúde da População de Souselas "Souselas 2001" - Relatório Preliminar. Março 2001 [on line] [citado 01 maio 2007]; 18:20. Disponível em http://co-incineracao.online.pt/SouselasMar2001.PDF.

Carvalheiro JR. Investigação epidemiológica e entrevistas domiciliárias. Rev Saude Publica. 1981;15:543-50.

Carvalho FM, Silvany Neto AM, Paim JS, Melo AMC, Ázaro MGA. Morbidade referida e utilização de consulta médica em cinco populações do Estado da Bahia. Cienc Cult (São Paulo). 1988;40(8):853-8.

Castanho VS, Oliveira LS, Pinheiro HP, Oliveira HCF, Faria EC. Sex differences in risk factors for coronary heart disease: a study a Brazilian population. BMC Public Health [periódico online]. April 32001 [citado 27 mar 2005];1:3. Disponível em http://www.biomedcentral.com/1/3.

Cauley JÁ, Confield SM, Laporte RE, Warhaftig NE. Physical activity by socioeconomic status in two population based cohorts. Med Sci Sports Exerc. 1991;23(3):343-51.

Cesar CLG, Figueiredo GM, Westphal MF, Cardoso MRA, Costa MZA, Gattás VL. Morbidade referida e utilização de serviços de saúde em localidades urbanas brasileiras: metodologia. Rev Saude Publica. 1996;30(2):153-60. 
Cesar CLG, Tanaka OY. O inquérito domiciliar como instrumento de avaliação de serviços de saúde: um estudo de caso na região sudoeste da área metropolitana de São Paulo, 19891990. Cad Saude Publica. 1996;12(Supl 2):59-70.

Cesar CLG, Carandina L, Alves MCGP, Barros MBA, Goldbaum M. Saúde e condição de vida em São Paulo. Inquérito multicêntrico de saúde no Estado de São Paulo. São Paulo: Imprensa Oficial;2005.

Cezar, LSB. Programa de saúde da família: uma avaliação no morro do Borel. [dissertação]. Rio de Janeiro: Instituto de Medicina Social, Universidade Estadual do Rio de Janeiro;2003.

Chaieb JA, Ruschel SP, Costa JTF. Estudo epidemiológico sobre tabagismo $-1^{\mathrm{a}}$ parte: informações epidemiológicas sobre área periférica de Porto Alegre. Rev AMRIGS. $1993 ; 37(4): 251-7$.

Chaieb JA, Fasolo P, Ruschel SP, Costa JTF. Aspectos epidemiológicos e tabagismo em Porto Alegre: prevalência do tabagismo e DPOC. J Pneumol. 1995;21(4):171-9.

Chaieb JA, Castellarin C. Associação tabagismo-alcoolismo: introdução às grandes dependências humanas. Rev Saude Publica. 1998;32(3):246-54.

Champagne F, Costandriopoulos AP, Pineault R. Un cadre conceptual pour l'évaluation des programmes de santé. Rev Epidemiol Sante Publique, 1985;33, 173-81. 
Chauhan TS. Diabetes' rising toll. CMAJ. 2003;169(10):1068.

Collucci C. Metade dos brasileiros é sedentária, diz pesquisa. Folha de São Paulo, São Paulo. 2007 set 09; Cotidiano, C1.

Conill EM. Políticas de atenção primária e reformas sanitárias: discutindo a avaliação a partir da análise do Programa Saúde da Família em Florianópolis, Santa Catarina, Brasil, 1994-2000. Cad Saúde Pública. 2002;18(Suplemento):191-202.

Costa JSC, Silveira MF, Fazalle FK, Oliveira SS, Hallal PC, Menezes AMB, Gigante DP, Olinto MTA, Macedo S. Consumo abusivo de álcool e fatores associados: estudo de base populacional. Rev Saude Publica. 2004;38(2):284-91.

Costa e Silva VL, Koifman S. Smoking in Latin America: a major public health problem. Cad. Saúde Pública. 1998;14(Supl 3):109-15.

Demarteau M. A theoretical framework and grid for analysis of programme-evaluation practices. Evaluation. 2002;8(4):454-73.

Duncan BD, Schmidt MI, Polanczyk CA, Homrich CS, Rosa RS, Achutti AC. Fatores de risco para doenças não-transmissíveis em área metropolitana na região Sul do Brasil. Prevalência e simultaneidade. Rev Saude Publica. 1993;27(1):143-8. 
Elias PEM. Por uma refundação macropolítica do SUS: a gestão para a eqüidade no cotidiano dos serviços. Saúde Soc. 2002;11(1):37-52.

Elias PE, Ferreira CW, Alves MCG, Cohn A, Kishima V, Escrivão Junior A, Gomes A, Bousquat A. Atenção Básica em Saúde: comparação entre PSF e UBS por estrato de exclusão social no município de São Paulo. Cienc Saúde Coletiva. 2006;11(3):633-41.

Facchini LA, Piccini RX, Tomasi E, Thumé E, Silveira DS, Siqueira FV, Rodrigues MA. Desempenho do PSF no Sul e no Nordeste do Brasil: avaliação institucional e epidemiológica da Atenção Básica à Saúde. Cienc Saúde Coletiva. 2006;11(3):669-81.

Felisberto E. Monitoramento e avaliação na atenção básica. Rev Bras Saúde Família. 2004; 5(7):24-9. [edição especial]

Franco TB e Merhy EE. Programa de Saúde da Família (PSF): contradições de um programa destinado à mudança do modelo tecnoassistencial. In: O trabalho em saúde: olhando e experimentando o SUS no cotidiano. São Paulo: Hucitec, 2003. p.55-124.

Galduróz JCF, Noto AR, Nappo SA, Carlini ELA. First household survey on drug abuse in São Paulo, Brazil, 1999: principal findings. Sao Paulo Med J. 2003;121(6):231-7. 
Gikas A, Sotiropoulos A, Panagiotakos D, Peppas T, Skliros E, Pappas S. Prevalence, and associated risk factors, of self-reported diabetes mellitus in a sample of adult urban population in Greece: MEDICAL Exit Poll Research in Salamis (MEDICAL EXPRESS 2002). BMC Public Health [periódico online]. 2004 Feb 14 [citado 27 mar 2005]; 4:2. Disponível em http://www.biomedcentral.com/1471-2458/4/2.

Giovanella L. A atenção primária à saúde nos países da União Européia: configurações e reformas organizacionais na década de 1990. Cad. Saúde Pública. 2006;22(5):951-63.

Glover JD, Hetzel DMS, Tennant SK. The socioeconomic gradient and chronic illness and associated factors in Australia. Aust New Zealand Health Policy [periódico online]. 2004 Dec 12 [citado 27 mar 2005]; 1:8. Disponível em http://www.anzhealthpolicy.com/content/1/1/8.

Goldbaum M, Gianini RJ, Novaes HMD, Cesar CLG. Utilização de serviços de saúde em áreas cobertas pelo programa saúde da família (Qualis) no Município de São Paulo. Rev Saude Publica. 2005;39(1):90-9.

Goldenberg, P, Schenkman, S, Franco LJ. Prevalência de Diabetes Mellitus: Diferenças de Gêneros e Igualdade Entre os Sexos. Rev Bras Epidemiol. 2003;1(6):18-28.

Gomes KRO, Tanaka ACD. Morbidade referida e uso dos serviços de saúde por mulheres trabalhadoras, município de São Paulo. Rev Saude Publica. 2003;37(1):75-82. 
Gomes VB, Siqueira KS, Sichieri R. Atividade física em uma amostra probabilística da população do Município do Rio de Janeiro. Cad. Saúde Pública. 2001;17(4):969-76.

Gonzalez AM. Percentage of adult population practising any leisure-time physical activity. Med Sci Sports Exerc. July 2001;33(7):1142-6.

Grant BF. Prevalence and correlates of alcohol use and DSM-IV alcohol dependence in the United States: results of the National Longitudinal Alcohol Epidemiologic Survey. $J$ Studies Alcohol. Sept 1997;464-73.

Green A, Ross D, Mirzoev T. Primary Health Care and England: The coming of age of Alma Ata? Health Policy. 2007;80:11-31.

Gulliford MC, Sedgwick JEC, Pearce AJ. Cigarette smoking, health status, socioeconomic status and access to health care in diabetes mellitus: a cross-sectional survey. BMC Health Services Research [periódico online]. 2003 Feb 11 [citado 27 março 2005]; 3:4. Disponível em http://www.biomedcentral.com/1472-6963/3/4.

Haapanen N, Miilunpalo S, Pasanen M, Oja P, Vuori I. Agreement between questionnaire data and medical records of chronic diseases in middle-aged and elderly finnish men and women. Am J Epidemiol. 1997;145(8):762-9. 
Habicht JP, Victora CG, Vaughan JP. Evaluation designs for adequacy, plausibility and probability of public health programme performance and impact. Int $J$ Epidemiol. $1999 ; 28: 10-18$.

Haddad N. Inquérito Epidemiológico sobre cardiopatias crônicas em um bairro periférico de Ribeirão Preto - São Paulo - Brasil. Arq. Hig. Saúde Pub. 1967-8;32/33(111/118):2777.

Hallal PC, Victora CG, Wells JCK, Lima RC. Physical inactivity: prevalence and associated variables in Brazilian adults. Med Sci Sports Exerc. Nov 2003;35(11):18941900.

Hallal PC, Matsudo SM, Matsudo VKR, Araújo TL, Andrade DR, Bertoldi AD. Physical activity in adults from two Brazilian areas: similarities and differences. Cad Saúde Pública. 2005;21(2):573-80.

Haskell WL, Lee I-M, Pate RR, Powell KE, Blair SN, Franklin BA, Macera CA, Heath GW, Thompson PD, Bauman A. Physical Activity and Public Health: Updated Recommendations for Adults from the American College of Sports Medicine and the American Heart Association. Med Sci Sports Exerc. 2007;39(8):1423-34.

Helmrich SP, Ragland DR, Leung RW, Paffenbarger Jr RS. Physical activity and reduced occurrence of non-insulin-dependent diabetes mellitus. N Eng J Med. 1991;325(3):147-52. 
Hennekens $\mathrm{CH}$ e Buring JE. Epidemiology in Medicine. $1^{\text {st }}$. ed. Philadelphia: Lippincott Williams \& Wilkins; 1987.

Ibañez N, Rocha JSY, Castro PC, Ribeiro MCSA, Forster AC, Novaes MHD, Viana ALd'A. Avaliação do desempenho da atenção básica no Estado de São Paulo. Cienc Saúde Coletiva. 2006;11(3):683-703.

Kaplan GA, Strawbridge WJ, Cohen RD, Hungerford LR. Natural history of leisure-time physical activity and its correlates: associations with mortality from all causes and cardiovascular disease over 28 years. Am J Epidemiol. 1996;144(8):793-7.

Kroeger A. Health interview in developing countries: a review of the methods and results. Int J Epidemiol. 1983;12:465-81.

Kroeger A. Errores de respuesta y otros problemas de encuestas de salud mediante entrevista en los paises en desarollo. Bol Sanit Panam. 1986;100(3):253-82.

Kujala UM, Kaprio J, Sarna S, Koskenvuo M. Relationship of leisure-time physical activity and mortality: the Finnish twin cohort. JAMA. 1998;279(6):440-4.

Lebrão ML, Carandina L, Magaldi C. Análise das condições de saúde e de vida da população urbana de Botucatu, São Paulo (Brasil). IV - Morbidade referida em entrevistas domiciliárias, 1983-1984. Rev Saude Publica. 1991;25(6):452-60. 
Leon AS, Connett J, Jacobs DR, Rauramaa R. Leisure-time physical activity levels and risk of coronary heart disease and death - the multiple risk factor intervention trial. JAMA. $1987 ; 258(17): 2388-95$.

Lipscombe LL, Hux JE. Trends in diabetes prevalence, incidence, and mortality in Ontario, Canada 1995-2005: a population-based study. Lancet. 2007;369:750-756.

Lolio CA, Souza JMP, Santo AH, Buchalla CM. Prevalência de tabagismo em localidade urbana da região Sudeste do Brasil. Rev Saude Publica. 1993;27(4):262-5.

Mano GMP, Pierin AMG. Avaliação de pacientes hipertensos acompanhados pelo Programa Saúde da Família em um Centro de Saúde Escola. Acta Paul. Enfermagem. $2005 ; 18(3): 269-75$.

Marinho VM. Estudo de prevalência sobre o uso de tabaco em idosos vivendo na comunidade e associação com fatores sócio-demográficos e de saúde física e mental [tese]. São Paulo: Faculdade de Medicina, Universidade Federal de São Paulo;2006.

Martins IS, Coelho LT, Casajus MI, Okani ET. Smoking, consumption of alcohol and sedentary life style in population grouping and their relationships with lipemic disorders. Rev Saude Publica. 1995;29(1):38-45. 
Masson CR, Dias-da-Costa JS, Olinto MTA, Meneguel C, Costa CC, Bairros F, Hallal PC. Prevalência de sedentarismo nas mulheres adultas da cidade de São Leopoldo, Rio Grande do Sul, Brasil. Cad. Saúde Pública. 2005;21(6):1685-94.

Matsudo SM, Matsudo VR, Araújo T, Andrade D, Andrade E, Oliveira L, Braggion G. Nível da atividade física da população do Estado de São Paulo: análise de acordo com o gênero, idade, nível socioeconômico, distribuição geográfica e de conhecimento. Rev Bras Cienc Mov. 2002;10:41-50.

McDowell I, Newell C. Measuring health: a guide to rating scales and questionnaires. 2nd. ed. New York: Oxford University Press;1996.

Medina MG, Aquino R. Avaliando o Programa de Saúde da Família. In: Sousa MF. Os sinais vermelhos do PSF. São Paulo: Editora Hucitec; 2002. p.135-51.

Mendoza-Sassi R, Béria JU, Barros AJD. Fatores associados à utilização de serviços ambulatoriais: estudo de base populacional. Rev Saude Publica. 2003;37:372-8.

Monteiro CA, Conde WL, Matsudo SM, Matsudo VR, Benseñor IM, Lotufo PA. A descriptive epidemiology of leisure-time physical activity in Brazil, 1996-1997. Rev Panam Salud Publica. 2003;14(4):246-54.

Monteiro CA, Moura EC, Jaime PC, Lucca A, Florindo AA, Figueiredo ICR, Bernal R, Silva NN. Monitoramento de fatores de risco para doenças crônicas por entrevistas telefônicas. Rev Saude Publica. 2005;39(1)47-57. 
Moreira LB, Fuchs FD, Moraes RS, Bredemeier M, Cardozo S. Prevalência de tabagismo e fatores associados em área metropolitana da região Sul do Brasil. Rev Saude Publica. 1995;29(1):46-51.

Moreira LB, Fuchs FD, Moraes RS, Bredemeier M, Cardozo S, Fuchs SC, Victora CG. Alcoholic beverage consumption and associated factors in Porto Alegre, a southern brazilian city: a population-based survey. J Studies on Alcohol. May 1996;253-9.

Nordberg E. Household health surveys in developing countries: could more use be made of them in planning? Health policy planning. 1988;3(1):32-9.

Oldridge NB. Compliance and exercise in primary and secondary prevention of coronary heart disease: a review. Prev Med. 1982;11:56-70.

Paffenbarger Jr RS, Hyde RT, Wing AL, Chung-Cheng H. Physical activity, all-cause mortality, and longevity of college alumni. N Eng J Med. 1986;314(10):605-13.

Passos VMA, Barreto SM, Diniz LM, Lima-Costa MF. Type 2 diabetes prevalence and associated factors in a Brazilian community: the Bambuí health and aging study. Sao Paulo Med J. 2005;123(2):66-71. 
Pate RR, Pratt M, Blair SN, Haskell, WL, Macera CA, Bouchard C, Buchner D, Ettinger W, Heath GW, King AC, Kriska A, Leon AS, Marcus BH, Morris J, Paffenbarger RS Jr, Patrick K, Pollock ML, Rippe JM, Sallis J, Wilmore JH. Physical activity and public health - a recommendation from the Centers for Disease Control and Prevention and the American College of Sports Medicine. JAMA. 1995;273(5):402-7.

Pereira MA, Folsom AR, McGovern PG, Carpenter M, Arnett DK, Liao D, Szklo M, Hutchinson RG. Physical activity and incident hypertension in black and White adults: the Atherosclerosis Risk in Communities Study. Prev Med. 1999;28:304-12.

Piccini RX, Facchini LA, Tomasi E, Thumé E, Silveira DS, Siqueira FV, Rodrigues MA. Necessidades de saúde comuns aos idosos: efetividade na oferta e utilização em atenção básica à saúde. Cienc Saúde Coletiva. 2006;11(3):657-67.

Pitsavos C, Panagiotakos DB, Chrysohoou C, Stefanadis C. Epidemiology of cardiovascular risk factors in Greece: aims, design, and baseline characteristics of the ATTICA study. BMC Public Health [periódico online]. 2003 Oct 20 [citado 27 mar 2005]; 3:32. Disponível em http://www.biomedcentral.com/1471-2458/3/32.

Pohlmann PR, Loss JF, Flores C, Bolzzoni A, Duncan B, Zimmer PM. Tabagismo em Porto Alegre: prevalência e o papel dos profissionais da saúde na prevenção. Rev Assoc Med Bras. 1991;37(1):8-14. 
Rego RA, Berardo FAN, Rodrigo SSR, Oliveira ZMA, Oliveira MB, Vasconcellos C, Aventurato LVO, Moncau, JEC, Ramos LR. Fatores de risco para doenças crônicas nãotransmissíveis: inquérito domiciliar no município de São Paulo, SP (BRASIL). Metodologia e resultados preliminares. Rev Saude Publica. 1990; 24(4):277-85.

Rio Grande do Sul. Secretaria Estadual de Saúde. Pesquisa sobre fatores de risco para a doença coronariana no Rio Grande do Sul. Boletim Epidemiológico da SES-RS. 2001;3:45.

Rocha, NSPD. Análise do programa saúde da família no município de Natal-RN: inovações assistenciais. [dissertação]. Rio de Janeiro: Instituto de Medicina Social, Universidade Estadual do Rio de Janeiro;2000.

Santana ML, Carmagnani MI. Programa Saúde da Família no Brasil: um enfoque sobre seus pressupostos básicos, operacionalização e vantagens. Saúde Soc. 2001;10(1):33-53.

Santana VS, Almeida-Filho, N, Fernandes RNR. Prevalência de alcoolismo em uma área urbana de Salvador-Bahia. II - variáveis sócio-econômicas. J Bras Psiq. 1989;38(2):7581.

São Paulo. Prefeitura do Município de São Paulo. Secretaria Municipal da Saúde. Município de São Paulo: implantando o PSF. 2001. (mimeo.) 
São Paulo. Prefeitura do Município de São Paulo. Secretaria Municipal da Saúde. CEInfo. Síntese da situação da cidade de São Paulo em relação às demais capitais. Setembro 2004 [citado em 01 maio 2007];9:11. Disponível em: http://ww2.prefeitura.sp.gov.br//arquivos/secretarias/saude/morbidade/0018/InCA_2002_2 003 alterada.pdf.

Schulpen TWJ, Swinkels WJAM. MACHAKOS PRJECT SUDIES. Agents affecting health of mother and child in a rural area of Kenya. XIX. The utilization of health services in a rural area of Kenya. Trop geogr Med. 1980;32:340-9.

Sen A. Health perception versus observation. BMJ. 2002;324:860-1.

Senna MCM. Eqüidade e política de saúde: algumas reflexões sobre o Programa Saúde da Família. Cad. Saúde Pública. 2002;18(Suplemento):203-11.

Silva JA, Dalmaso ASW. Agente Comunitário de Saúde: o ser, o saber, o fazer. Rio de Janeiro: Editora Fiocruz; 2002.

Simpson D. Trends in major risk factors. Cigarette smoking. Postgrad Med J. 1984; $60: 20-5$ 
Skoumas J, Pitsavos C, Panagiotakos DB, Chrysohoou C, Zeimbekis A, Papaioannou I, Toutouza M, Toutouzas P, Stefanadis C. Physical activity, high-density lipoprotein cholesterol and other lipids levels, in men and women from the ATTICA study. Lipids Health Dis [periódico on-line]. 2003; [citado 27 março 2005];2:3. Disponível em: http://www.lipidworld/content/2/1/3.

Souza ALL. Prevalência da hipertensão arterial referida, percepção de sua origem e formas de controle em área metropolitana de São Paulo - SP (1989-1990) [tese]. São Paulo: Faculdade de Saúde Pública, Universidade de São Paulo; 1999.

Sousa MF. A Cor-Agem do PSF. São Paulo: Editora Hucitec; 2001.

Sousa MF (Org.). Os sinais vermelhos do PSF. São Paulo: Editora Hucitec; 2002.

Souza CN, Góes WB, Grisi SJFE. Avaliação do atendimento médico de equipes do Programa da Saúde da Família através da auditoria de prontuários. In: Cianciarullo TI, Gualda DMR, Cunha ICKO, Silva GTR, organizadores. Saúde na família e na comunidade. São Paulo: Robe Editorial; 2002. p. 142-66.

StataCorp. 2005. Stata Statistical Software: Release 9.0. College Station, Texas: Stata Corporation.

Sturm R, Gresenz CR. Relations of income inequality and family income to chronic medical conditions and mental health disorders: national survey. BMJ. 2002;324:20. 
Szwarcwald CL, Mendonça MHM, Andrade CLT. Indicadores de atenção básica em quatro municípios do Estado do Rio de Janeiro, 2005: resultados de inquérito domiciliar de base populacional. Cienc Saúde Coletiva. 2006;11(3):643-55.

Theme-Filha MM, Szwarcwald CL, Souza-Júnior PRB. Socio-demographic characteristics, treatment coverage, and self-rated health of individual who reported six chronic diseases in Brazil, 2003. Cad. Saúde Pública. 2005;21 Sup:S43 -S53.

Vargas CM, Burt VL, Gillum RF, Pamuk ER. Validity of self-reported hypertension in the National Health and Nutrition Examination Survey III, 1988-1991. Prev Med. $1997 ; 26: 678-85$.

Vasconcellos MPC. Reflexões sobre a saúde da família. In: Mendes EV, organizador. A organização da saúde no nível local. São Paulo: Hucitec; 1998. p. 155-72.

Viacava F. Informações em saúde: a importância dos inquéritos populacionais. Cienc Saúde Coletiva. 2002;7(4):607-21.

Viana ALd'A, Dal Poz MR. A reforma do sistema de saúde no Brasil e o Programa de Saúde da Família. PHYSIS. (Rio J). 1998;8(2):11-48.

Viana ALd'A, Fausto MCR. Atenção Básica e proteção social: universalismo x focalismo e espaço não mercantil da assistência. In: Viana ALd'A, Elias PEM, Ibañez N, organizadores. Proteção social: dilemas e desafios. São Paulo: Hucitec; 2005. p.150-67. 
Wells S, Broad J, Jackson R. Alcohol consumption and its contribution to the burden of coronary heart disease in middle-aged and older New Zealanders: a population-based casecontrol study. N Z Med J. 12 March 2004; [citado 04 nov 2005]; 117(1190). Disponível em: http:/www.nzma.org.nz/journal/117-1190/793/.

White KL. Health surveys: who, why and what? World Health Stat Q. 1985;38:2-14.

White IR, Altmann DR, Nanchahal K. Alcohol consumption and mortality: modeling risks for men and women at different ages. BMJ. 27 2002; [citado 13 ago 2005];325 (191). Disponível em http://bmj.bmjjournals.com/cgi/content/full/325/7357/191.

World Health Organization. Diabetes. 2005a; [citado 28 junho 2005]; 1-2. Disponível em: htpp://www.who.int/dietphysicalactivity/publications/facts/diabetes/en/print.html.

World Health Organization. Physical activity. 2005b; [citado 28 junho 2005]; 1-2 [2 telas]. Disponível em: htpp://www.who.int/dietphysicalactivity/publications/facts/pa/en/print.html.

Wu SC, Li CY, Ke DS. The agreement between self-reporting and clinical diagnosis for selected medical conditions among the elderly in the Taiwan. Public Health. 2000;114:137-42. 


\section{À minha esposa}

Neiva e minha filha

Nina. 


\section{Agradecimentos}

Ao Prof . Dr. Reinaldo Gianini, pelo carinho, disposição e bom humor durante todo o trabalho.

Ao Prof. Dr. Moisés Goldbaum, pela seriedade de sua orientação.

À Profa. Hillegonda Maria Dutilh Novaes, pelo seu apoio e disposição em partilhar toda a história documentada desse projeto, assim como a firme defesa, na banca de qualificação, do que tornar-se-ia o principal objetivo dessa tese (a avaliação do PSF).

Ao Prof. Paulo Eduardo Mangeon Elias pela orientação inicial, análise crítica na banca de qualificação e compartilhamento de bibliografia e expertise no assunto.

Ao Ivaldo Olímpio da Silva, sempre pronto para nos socorrer nas não raras dúvidas de informática.

À Miriam Regina de Souza, que, tendo digitado o banco de dados, tornou-se informante-chave para diversos detalhes, além de ter escaneado o questionário para apresentações desse trabalho.

À Marluce Santinati, pela inestimável ajuda na confecção das tabelas e outras dicas preciosas. 
Ao Rafael Kamassutti Belone, Estela Madalosso e Paulo Américo Sebastiany Rufino, pelo empréstimo de seus "laptops", que permitiram que eu estivesse em locais mais inspiradores para escrever a tese, assim como mais próximo de minha família. 
Se o país não for pra cada um

Pode estar certo

Não vai ser pra nenhum

(Samuel Rosa/Chico Amaral) 
Esta tese está de acordo com as seguintes normas, em vigor no momento desta publicação:

Referências: adaptado de International Committee of Medical Journals Editors (Vancouver).

Universidade de São Paulo, Faculdade de Medicina. Serviço de Biblioteca e Documentação. Guia de apresentação de dissertações, teses e monografias. Elaborado por Anneliese Carneiro da Cunha, Maria Júlia de A. L. Freddi, Maria F. Crestana, Marinalva de Souza Aragão, Suely Campos Cardoso, Valéria Vilhena. 2a ed. São Paulo: Serviço de Biblioteca e Documentação; 2005.

Abreviaturas dos títulos dos periódicos de acordo com List of Journals Indexed in Index Medicus. 


\section{Sumário}

Lista de siglas

Resumo

Summary

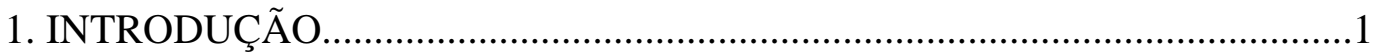

1.1 Programa de Saúde da Família (PSF) .............................................................

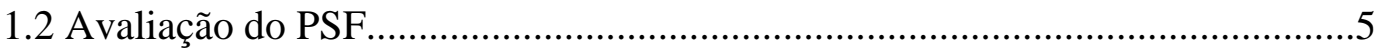

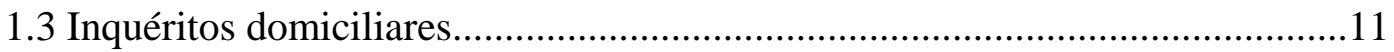

\section{OBJETIVOS}

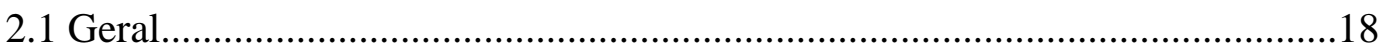

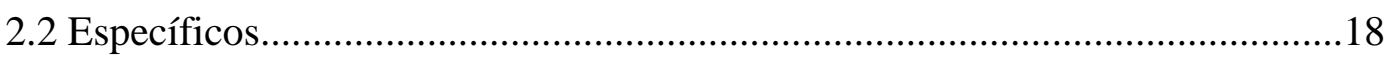

3. MÉTODOS

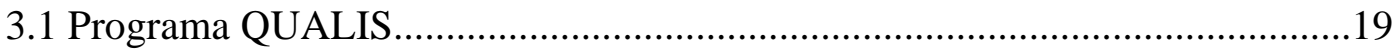

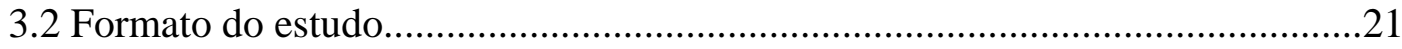

3.3 Área do estudo e população......................................................................22

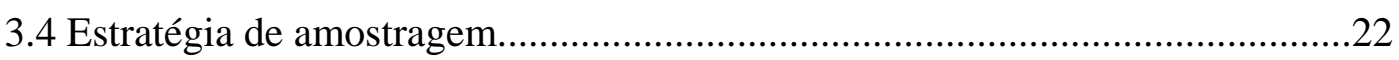

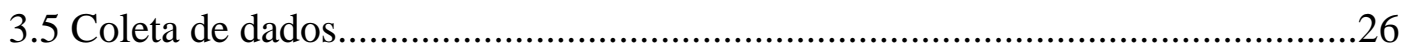

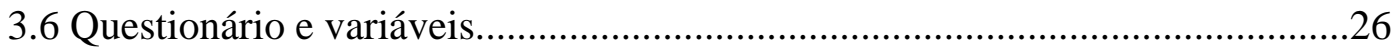

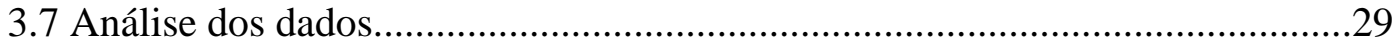

4. RESULTADOS

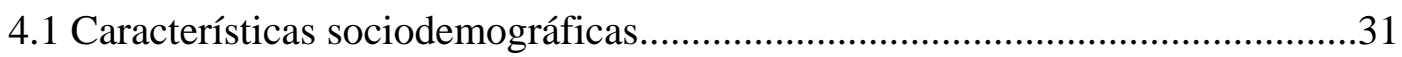

4.2 Morbidade

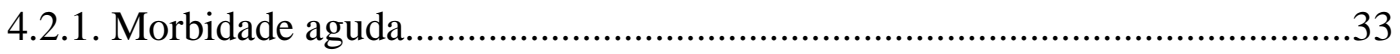

4.2.2 Morbidade crônica......................................................................................39 
4.3. Estilo de vida

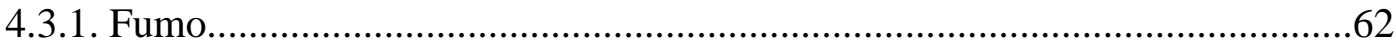

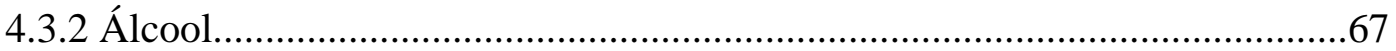

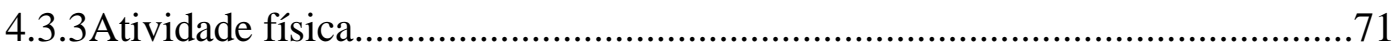

5. DISCUSSÃO

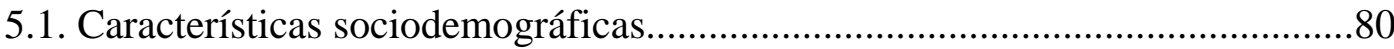

\subsection{Morbidade}

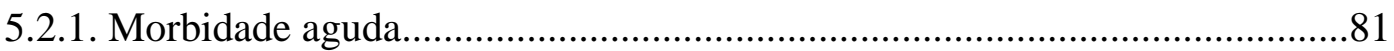

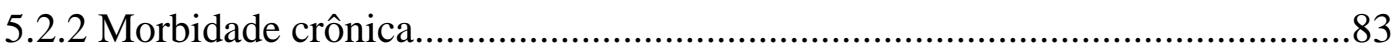

5.3 Estilo de vida

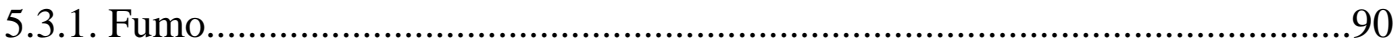

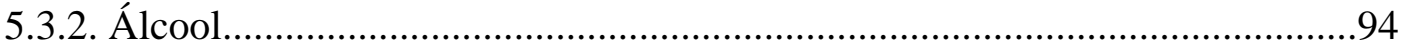

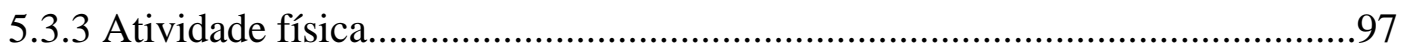

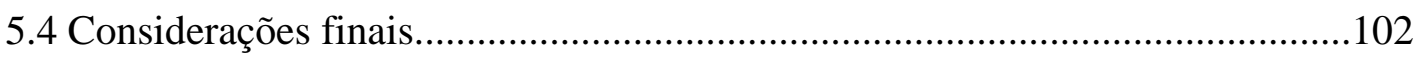

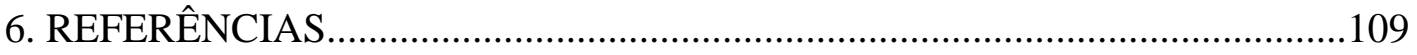

Apêndice 


\section{LISTA DE SIGLAS}

ACS - Agente Comunitário de Saúde

CAPPesq - Comitê de Ética em Pesquisa do Hospital das Clínicas da Faculdade de Medicina da Universidade de São Paulo

CEInfo - Coordenação de Epidemiologia e Informação da Secretaria Municipal de Saúde de São Paulo

CSE - Centro de Saúde Escola

CSSM - Casa de Saúde Santa Marcelina

DAB - Departamento de Atenção Básica

DIC - Doença Isquêmica do Coração

DM - Diabetes mellitus

ELB - Estudos de Linha de Base

ENSP - Escola Nacional de Saúde Pública

ESF - Estratégia de Saúde da Família

EUA - Estados Unidos da América

FAPESP - Fundação de Amparo à Pesquisa no Estado de São Paulo

GHS - General Health Survey

HAS - Hipertensão Arterial Sistêmica

HSE - Health Survey for England

IAM - Infarto Agudo do Miocárdio

IBGE - Instituto Brasileiro de Geografia e Estatística

IDH - Índice de Desenvolvimento Humano

INCA - Instituto Nacional de Câncer

INSS - Instituto Nacional de Seguridade Social 
IPEA - Instituto de Pesquisa Econômica Aplicada

JNC - Joint National Committee

NASF - Núcleos de Atenção à Saúde da Família

NHANES - National Health and Nutrition Examination Survey

NHIS - National Health Interview Survey

NHS - National Health Service

NLAES - National Longitudinal Alcohol Epidemiologic Survey

OMS - Organização Mundial da Saúde

PA - Pressão Arterial

PACS - Programa de Agentes Comunitários de Saúde

PAS - Programa de Assistência à Saúde

PCAT - Primary Care Assessment Tool

PMS - Pesquisa Mundial de Saúde

PNAD - Pesquisa Nacional por Amostragem de Domicílios

PPV - Pesquisa Sobre Padrão de Vida

PROESF - Projeto de Expansão e Consolidação do Saúde da Família

PSF - Programa de Saúde da Família

QIAF/IPAC - Questionário Internacional de Atividade Física

QUALIS - Qualidade Integral em Saúde

SES - Secretaria de Estado da Saúde

SHI - Social Health Insurance

SM - Salário Mínimo

SP - São Paulo

SPHC - Selective Primary Health Care

SUS - Sistema Único de Saúde 
UBS - Unidade Básica de Saúde

UNICEF - Fundo das Nações Unidas para a Infância

UNIMED - União dos Médicos

USF - Unidade de Saúde da Família

VC - Vila Curuçá

VNC - Vila Nova Cachoeirinha

WHO - World Health Organization 
Brandão JRM. Análise do Programa "Qualidade Integral em Saúde” (QUALIS) a partir de um inquérito domiciliar de saúde [tese]. São Paulo: Faculdade de Medicina, Universidade de São Paulo; 2007.

INTRODUÇÃO: O Programa de Saúde da Família (PSF) tem-se estruturado como uma estratégia para a Atenção Primária no Brasil. Tendo-se iniciado em 1994, vem apresentando um crescimento vertiginoso, impondo a necessidade de avaliações constantes. Só mais recentemente, o programa tem sido alvo de avaliações de resultados, em contrapartida às avaliações de infra-estrutura e de processo que sofreu nos seus primeiros anos de existência. MÉTODOS: Em 2001, foi realizado um inquérito domiciliar de saúde em dois distritos administrativos periféricos da cidade de São Paulo (compreendendo uma população de 190 mil habitantes), ambos parcialmente cobertos pelo PSF (denominado QUALIS nesses locais). Utilizando-se a análise própria para conglomerados, estudaram-se a morbidade aguda, crônica (Hipertensão Arterial Sistêmica, Diabetes, Doenças Isquêmicas do Coração, Doenças Pulmonares Obstrutivas Crônicas, Câncer e Tuberculose) e estilo de vida (consumo de fumo, álcool e atividade física) das populações de 15 anos ou mais, cobertas ou não pelo PSF. Procederam-se às análises uni e multivariada utilizando-se de diversas características socioeconômicas dessas populações. RESULTADOS: Os perfis de morbidade dessas populações se distinguem por características que sugerem um acesso diferenciado nas áreas cobertas pelo PSF. CONCLUSÃO: Populações cobertas pela Estratégia de Saúde da Família (ESF) apresentam algumas características de saúde que sugerem, no município de São Paulo, um maior acesso à Atenção Primária. 
Brandão JRM. Analysis of Program 'Comprehensive Quality in Health' (QUALIS) applying a health survey [thesis]. Faculty of Medicine, University of Sao Paulo, SP (Brazil); 2007.

INTRODUCTION: The "Family Health Program" (FHP) has been implemented as a strategy for Primary Care in Brazil. It started in 1994 and has grown enormously since then, demanding constant evaluation. In spite of that, only recently has the program been submitted to evaluation for results, in contrast to the more common evaluations of infrastructure and process. METHODS: In 2001, a health survey was carried out in two administrative districts of the outskirts of the city of Sao Paulo (where 190,000 people live), both partially served by the FHP (named QUALIS in these areas). Through cluster analysis, we studied acute morbidity, chronicle (Hypertension, Diabetes, Ischemic Coronary Disease, Chronicle Pulmonary Obstructive Diseases, Cancer and Tuberculosis) and lifestyle (use of tobacco, alcohol and physical activity) of those 15 or older, served or not by the FHP. We applied univariate and multivariate analysis with several socioeconomic characteristics of these populations. RESULTS: Distinct characteristics in the morbidity profile of these populations suggest a differentiated access in the areas served by the FHP. CONCLUSION: Populations served by the "Family Health Strategy" show some health characteristics that suggest, in the city of Sao Paulo, a larger access to Primary Care. 